\title{
Seismic constraints on the processes and consequences of secondary igneous evolution of Pacific oceanic lithosphere
}

\author{
by \\ Helen Shao-Hwa Feng \\ B.S., University of California, Los Angeles, 2010 \\ Submitted in partial fulfillment of the requirements for the degree of \\ Doctor of Philosophy \\ at the \\ MASSACHUSETTS INSTITUTE OF TECHNOLOGY \\ and the \\ WOODS HOLE OCEANOGRAPHIC INSTITUTION
}

February 2016

(C) 2016 Helen S. Feng

All rights reserved.

The author hereby grants to MIT and WHOI permission to reproduce and to distribute publicly paper and electronic copies of this thesis document in whole or in part in any medium now known or hereafter created.

Signature of Author

Joint Program in Oceanography/Applied Ocean Science and Engineering Massachusetts Institute of Technology and Woods Hole Oceanographic Institution January 27,2016

Certified by

Daniel Lizarralde Associate Scientist, Department of Geology and Geophysics, WHOI Thesis Supervisor

Accepted by

Timothy L. Grove Professor of Geology, Department of Earth, Atmospheric and Planetary Sciences, MIT Chair, Joint Committee for Marine Geology and Geophysics 


\title{
Seismic constraints on the processes and consequences of secondary igneous evolution of Pacific oceanic lithosphere
}

\author{
by \\ Helen Shao-Hwa Feng \\ Submitted to the Department of Marine Geology and Geophysics, \\ MIT/WHOI Joint Program in Oceanography/Applied Ocean Science and Engineering \\ on January 27, 2016 in partial fulfillment of the requirements \\ for the degree of Doctor of Philosophy
}

\begin{abstract}
This thesis examines the structure of Pacific oceanic lithosphere that has been modified by post-formation magmatism in order to better understand the processes of secondary magmatic evolution of the lithosphere, which can have global-scale implications for oceanic and atmospheric chemistry. In the western Pacific, widespread Cretaceous magmatism has modified oceanic lithosphere over hundreds of millions of square kilometers. Seismic models of the upper crust from within the Jurassic Quiet Zone and the crust and upper mantle near the Mariana Trench reveal crust that is locally thickened via focused extrusive volcanism and crust that is modestly but uniformly thickened over broad regions. These distinct modes of magmatic emplacement suggest the operation of both focused and diffuse modes of melt transport through the lithosphere. Analysis of seismic observations from Guaymas Basin, in the Gulf of California, endeavor to advance our understanding of sill-driven alteration of sediments, an important consequence of secondary magmatism. We show that seismically imaged physical disruption to sediments due to igneous sill intrusion can be related to changes in sediment physical properties that reflect alteration processes. We also show how sill thickness can be estimated, enabling alteration intensity to be related to sill thickness in a variety of settings.
\end{abstract}

Thesis Supervisor: Daniel Lizarralde Title: Associate Scientist, Department of Geology and Geophysics, WHOI 


\section{Acknowledgements}

I am deeply appreciative of the time and effort invested by my advisor, Dan Lizarralde, to get me through this program with an unwavering belief in my capabilities, even when I was doubtful. Dan has a special ability to communicate science in a compelling, creative way that I greatly benefited from. I thank my thesis committee for their support: Rob Evans, John Collins, Adam Soule, Maurice Tivey, Oli Jagoutz, and Masako Tominaga. These experts in their respective fields have continuously encouraged and challenged me to think about my work in a constructive way, while still meshing well together to bring some levity to my committee meetings. Extra thanks to Masako for constantly checking in on me in the final few months to push me through the finish line.

I have had amazing opportunities to work with people at MIT and WHOI to broaden my knowledge through various classes and projects. During my brief foray into planetary science, Ben Weiss let me cut up a meteorite, mess with its magnetic field, and experience life in a lab with the help of extremely competent lab members Sonia Tikoo, Jerome Gattacceca, Eduardo Lima, and Clement Suavet. I enjoyed classes taught by Ralph Stephen and Dale Morgan, and geodynamics seminars organized by Andrew Daly every spring. I also thank the scientific cast and crew of the R/V Langseth during the 2011 NoMelt and 2012 Marianas cruises, especially Jimmy Elsenbeck, Chris Judge, Jake Siegel, and Justin Ball for solid crossword puzzle skills, pineapple videos, politically incorrect endianness, AGU get-togethers, and interesting discussions on chaos theory.

Integral to surviving grad school, my friends at MIT and WHOI have been great sources of inspiration and entertainment. I could not have asked for a harder working or more supportive peer than Aleja Ortiz. From outdoor adventures to spaghetti westerns, I've learned a lot from Martina Coccia not covered in our P-sets or classes. I was so lucky to have a wonderful cohort of graduating officemates my first year: Emily Roland, Maya Bhatia, Evy Mervine, and Andrea Burke. Fortunately, Claire Pontbriand joined me in Clark South and set the standard for completing a Ph.D. with grace. I'm also thankful for all the fun times shared with Laura Stevens (ball is life), Harriet Alexander, Katie Pitz, Arthur Olive, Marie Giron, Aimee Gillespie, Ruel Jerry, Yodit Tewelde, Jaap Nienhuis, Isabela Le Bras, Becca Jackson, Sarah Rosengard, Kyrstin Fornace, Net Charoenpong, Luyao Li, Min Ding, Nathan Miller, Niya Grozeva, Sara Bosshart, Sedar Sahin, and Kat Saad. Support from the Academic Programs Office, especially Julia Westwater, was always there when I needed it, and even when I didn't know I needed it.

Living on Cape Cod and swimming in the ocean is great if you don't accidentally touch a jellyfish, but I have learned that spending time in a chlorinated pool is a cherished outlet for my well-being. I loved playing with the MIT Women's Water Polo Team and swimming with MIT Masters. For the most difficult year of my thesis, I thank Coach Cholace, Coach Joe, and all the friendly faces I got to see every morning at the Cape Cod Swim Club. I never imagined I could be so grateful to have someone yell at me to move faster at 6 in the morning.

Finally, I would like to thank my family. I know that there are people I can count on, no matter what, and I don't even feel that guilty for calling home at strange hours sometimes. 
This research was supported by funding from the National Science Foundation Division of Earth Sciences (EAR) contract \#1144829, Division of Ocean Sciences (OCE) contracts \#0928663 and \#1029965, and the WHOI Academic Programs Office. 


\section{Table of Contents}

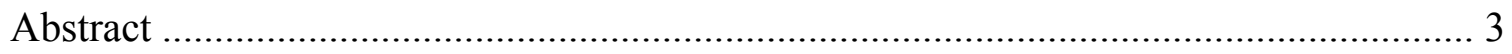

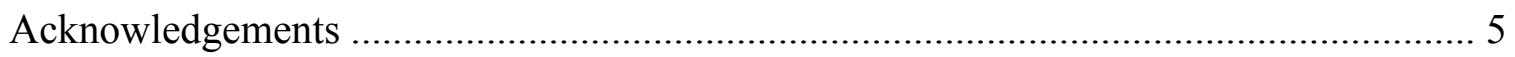

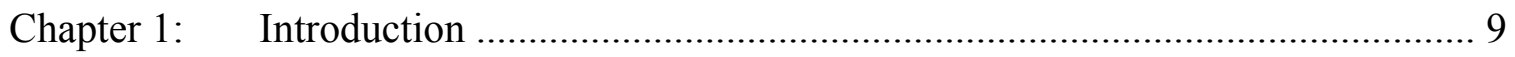

Chapter 2: Effects of igneous sill intrusion on sediments in Guaymas Basin, Gulf of California, as inferred by seismic methods ............................ 17

Chapter 3: Extent and impact of Cretaceous magmatism on the evolution of Jurassic-age oceanic crust in the western Pacific ............................... 57

Chapter 4: Lithospheric-scale influence of magmatic activity on the subducting plate at the Mariana Trench .................................................................. 95

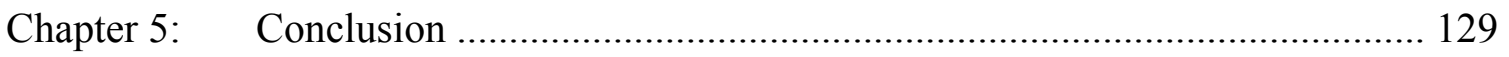




\section{Chapter 1: Introduction}

This thesis focuses on the architecture of oceanic lithosphere and the processes that modify it - namely different scales of post-formation crustal magmatism that occur away from conventional mid-ocean ridge (MOR) processes. The formation and evolution of oceanic lithosphere play a key role in the chemical differentiation and physical construction of our planet. On a global scale, oceanic lithosphere is created and destroyed every 100-200 million years, completely changing the structure of the ocean basins and configuration of the longer-lived continents. During the formation of lithosphere at MORs, magmatic material is transported and transformed from the depths of the mantle to the crust, with potentially impactful consequences for the ocean and atmosphere. The progression of hot, newly formed oceanic lithosphere to cold, subsiding lithosphere may be complicated by hosting a suite of biogeochemical/tectonic/volcanic processes, many of which arise from nonsystematic or localized environmental conditions, until the lithospheric life cycle is restarted by subduction processes that mobilize old lithosphere, overriding material, and seawater back into the mantle.

Our current understanding of the structure of oceanic lithosphere formed at MORs is largely inferred from the Penrose ophiolite model [Conference Participants, 1971], in which melt extraction from a partial-melt domain of decompressing mantle is focused into a zone of crustal accretion [e.g., Perfit et al., 1994], resulting in crust that, on average, has remarkably uniform structure throughout the oceans [e.g., White et al., 1992]. Typical oceanic crust is $\sim 6 \mathrm{~km}$-thick and consists of three layers: (1) a thin layer $(<0.5 \mathrm{~km}$-thick $)$ of sediments that accumulates with distance away from the spreading ridge, (2) extrusive pillow basalts overlying sheeted diabase dikes, and (3) intrusive gabbroic rocks that form the bulk of the crust [Raitt, 1963; Collins et al., 1989]. The standard model of a uniformly layered ocean crust has since evolved with the acquisition of ocean drilling and geophysical data, with major differences in crustal structure attributed to either fast- or slow-spreading regimes [Bown and White, 1994]. However, the Penrose model is widely accepted for Pacific crust created at fast-spreading MORs [Dick et al., 2006], so we use this structure as a basic reference for our observations and interpretations of crustal modification processes. 
In this thesis, we focus on three study areas in which Pacific oceanic lithosphere has been affected by secondary magmatic processes. Oceanic lithosphere at different stages in the lithospheric life cycle is examined in the following chapters, from that newly formed at a young rift basin in the Gulf of California (Chapter 2), to the oldest in situ in existence comprising large regions of the western Pacific (Chapter 3), to that finally being subducted at the Mariana Trench (Chapter 4). At each of these locations, anomalous geodynamic and/or surficial conditions have contributed to the development of off-axis or intraplate magmatic activity that has modified the original structure of the lithosphere. These processes occurring away from MORs are poorly constrained, yet essential to understanding upper-mantle dynamics and composition [Ballmer et al., 2013]. With the acquisition of new seismic datasets, we are able to improve our understanding of how secondary magmatism is manifest within the lithosphere, assessing these processes within the context of deviations from the general Penrose ophiolite model. Igneous features observed throughout the crust in each study area provide a broader perspective on the various modes of magmatic emplacement, transport, and distribution, as described in detail for each chapter below.

Chapter 2 presents observations of off-axis igneous sill emplacement and a detailed analysis of sill/sediment interactions arising from the estimation of key sill properties. In Guaymas Basin, located in the central Gulf of California, continental rifting has transitioned into seafloor spreading in a heavily sedimented system [Schrader, 1982], generating new oceanic crust that differs in structure from typical oceanic crust formed at MORs [Lizarralde et al., 2007]. Melt does not focus at the spreading axis to produce typical oceanic Layer 2 extrusive pillow basalts and flows; instead it is emplaced within crustal sediments and pre-existing intrusive igneous material via active sill intrusion over a region spanning tens of kilometers away from the plate boundary [Lizarralde et al., 2010]. The intrusion of magma into sediments promotes thermogenic alteration of sediments that can produce high order hydrocarbons, which may be of economic interest, and can also release significant amounts of $\mathrm{CO}_{2}, \mathrm{CH}_{4}$, and other greenhouse gases into the ocean and atmosphere [Einsele et al., 1980], which may have implications for global carbon cycling [e.g., Svensen et al., 2007; Svensen et al., 2009; Aarnes et al., 2010]. Understanding the impact of igneous sill intrusion on sediments and carbon release from 
those sediments requires measurements of sill-driven sediment alteration and a means of modeling those effects.

In order to quantitatively examine sill/sediment interactions in Guaymas Basin, we use multi-channel seismic (MCS) data to identify igneous sill intrusions and estimate changes in the bulk physical properties of crustal sediments modified by sill intrusion. Additionally, we analyze seismic waveform spectral properties of interpreted sill reflections in order to quantify the thickness and velocity of the inferred igneous sill intrusion. We find an increase in bulk velocity of up to $15 \%$ for disrupted sediments above interpreted sills relative to unaltered sediments from the same stratal units, which suggests that structural and compositional changes result from thermogenic alteration due to sill intrusion. Results from the spectral analysis indicate that both the seismic velocity of the sill and its thickness are readily estimated from diagnostic features of amplitude versus ray parameter and frequency notches as a function of ray parameter arising from interference of reflections from the top and bottom of an igneous sill. Our results from Guaymas Basin show that two key parameters needed to model and understand silldriven hydrothermal alteration processes, in particular a measure of sediment alteration and igneous sill thickness, can be estimated in a relatively straightforward way from surface-towed MCS data. Crustal modification on this scale, although limited to shallow crustal depths, may have significant implications for similar processes occurring in other back-arc basins and newly rifted ocean basins that are part of the global carbon cycle (as well as magmatic emplacement events occurring on scales several orders of magnitude larger, as examined in the following chapters).

Chapter 3 investigates the effects of magmatic processes that have modified old (Jurassic-age) oceanic lithosphere throughout the western Pacific, as part of the massive Cretaceous magmatic event that produced vast seamount chains and igneous plateaus over millions of square kilometers in the deep ocean basins [e.g., Larson, 1991; Koppers et al., 2003]. The growth of the Pacific plate and its interaction with underlying mantle processes have produced many prominent, yet poorly understood, crustal features. Mesozoic magnetic anomaly lineations converge around a region of low-amplitude, short-wavelength magnetic anomalies known as the Jurassic Quiet Zone (JQZ). In this region, the widespread emplacement of large volumes of igneous material into pre- 
existing Jurassic crust brings into question the relationship between Cretaceous-age seafloor volcanic features and JQZ magnetic anomalies [e.g., Sager et al., 1988, Tivey et al., 2006; Tominaga et al., 2008]. We model the structure of modified oceanic crust in the JQZ using MCS images and wide-angle sonobuoy data in order to gauge the impact of Cretaceous magmatism on crustal structure and study how crustal evolution occurs through the transport and emplacement of a large distribution of melt through the lithosphere and into the crust. Observations of various igneous features (seamounts, flows, and sills) throughout our $800 \mathrm{~km}$-long survey transect and laterally extensive $(\sim 400 \mathrm{~km})$ thickening of oceanic Layer 2 suggest that multiple modes of melt transport exist, ranging from focused conduits that supply a robust source of magma through the lithosphere to unfocused, pervasive fingering of melt channels that uniformly thicken the crust via widespread sill emplacement.

Chapter 4 of this thesis has a similar focus as the previous chapter, but approaches the subject on a lithospheric scale. As part of an experiment to investigate mantle hydration processes in the Marianas subduction system, several active-source wide-angle refraction lines were collected across the Pacific and Philippine Sea Plates. Data from ten ocean bottom seismometers (OBSs) were recovered from Line $\mathrm{E}$ of the experiment on the subducting plate, with the goal of providing reference mantle velocities unaltered by cracks and serpentinization to be used for comparison with the results of cross-trench and forearc seismic lines studying faulting and fluid flux processes associated with the subduction zone. Seamount provinces on the Pacific plate indicate that the subducting oceanic lithosphere has been affected by voluminous Cretaceous magmatism [e.g., Koppers et al., 2003; Kaneda et al., 2010; Stadler and Tominaga, 2015]. We determine the seismic velocity structure of the downgoing plate along Line E using P-wave travel time tomography. Our preferred model from the tomographic inversion indicates that widespread magmatic activity has resulted in significant crustal thickening beneath seamounts, likely via crustal underplating [e.g., Caress et al., 1995; Grevemeyer et al., 2001]. Thickening of oceanic Layers 2 and 3 along our line seems to imply two distinct modes of melt transport within the lithosphere, either broadly pooling at the Moho (lowflux) or channeling through the crust to form extrusive additions (high-flux). Additionally, our observation of a strong seismic reflector originating in the shallow 
upper mantle suggests that detailed upper mantle structures occur as a result of phase transitions under varying temperature and pressure conditions, namely the plagioclase-tospinel transition at depths of $\sim 8-12 \mathrm{~km}$ [Stixrude and Lithgow-Bertelloni, 2005; Afonso et al., 2008]. This may have implications for our understanding of melt evolution in a depleted harzburgite mantle and the possibility of off-axis magmatism introducing basaltic components into an evolved mantle. 


\section{References}

Aarnes, I., Svensen, H., Connolly, J.A.D., and Podladchikov, Y.Y., 2010, How contact metamorphism can trigger global climate changes: Modeling gas generation around igneous sills in sedimentary basins: Geochimica et Cosomochimica Acta, v. 74, p. 7179-7195, doi:10.1016/j.gca.2010.09.011.

Afonso, J.C., Fernandez, M., Ranalli, G., Griffin, W.L., and Connolly, J.A.D., 2008, Integrated geophysical-petrological modeling of the lithosphere and sublithospheric upper mantle: Methodology and applications: Geochemistry, Geophysics, Geosystems, v. 9, No. 5, doi: 10.1029/2007/GC001834.

Ballmer, M.D., Conrad, C.P., Smith, E.I., and Harmon, N., 2013, Non-hotspot volcano chains produced by migration of shear-driven upwelling toward the East Pacific Rise: Geology, v. 41, No. 4, p. 479-482, doi: 10.1130/G33804.

Bown, J.W., and White, R.S., 1994, Variation with spreading rate of oceanic crustal thickness and geochemistry: Earth and Planetary Science Letters, v. 121, p. 435449.

Caress, D.W., McNutt, M.K., Detrick, R.S., and Mutter, J.C., 1995, Seismic imaging of hotspot-related crustal underplating beneath the Marquesas Islands: Nature, v. 373, p. 600-603.

Christie, D.M., Ildefonse, B., Abe, N., Arai, S., Bach, W., Blackman, D.K., Duncan, R., Hooft, E., Humphris, S.E., and Miller, D.J., 2006, Mission Moho: Formation and evolution of oceanic lithosphere: Eos, v. 87, No. 48, p. 538-539.

Collins, J.A., Purdy, M.G., and Brocher, T.M., 1989, Seismic velocity structure at Deep Sea Drilling Project Site 504B, Panama Basin: Evidence for thin oceanic crust: Journal of Geophysical Research, v. 94, No. B7, p. 9283-9302.

Conference Participants, 1972, Penrose Field Conference: Ophiolites, Geotimes, v. 17, p. 24-25.

Dick, H.J.B., Natland, J.H., and Ildefonse, B., 2006, Past and future impact of deep drilling in the oceanic crust and mantle: Oceanography, v. 19, p. 72-80.

Einsele, G., Gieskes, J.M., Curray, J., Moore, D.M., Aguayo, E., Aubry, M.-P., Fornari, D., Guerrero, J., Kastner, M., Kelts, K., Lyle, M., Matoba, Y., Molina-Cruz, A., Niemitz, J., Rueda, J., Saunders, A., Schrader, H., Simoneit, B., and Vacquier, V., 1980, Intrusion of basaltic sills into highly porous sediments, and resulting hydrothermal activity: Nature, v. 283, p. 4411-445.

Grevemeyer, I., Flueh, E.R., Reichert, C., Bialas, J., Kläschen, D., and Kopp, C., 2001, Crustal architecture and deep structure of the Ninetyeast Ridge hotspot trail from 
active-source ocean bottom seismology: Geophysical Journal International, v. 144, p. 414-431.

Kaneda, K., Kodaira, S., Nishizawa, A, Morishita, T, and Takahashi, N., 2010, Structural evolution of preexisting oceanic crust through intraplate igneous activities in the Marcus-Wake seamount chain: Geochemistry, Geophysics, Geosystems, v. 11, No. 10, doi: 10.1029/2010GC003231.

Koppers, A.A.P., Staudigel, H., and Duncan, R.A., 2003b, High-resolution ${ }^{40} \mathrm{Ar} /{ }^{39} \mathrm{Ar}$ dating of the oldest oceanic basement basalts in the western Pacific basin: Geochemistry, Geophysics, Geosystems, v. 4, No. 11, doi: 10.1029/2003GC000574.

Larson, R.L., 1991, Latest pulse of Earth: Evidence for a mid-Cretaceous superplume: Geology, v. 19, p 547-550.

Lizarralde, D., Axen, G.J., Brown, H.E., Fletcher, J.M., González-Fernández, A., Harding, A.J., Holbrook, W.S., Kent, G.M., Paramo, P., Sutherland, F., and Umhoefer, P.J., 2007, Variation in styles of rifting in the Gulf of California: Nature, v. 448, p. 466-469, doi: 10.1038/nature06035.

Lizarralde, D., Soule, S.A., Seewald, J.S., and Proskurowski, G., 2010, Carbon release by off-axis magmatism in a young sedimented spreading centre: Nature Geoscience, doi: 10.1038/NGEO1006.

Perfit, M.R., Fornari, D.J., Smith, M.C., Bender, J.F., Langmuir, C.H., and Haymon, R.M., 1994, Small-scale spatial and temporal variations in mid-ocean ridge crest magmatic processes: Geology, v. 22, p. 375-379.

Raitt, R.W., 1963, The crustal rocks, in Hill, M.N., eds., The Sea, v. 3, WileyInterscience, New York, p. 85-102.

Sager, W.W., Handschumacher, D.W., Hilde, T.W.C., and Bracey, D.R., 1988, Tectonic evolution of the northern Pacific plate and Pacific-Farallon-Izanagi triple junction in the Late Jurassic and Early Cretaceous (M21-M10): Tectonophysics, v. 155, p. 345-364.

Schrader, H., 1982, Diatom biostratigraphy and laminated diatomaceous sediments from the Gulf of California, in Curray, J.R., Moore, D.G., et al., Init. Repts. DSDP, 64: Washington, p. 973-981.

Stadler, T.J., and Tominaga, M., 2015, Intraplate volcanism of the western Pacific: New insights from geological and geophysical observations in the Pigafetta Basin: Geochemistry, Geophysics, Geosystems, v. 16, No. 9, p. 3015-3030. 
Stixrude, L., and Lithgow-Bertelloni, C., 2005, Mineralogy and elasticity of the oceanic upper mantle: Origin of the low-velocity zone: Journal of Geophysical Research, v. 110, doi: 10.1029/2004JB002965.

Svensen, H., Planke, S., Chevallier, L., Malthe- Sørenssen, A., Corfu, F., and Jamtveit, B., 2007, Hydrothermal venting of greenhouse gases triggering Early Jurassic global warming: Earth and Planetary Science Letters, v. 256, p. 554-566, doi: 10.1016/j.epsl.2007.02.013.

Svensen, H., Planke, S., Polozov, A.G., Schmidbauer, N., Corfu, F., Podladchikov, Y.Y., and Jamtveit, B., 2009, Siberian gas venting and the end-Permian environmental crisis: Earth and Planetary Science Letters, v. 277, p. 490-500, doi: 10.1016/j.eps1.2008.11.015.

Tivey, M.A., Sager, W.W., Lee, S.-M., and Tominaga, M., 2006, Origin of the Pacific Jurassic quiet zone: Geology, v. 34, no. 9, p. 789-792, doi: 10.1130/G22894.1.

Tominaga, M., Sager, W.W., Tivey, M.A., and Lee, S.-M., 2008, Deep-tow magnetic anomaly study of the Pacific Jurassic Quiet Zone and implications for the geomagnetic polarity reversal timescale and geomagnetic field behavior: Journal of Geophysical Research, v. 113, B07110, doi: 10.1029/2007JB005527.

White, R.S., McKenzie, D., and O'Nions, R.K., 1992, Oceanic crustal thickness from seismic measurements and rare earth element inversions: Journal of Geophysical Research, v. 97, No. B13, p. 19683-19715. 


\title{
Chapter 2:
}

\section{Effects of igneous sill intrusion on sediments in Guaymas Basin, Gulf of California, as inferred by seismic methods}

\begin{abstract}
We use multi-channel seismic (MCS) data to identify igneous sill intrusions in Guaymas Basin, in the Gulf of California, and to estimate changes in sediment properties where sills have intruded and altered sediments. The intrusion of magma into sediments promotes thermogenic alteration of sediments that can produce high order hydrocarbons, which may be of economic interest, and can also release significant amounts of $\mathrm{CO}_{2}$, $\mathrm{CH}_{4}$, and other greenhouse gases into the ocean and atmosphere, which may have implications for global carbon cycling. Understanding the impact of sill intrusion on sediments and carbon release from those sediments requires measurements of sediment alteration due to sill intrusion and a means of modeling those effects. We use seismic travel time modeling to quantify changes in sedimentary physical properties due, presumably, to alteration driven by igneous sill intrusion. Our results show an increase in bulk velocity of up to $15 \%$ for disrupted sediments above interpreted sills relative to unaltered sediments from the same stratal units. These results suggest that the observed sedimentary disruption is not purely structural, but also involves changes, such as decreased porosity and perhaps chemical alteration, that are known to result from thermogenic alteration due to sill intrusion. Additionally, we analyze seismic waveform spectral properties of interpreted sill reflections in order to quantify the thickness and velocity of the inferred igneous sill intrusion. Our analysis indicates that both the seismic velocity of the sill (which we find to be consistent with an igneous body) and its thickness are readily estimated from diagnostic features of amplitude versus ray parameter and frequency notches as a function of ray parameter arising from interference of reflections from the top and bottom of an igneous sill. Our results from Guaymas Basin show that two key parameters needed to model and understand sill-driven hydrothermal alteration processes, in particular a measure of sediment alteration and igneous sill thickness, can be estimated in a relatively straightforward way from surfacetowed MCS data.
\end{abstract}




\section{Introduction}

This chapter focuses on what happens when magma is emplaced into sediments as an igneous sill intrusion. In brief, magmatic intrusions physically and chemically alter intruded sediments and drive hydrothermal circulation, which transports alteration products such as methane and carbon dioxide from the subsurface to the seafloor and into the ocean. These processes represent a broad scientific topic, but this chapter focuses on two particular seismic measurements made in one particular location: we measure the change in sedimentary properties due to an igneous sill intrusion, and we measure properties of the intruded igneous sill. We make these measurements using a multichannel seismic (MCS) dataset from Guaymas Basin, in the Gulf of California, at a location where there is an unambiguous relationship between an unmodified sequence of sedimentary strata and the same sequence of sediments that have been modified by an intruded igneous sill. This work is motivated by the important consequences of magmatic emplacement into sediments, a process that can have global-scale implications for oceanic and atmospheric chemistry. We thus begin with a brief introduction to this

process and also to the setting of Guaymas Basin, which is an ideal location for studying igneous sill intrusion into sediments.

Field studies and laboratory experiments have shown that the intrusion of igneous sills into organic-rich sediments leads to the physical and chemical alteration of the sediments within contact aureoles surrounding the sills. Many of these observations have come from Guaymas Basin, where Deep Sea Drilling Project (DSDP) Leg 64 drilled three sites (Site 477, Site 478, and Site 481) near the axial graben of this young, sedimented spreading system [Curray et al., 1982]. Drill cores from these sites recovered doleritic sills, and sediments surrounding those sills, at all three sites at depths ranging from $\sim 50$ to $350 \mathrm{~m}$ below the seafloor. The intruded sediments surrounding the sills showed evidence of alteration over tens of meters from the sills. Changes in the sediments include the expulsion of pore fluids and decreased porosity [Einsele et al., 1980], the dissolution of old mineral phases and the formation of new ones [Kastner, 1982], and the breakdown and creation of organic compounds [Simoneit and Bode, 1982]. Studies on exposed, ancient sills in contact with intruded sediments of the Karoo 
volcanic province in South Africa [Svensen et al., 2007] and the North Atlantic volcanic province in Scotland [Raymond and Murchison, 1988] have shown similar alteration within metamorphic aureoles that extend approximately a sill thickness away from the sill/sediment contact. Laboratory studies and numerical thermo-chemical modeling have shown that conditions likely to exist within a sill aureole can lead to the production and release of organically derived thermogenic alteration products dominated by carbon dioxide, methane, and higher order hydrocarbons [e.g. Seewald et al., 1990; Aarnes et al., 2010].

Regionally extensive magmatic intrusion into sediments occurs in two main settings: at sedimented spreading systems and during the formation of large igneous provinces (LIPs). The processes of sediment alteration are presumably similar in both of these settings, but the geodynamic processes producing magmatism in these environments, while not well understood, are almost certainly very different. The consequences attributed to sill-driven carbon release from sediments are correspondingly different for these different settings. LIPs are truly exceptional events of voluminous, transient magmatism extending over vast regions [e.g., Coffin and Eldholm, 1994], such as the Cretaceous magmatic event extending over millions of square kilometers of the Pacific [e.g., McNutt and Fisher, 1987; Larson, 1991] and the Jurassic Central Atlantic Magmatic Province (CAMP) event extending from Brazil through Nova Scotia and Northern Africa [Olsen, 1997]. These and other similar events have been implicated in extinction episodes and global-scale changes in climate and ocean chemistry, and the effects of sill intrusion are increasingly being invoked as a mechanism for these consequences [e.g., Svensen et al., 2004; Bralower, 2008; Turgeon and Creaser, 2008; Svensen et al., 2009; Aarnes et al., 2010; Sell et al., 2014]. In contrast to punctuated LIP events of the past, sill intrusion into sediments occurs continuously today, with less dramatic consequences than LIP events, at sedimented spreading systems around the globe. Sedimented spreading systems occur mostly in back-arc basins and newly rifted ocean basins where spreading centers are close to terrigenous sediment sources and/or high oceanic productivity. Guaymas Basin is such a system, and here, and likely at other similar systems, active sill intrusion into sediments occurs over a region of tens of kilometers away from the plate boundary [Lizarralde et al., 2010]. This broad region of 
magmatic emplacement may substantially alter a large volume of the sediments in these systems, perhaps offsetting the carbon sequestration associated with young rift basins [Lerman et al., 2007]. Very little is known, however, about the dynamic processes of sediment alteration due to sill intrusion. For example, the effects of key parameters such as sill thickness, burial depth, and sediment type on thermo-chemical alteration processes have not been studied in a systematic way, and the most detailed studies of an active system have been those conducted on cores from DSDP Leg 64 .

Guaymas Basin provides an active, accessible setting for studying the processes and consequences of magmatic emplacement within an active system. Guaymas Basin is a young spreading system in the central Gulf of California. The Gulf of California has formed through rifting that began at 12-15 Ma when subduction on the western side of the Baja California peninsula stalled and a new, divergent plate boundary was formed inboard of the peninsula to accommodate Pacific/North America relative plate motion [Stock and Lee, 1994]. Rifting in Guaymas Basin had proceeded to seafloor spreading by $\sim 6 \mathrm{Ma}$ [Lizarralde et al., 2007; Miller and Lizarralde, 2012], and spreading continues today within the two short spreading segments of the basin (Fig. 1). High sedimentation rates $(\sim 1 \mathrm{~km} / \mathrm{Myr})$ observed within the basin [Schrader, 1982] have resulted in the deposition of thick, organic-rich sediments that range from $\sim 600 \mathrm{~m}$ thick at the spreading center to almost $3 \mathrm{~km}$ at the margins. The presence of this thick sedimentary cover has precluded the formation of a typical oceanic Layer 2 consisting of extrusive basalt pillows and flows. Instead, shallow magmatic emplacement within Guaymas Basin involves sill intrusion into sediments, producing new oceanic crust that has a "Layer 2" equivalent of heavily intruded sediments overlying a 6- to 8-km-thick Layer 3 of intrusive igneous crust [Einsele, 1985; Lizarralde et al., 2007]. In the northern spreading segment, active sill intrusion occurs over a broad region, up to $\sim 50 \mathrm{~km}$ away from the plate boundary [Lizarralde et al., 2010], exposing a correspondingly large volume of sediment to alteration. This broad region of active sill emplacement also provides a variety of settings to study sill/sediment interactions, with sills intruded at different depths into different sediment types and, at present, in different stages of their cooling history. 
The seismic observations indicating widespread, ongoing sill emplacement in Guaymas Basin come from multi-channel seismic (MCS) data acquired during the 2002 R/V Maurice Ewing cruise EW0210. Images from Transect 3 of this dataset show a nearly continuous sill horizon extending over $\sim 50 \mathrm{~km}$ to the northwest and $\sim 40 \mathrm{~km}$ to the southeast of the seafloor graben that marks the plate boundary (Fig. 2). The depth to this horizon does not increase systematically away from the plate boundary, as it would if sills were only emplaced at or near the axis. Instead, the horizon rises and falls, indicative of sill emplacement at various times and at varying distances from the plate boundary. A key feature distinguishing the sill horizon from typical oceanic igneous basement is the age of overlying sediments. The sediments directly overlying the sill horizon are older than the underlying sill, which intruded those sediments, whereas sediments overlying igneous basement of typical oceanic crust are younger than the underlying basalt. The sill/sediment age relationship is indicated by the disruption to the overlying sediments observed in the MCS images (Fig. 2b-c). We interpret this disruption to be due to sill intrusion and the character of the disruption to be related in some way to the degree of alteration experienced by the intruded sediments.

Perhaps the best example of the temporal relationship between strata, sill intrusion, the disruption of strata, and the relative age of the intrusion is that described by Lizarralde et al. [2010] and shown in Fig. 2b, near the distal end of recent sill intrusion. At this location, an abrupt lateral transition is observed from unmodified, conformal strata to the same sequence of strata now tightly folded and uplifted above a bright reflector. The bright reflector is interpreted to be a sill and the uplift of and deformation to the overlying strata is interpreted to be due to the intrusion of the sill. Conformal, undisturbed sediments blanket the disturbed strata, indicating that those uppermost sediments were deposited after the intrusion of the sill. The thickness of those uppermost sediments date the sill intrusion event as occurring $\sim 120 \mathrm{ky}$ ago at a distance of $\sim 48 \mathrm{~km}$ from the plate boundary. These observations were used by Lizarralde et al. [2010] to argue that magmatism occurs over an exceptionally wide region in Guaymas Basin. The work presented here focuses on this observation, at this particular location, because it provides a simple setting in which to measure the change in sediment physical properties due to sill intrusion. 
Observations from drill cores and outcrops, noted above, indicate that sediments surrounding an igneous sill are substantially modified by the sill intrusion, and we interpret the seismically observed disruption to overlying sediments as indicative of this modification. Einsele [1982] gives a detailed analysis of the dramatic dewatering and porosity reduction observed in sediments surrounding sills in DSDP Leg 64 drill cores, attributing this reduction to a number of factors: the load of the sill, for underlying sediments, compression due to the emplacement of the sill, for overlying sediments, the dissolution and precipitation of mineral phases, hydrothermal fluid expulsion, and possibly the conversion of water to steam and the expulsion of that steam. It is very likely that the sum of all of these processes will substantially modify the imaged seismic structure of the altered sediments surrounding a sill to distances from the sill at least as great as the measurable changes in core-sample physical properties, which are on the order of the thickness of the intruding sill. The disruption of sediments above sills observed in the MCS images must therefore be indicative, in some ways, of the properties and processes Einsele [1982] describes, and understanding the relationship between disruption observed in the MCS images and changes to physical properties would provide a great deal of information about the processes of sill-driven sediment alteration.

This chapter focuses on seismic analysis techniques that will enable us to relate seismically imaged structure to sill/sediment processes. Whereas drill core data provide detailed observations of the physical and chemical alteration experienced by intruded sediments at one location, MCS images provide information about the same processes in a variety of settings, with a variety of expressions and with both local and regional context, but these visual expressions of alteration processes do not directly provide information about physical and chemical properties. For example, in Guaymas Basin there are first order differences in sediment type on either side of the axial graben. The sediments in the northwest are predominantly of biogenic origin; they are thick due to high productivity in that part of the basin, and they have a distinct, dimly reflective seismic expression due to their uniformity. The sediments in the southeast are dominated by turbidite deposits from the Yaqui delta system and have a brightly reflective seismic expression due to the inherent grain-size variation within turbidites. The sills observed in these two settings along Transect 3 of EW0210 (Fig. 2) differ in character, with smaller, 
hummocky sills found in the northwest and larger, cuspate sills found in the southeast. Perhaps sill emplacement and associated sediment alteration vary with sediment type. Observed sediment disruption varies between and within each of these domains, ranging from complete destruction of stratal coherency, to deformed but observable strata, to simply uplifted and faulted sediments above sills. These differences may relate to sill emplacement depth, sediment type, the vigor of sill-driven hydrothermal circulation, sill thickness, local history of intrusion, or other factors.

The variety of expressions of sediment disruption suggest a spectrum of sediment alteration intensity that may be controlled by a large number of factors - a number of factors too great to explore and understand through an approach as expensive as drilling. Seismic approaches are needed that can relate imaged sediment disruption to changes in physical properties and can also constrain the essential parameter of sill thickness, which as described above is known to scale with alteration extent and intensity as well as the thermal energy of the intrusion and vigor of hydrothermal circulation [Fisher and Becker, 1991; Aarnes et al., 2010]. The work presented in this chapter makes progress towards the development of these approaches. Focusing on the benchmark location indicated in Fig. $2 b$, we demonstrate that reflection travel time modeling can effectively constrain changes in sediment velocity due to sill intrusion, finding a bulk velocity increase of $\sim 15 \%$ within the disturbed sediments versus the adjacent undisturbed sediments at this location. We also present a novel technique for estimating sill thickness that takes advantage of the frequency dependence of destructive interference between reflections from the top and bottom of sills. These results provide a path forward for the use of seismic data to quantitatively characterize the consequences of igneous sill intrusion into sediments and to understand the key factors that control sill/sediment interaction. These results also demonstrate, for the first time, (1) that the sediments with seismically imaged physical disruption have also experienced significant change to their physical properties, and (2) that the bright reflector underlying the disturbed sediments comes from a feature with the thickness and distinct seismic properties expected for a doleritic sill and is thus almost certainly a sill.

\section{Methods and Results}


We use multi-channel seismic (MCS) data acquired along Transect 3 of the R/V Maurice Ewing cruise EW0210 in the Gulf of California to identify and analyze igneous sills and altered sediments in Guaymas Basin. Transect 3 is located in the northern spreading segment; it is oriented northwest-southeast along a plate-kinematic flowline, parallel to the long transform faults that define the basin, and crosses the plate boundary, which is marked by an axial graben within seafloor sediments. The source for the MCS dataset was a large-volume airgun array tuned for deep-crustal penetration, producing a wavelet with center frequency around $10 \mathrm{~Hz}$. Airgun shots were fired at 100-m intervals and recorded from a 6-km-long, 480-channel streamer at a sampling rate of $4 \mathrm{~ms}$. We use the MCS data in three ways. First, we use the stacked and migrated image of the subsurface to identify sills and associated sedimentary deformation to target for analysis. The migrated stack was created using the Paradigm Echos software suite and a standard processing flow of binning traces into 6.25-m-spaced common depth point (CDP) gathers, bandpass filtering with a minimum-phase Butterworth filter between 15 and 90 $\mathrm{Hz}$, semblance-based stacking-velocity analysis, normal moveout correction, stacking, and Kirchoff post-stack time migration. With targeted locations chosen, we then used the pre-stack CDP gathers, transformed into the intercept time/ray parameter (or $\tau-p$ ) domain for the velocity analysis of deformed sediments and the estimation of sill thickness.

The original conception of this project involved velocity analysis of deformed sediments at many locations along a 120-km length of Transect 3 and the determination of a relationship between deformed-sediment velocity, a proxy for alteration, and a quantitative parameterization of sediment disruption based on measures of lateral coherence. This relationship would then enable imaged sediment disruption to be used as a proxy for alteration intensity in a quantitative way. This proxy would then be coupled to estimates of sill thickness, creating a framework for understanding the influence of the factors noted above (sill thickness, intrusion depth, sediment type, etc.) on sediment alteration. We changed this plan, however, for several reasons. First, it soon became apparent that the scope of the first component would require far more time than originally thought. Second, we found that it is not possible to determine sill thickness using linearized waveform inversion because the velocity contrasts between sediments and igneous sills are too large for this approach to be applicable. Finally, we realized that the 
new approach that we developed for estimating sill thickness was a substantial result in its own right, and that this result, in combination with the demonstration that seismic velocity is significantly increased within deformed sediments above sills, represent substantial progress towards a better understanding of sill-driven sediment alteration. We mention these things mostly to note that, although we present here velocity analyses for sediments above a sill in a single location, we have performed similar analyses at several other locations along the line. Velocity within disturbed sediments is shown to increase relative to a nearby undeformed or moderately deformed reference section in each case except one, where indications of gas within the deformed sediments are observed and the velocity was found to decrease substantially.

\section{Sediment velocity analysis}

The goal of the sediment velocity analysis is to determine the change in sediment velocity that accompanies sill intrusion. This goal accomplishes at least two things. First, a measurement of significantly higher seismic velocities within deformed sediments above an interpreted sill relative to nearby undeformed sediments of the same stratal units provides strong support for the interpretation of the MCS image as representing that particular sill/sediment relationship. Second, the ability to remotely measure (e.g., using seismic data instead of drilling) changes in sedimentary properties due to sill intrusion is a necessary first step in understanding sill/sediment alteration processes. Measuring a change in the seismic velocity of a sedimentary section requires two measurements, one for a reference "pre-change" section and one for a correlative modified section. As noted above, the most compelling location for such a measurement is at the location indicated in Fig. $2 b$ and shown enlarged in Fig. 3. This section is ideal not only because of the unambiguous juxtaposition of undeformed sediments (at CDP 14267) and correlative deformed sediments directly overlying a sill (at CDP 14576), but also because the seafloor and strata are flat-lying, and the sill itself is relatively flat. Flatness enables the use of one-dimensional (1-D) travel time equations to estimate seismic velocity.

Our velocity analysis approach involves a 3-layer velocity-model parameterization that includes: the water layer, an upper layer of post-intrusion sediments that are undeformed at both CDP locations, and a layer that encompasses the same stratal 
units in undeformed and deformed states. We estimate interval velocities in these layers by fitting calculated reflection travel times to hand-picked reflection travel times. We perform the analysis in the intercept time-horizontal slowness $(\tau-p)$ domain because reflections are easier to distinguish in the $\tau-p$ domain [Henry et al., 1980] and travel times are easier to calculate. The velocity model is parameterized with constant velocities for Layers 1 and 2 and with a linear velocity gradient in Layer 3. The model is determined in a layer-stripping fashion, estimating the two parameters that define each layer by solving the following equations in succession:

$$
\begin{gathered}
\tau_{1}(p)=2 z_{1} \cdot\left(u_{1}^{2}-p^{2}\right)^{1 / 2} \\
\tau_{2}(p)=\tau_{1}(p)+2\left(z_{2}-z_{1}\right) \cdot\left(u_{2}^{2}-p^{2}\right)^{1 / 2} \\
\tau_{3}(p)=\tau_{1}(p)+\tau_{2}(p)+2 \frac{\left(z_{3}-z_{2}\right)}{\left(v_{3}-v_{2}\right)}\left[\ln \left(\frac{u(z)+\left(u(z)^{2}-p^{2}\right)^{1 / 2}}{p}\right)-\frac{\left(u(z)^{2}-p^{2}\right)^{1 / 2}}{u}\right]_{u_{u\left(z_{3}\right)},}^{\alpha\left(z_{2}\right)}
\end{gathered}
$$

where $u_{1}$ and $u_{2}$ are the slownesses (reciprocal of velocity, $u_{i}=1 / v_{i}$ ) in Layers 1 and 2, $z_{i}$ are the depths to the base of each layer, and the slowness at the top of Layer 3 is fixed as $u_{2}=u\left(z_{2}\right)=1 / v_{2}$ so that Equation (3) is used to estimate only the two parameters $z_{3}$ and $u\left(z_{3}\right)$. The expression for travel time through the third layer in Equation (3) is obtained by solving the integral:

$$
\tau(p)=2 \int_{z_{1}}^{z_{2}}\left(u(z)^{2}-p^{2}\right)^{1 / 2} d z, \quad v(z)=v_{1}+\frac{\left(v_{2}-v_{1}\right)}{\left(z_{2}-z_{1}\right)} z, \quad u(z)=1 / v(z),
$$

which is straightforward to evaluate [Chapman et al., 1988].

The first step in the velocity analysis is transforming the CDP gathers from the observational time-offset $(T-X)$ domain into the $\tau-p$ domain, which we did using the method of Korenaga et al. [1997]. Next, phases corresponding to reflections from the base of the 3 model layers are identified in the $\tau-p$ section and their arrival times are picked (Fig. 4). The two parameters defining each layer $\left(z_{1}, v_{1} ; z_{2}, v_{2}\right.$; and $\left.z_{3}, v_{3}\right)$ are then determined by solving Equations (1)-(3) over a grid that spans an appropriate portion of the two-parameter model space. Predicted arrival times are calculated for each parameter 
combination, and residuals between observed and predicted travel times as well as an estimate of residual correlation are also determined for the entire parameter grid (Fig. 5). The best-fit velocity model is chosen as the model with minimum root-mean-square error (RMSE) among models with uncorrelated residuals. We use the D-statistic, a rank-order estimator for correlation [Press et al., 1986], to test for correlated residuals. Trends in travel time residuals reflect systematically incorrect travel time predictions and thus incorrect model parameters that can be removed from consideration. These trends are easy to discern for highly correlated array data and two-parameter models and so are equally easy to eliminate.

Uncertainties in the estimated model parameters are constrained in two ways. First, by combining the RMSE grid, D-statistic, and standard deviation of the residuals (Fig. 5), we assess the statistical uncertainty, which is akin in this case to the precision, or reproducibility, of the measurement. We test the significance of the D value, along with its variance, and determine a probability for the $\mathrm{D}$ value. Models with purely uncorrelated residuals lie along the curve where $\mathrm{D}=1$, and all models with probably uncorrelated residuals $(|D|>0.5)$ lie very close to this curve. We thus select the best-fit model as that with the minimum RMSE along the $\mathrm{D}=1$ line in the two-parameter space, and we estimate the uncertainty of each parameter as the range spanned by two standard deviations in RMSE along that line. The best-fit velocity models for three adjacent CDPs at the two locations are shown in (Fig. 6). Uncertainty estimates based on the residuals are represented by the thickness of the velocity/depth curves; the uncertainties are quite small and not significant enough to affect the velocity trends observed. Propagation of individual-layer uncertainties through to deeper layers yields uncertainty estimates of $<1 \%$ for Layer $1, \sim 1 \%$ for Layer 2 , and $\sim 2 \%$ for Layer 3 parameters. For Layer 3 , these uncertainties correspond to RMSE values of $\sim 2 \mathrm{~ms}$, or $\sim 0.01 \mathrm{~km} / \mathrm{s}$ in the sedimentary strata directly above sill intrusions. Layer thickness estimates have an uncertainty of $\sim 0.001 \mathrm{~km}$ for an RMSE value of $\sim 2 \mathrm{~ms}$. The precision of the velocity/depth estimates is quite high, commensurate with the resolving potential of pre-stack streamer data with this aperture and for these target depths [Stork, 1992].

The accuracy of the model parameter estimates is assessed by making the measurement at three adjacent CDPs at each location. Adjacent CDP gathers provide 3 
nearly independent estimates of velocity of a nearly identical volume of sediments. The estimates are independent because each of the adjacent CDP gathers consists of traces that are a distinct set of source/receiver pairs. The volume of sediments being sampled is nearly identical because the area spanned by reflection rays is large compared to the 6.25$\mathrm{m}$ spacing of adjacent CDPs. Consider the shape of the fan of rays for a reflection off the base of Layer 3. Within Layer 3, this fan is a triangle with a point at the base of the layer and one side along the top of the layer that is $\sim 300 \mathrm{~m}$ long. The travel time data are sensitive to the average velocity of that volume, and the average velocity of that volume changes very little when it is moved laterally by $6.25 \mathrm{~m}$.

The velocity/depth curves shown in Fig. 6 demonstrate that the accuracy of the velocity estimates is not as high as the precision. The estimated velocity for the base of Layer 3 around CDP 14267 differs by as much as $\sim 0.05 \mathrm{~km} / \mathrm{s}$ and around CDP 14567 by as much $\sim 0.10 \mathrm{~km} / \mathrm{s}$. There are three main reasons for loss of accuracy. The first is imperfection of the 1-D assumption by the presence of lateral velocity variation and reflectors that are not horizontal. The second is imperfections in the data. Each of the adjacent CDP gathers has a different near-trace offset, ranging from 380 to $355 \mathrm{~m}$ for CDPs 14267-14269 and from 218 to $193 \mathrm{~m}$ for CDPs 14576 to 14578 . Each travel time pick contains information about each of the two parameters, layer velocity and layer thickness, and the relative sensitivity of the pick to one parameter versus the other varies with offset [e.g., Stork, 1992]. Depth information is concentrated in near-offset traces and drops off rapidly with increasing offset. Thus, some part of the differences observed in the adjacent-CDP velocity profiles may be a result of this particular type of velocity/depth tradeoff, which would result in this case from differences in the wavelet shape at low $p$. Finally, imperfect correlation in travel time picks from one CDP to the next, equivalent to a bulk time shift of an entire reflection-branch travel time pick for one or more CDP, also contributes to loss of accuracy. In all cases however, the largest difference between adjacent CDPs is in the estimate of the velocity at the base of Layer 3 , and those differences $(0.05-0.10 \mathrm{~km} / \mathrm{s})$ are small compared to the differences in that parameter between the two sites $(0.20-0.41 \mathrm{~km} / \mathrm{s})$.

\section{Estimation of sill thickness}


We have developed an approach for estimating the thickness of igneous sills based on direct indicators of sill velocity and thickness evident in pre-stack $\tau$ - $p$ gathers and the spectra of those gathers. This development grew out of our initial attempts to invert for detailed velocity/depth structure using the iterative linearized waveform inversion approach of Kormendi and Dietrich [1991], and so we review those efforts first. The Kormendi and Dietrich [1991] approach aims to solve the highly nonlinear inverse problem via multiple iterations of a linearized waveform inversion based on Fréchet derivatives determined via perturbation theory and using the reflectivity approach of Kennett and Kerry [1979] to solve the forward problem. The inversion is performed in the $\tau-p$ domain and requires an accurate representation of the source wavelet, so determining this wavelet is the first step in the analysis.

We constructed a source wavelet similar to that of the airgun array from EW0210 through a combination of two methods. We first applied the method of Korenaga et al. [1997], where deconvolution of the primary and first-multiple seafloor reflections provides a seafloor response function that is then deconvolved from the seafloor reflection to yield an estimate of the source wavelet. The subsurface near CDP 14500 is not ideal for this analysis. The seafloor reflection is weak, and the correspondingly weak multiple reflection lies within the time region of strong sill reflectors. We stacked the traces from near-offset channels along a section of flat-lying seafloor near CDP 14500 in order to increase the strength of the primary and multiple seafloor reflections relative to deeper scatters and used this stacked trace for the successive deconvolutions. The resulting wavelet had an expected nearly minimum-phase shape, but the frequency spectrum of the wavelet contained anomalously high frequencies that did not match the frequency spectra of the shallow stacked section. We thus designed a Butterworth frequency filter that, when applied to a spike, created a wavelet that matches the shape of the wavelet obtained via deconvolution and also matches the same frequency spectra of the stacked data over the 21-62 $\mathrm{Hz}$ frequency band. This wavelet was used in our attempted application of the waveform inversion approach and also in the creation of subsequent synthetic seismograms shown here. 
A number of tests of the waveform inversion scheme on synthetic datasets demonstrated that this approach would not work for igneous sills intruded into soft sediments. A careful reading of Dietrich and Kormendi [1990] gives a clear indication of why this is the case. The linearized inversion is based on a Born approximation suitable for small, weak scatterers. For the case of 1-D, layered strata, this means thin layers (fractions of a wavelength) with small velocity differences, cumulatively, in density and P- and S-wave velocity between layers. Dietrich and Kormendi [1990] note that the wavefield predicted from perturbation theory "fails radically" near the critical ray parameters for P- and S-waves, and that it fails for large layer thicknesses of a wavelength or more. Those two features are characteristic of sills in sediments. To understand the nature of the failure better, we generated a suite of synthetic $\tau-p$ sections for models containing igneous sills with a range of thicknesses and constant velocities using the reconstructed source wavelet and the velocity models from our travel time results for sediment structure. We modeled a 50-m-thick sill with $\mathrm{V}_{\mathrm{P}}$ ranging from 3.5 to $5.0 \mathrm{~km} / \mathrm{s}$ (Fig. 8), and sills with a constant $\mathrm{V}_{\mathrm{P}}$ of $4.0 \mathrm{~km} / \mathrm{s}$ at thicknesses from 10 to 200 $\mathrm{m}$. Densities and $\mathrm{V}_{\mathrm{S}}$ for these models were determined from $\mathrm{V}_{\mathrm{P}}$ using relationships given by Brocher [2005]:

$$
\begin{aligned}
& \rho=1.6612 V_{P}-0.4721 V_{P}^{2}+0.0671 V_{P}^{3}+0.0043 V_{P}^{4}+0.000106 V_{P}^{5} \\
& V_{S}=0.7858-1.2344 V_{P}+0.7949 V_{P}^{2}-0.1238 V_{P}^{3}+0.00464 V_{P}^{4} .
\end{aligned}
$$

The synthetic $\tau-p$ sections have distinctive characteristics that are diagnostic of sill properties. The most important feature is the onset of a $\pi / 2$ phase shift at $p=1 / V_{P_{s i l l}}$ followed by a rapid decay in reflection amplitude with increasing $p$. It is this phase shift and corresponding amplitude decay that are not captured by the perturbation theory of the linearized inversion. The phase shift is driven by evanescent converted S-wave energy which, in contrast to the acoustic synthetics on the right panels of Figs. 8 and 9, destructively interferes with the top-side sill reflection. This feature is important because it provides a direct indicator of P-wave velocity within the sill layer, indicated by the red arrows in Fig. 8, irrespective of sill thickness. With this velocity directly indicated and the velocity of the overlying sediments known from travel time modeling, the thickness of the sill can be estimated through forward modeling of the waveforms. A second 
diagnostic feature that can guide this forward modeling is the strengthening of reflection amplitude at larger $p$. This strengthening is due to the weakening of destructive interference and also to tuning of the converted S-wave reflection from the base of the layer, which is approaching the critical angle for that phase.

The direct indicator of sill $V_{P}$ provided by the amplitude versus $p$ behavior of the sill reflector also provides the opportunity to directly estimate sill thickness and, in principal, $V_{S}$ from the spectra of the reflection. This can be done by modeling notches in the spectra predicted to arise from the destructive interference of phases reflecting off the top and bottom boundaries of the sill, which should have reflection coefficients of nearly equal magnitude but opposite sign (Fig. 7). To understand how this can be done, consider a frequency-domain form of the seismic reflection response from a single layer (i.e., the displacement of the upward propagating wave from the layer) that can be written as

$$
R(\omega, p)=A(p) e^{i \omega \tau_{1}}+\sum B_{i}(p) e^{i \omega \tau_{i}}, \quad \tau_{i}=\tau_{1}+z q_{i}^{d o w n}+z q_{i}^{u p}, \quad q_{k}=\sqrt{u_{k}^{2}-p^{2}}
$$

where the $A$ and $B_{i}$ terms are reflection/transmission coefficients (RTCs) from the top $(A)$ and bottom $(B)$ of the layer, $z$ is the thickness of the layer, $p$ is the ray parameter, $i$ indexes a particular seismic phase (example below), $u_{i}$ are layer slownesses, and $q_{k}$ are vertical slownesses, which might differ for the up- and down-going legs of the reflection from the base of the layer if the reflection converts from $\mathrm{P}$ to $\mathrm{S}$ or vice versa. Marine MCS data only record compressional waves, and so we are only concerned with energy that is traveling upward from the top of the sill as a P-wave. This includes a P-wave incident on and reflected from the top of the sill as a P-wave (the $A(p)$ term in Equation 7) plus other phases that are transmitted into the sill, reflected off its base, and then transmitted out of the sill as a P-wave. A phase that we are interested in, for example, is a P-wave incident on the top interface, transmitted into the sill as an S-wave, reflected upward off the bottom of the sill as a P-wave, and transmitted through the top of the sill as a P-wave. The $B_{i}$ of this phase (from Equation 7), which we could call $\mathrm{B}_{\mathrm{PSPP}}$, consists of the product of a downgoing transmission coefficient converting $\mathrm{P}$ to $\mathrm{S}$, a reflection coefficient converting S to $\mathrm{P}$, and an upgoing P-to-P transmission coefficient:

$$
B_{P S P P}=\stackrel{\prime}{P} \stackrel{I}{1}_{S} \cdot S_{2} \stackrel{\prime}{P} \cdot \stackrel{P}{P}_{1} \stackrel{\prime}{P} .
$$


In this nomenclature, the other relevant $B_{i}$ phases summed in Equation (7) are $B_{P P P P,}$ $B_{P P S P}$ and $B_{P S S P}$. Expressions for each of the RTCs in these phases are quite long and also well known [Aki and Richards, 1980], and so we do not reproduce them here but note that they are in general complex quantities. Vertical slownesses for P- and S-waves $\left(q_{k}\right.$ in Equation 7) appear throughout those expressions, and vertical slowness becomes complex for angles of incidence where $p>u_{k}$. The effect of the product of these complex components is to introduce a phase shift into the displacement of the interface.

The reflection response from a sill layer with reflection coefficients at the top and bottom interfaces of nearly equal magnitude but opposite sign will have spectral notches due to destructive interference at $f(p)=1 / \tau(p)$ when the reflection coefficients and vertical slowness are purely real. When the vertical slowness of either reflection leg is imaginary for a given phase, the notch is shifted in the manner that the slowness vector is rotated in the complex plane. The product of the RTCs is likely to also be complex in this case, producing corresponding phase shifts in the response and thus the notch location. At present we are only interested in estimating sill thickness, which can be determined from pre-critical P-wave reflections, and so we ignore the phase shifts due to complex RTCs and plot notch locations using the expressions:

$$
\begin{gathered}
f_{i}(p)=n /\left(\left|\tau_{i}(p)\right| \cdot \cos (\theta(p))\right) \\
\theta_{i}(p)=\operatorname{phase}\left(q_{i}^{\text {down }}+q_{i}^{\text {down }}\right)
\end{gathered}
$$

where the index $n$ in Equation (9) indicates the harmonic of the frequency notch being calculated and the function phase in Equation (10) returns a phase angle in the correct quadrant. The notch according to Equation (9) is shown plotted for $n=1,2$ and phases $B_{P P P P}, B_{P P S P}$ and $B_{P S S P}$ with the spectra of the calculated synthetics in Figs. 10 and 11. For the acoustic case on the right, the relationship between the $B_{P P P P}$ and the single notch is evident. For the elastic case, the spectral notches appear in locations where amplitudes are strong, though the predicted notch curves are drawn for all $p$. The $B_{P P P P}$ phase is strong at small $p$ values, the $B_{P P S P}$ phase increases in strength as critical $V_{P}$ is approached, and the $B_{P S S P}$ phase is only strong beyond critical $V_{P}$. Our main interest is in the Preflection notch near normal incidence. 
The distinct character of a sill reflection relative to a sedimentary reflection is demonstrated in Figs. 12 and 13. The $\tau-p$ gather for CDP 14288, where sediments are undisturbed, is shown in Fig. 12 along with an isolated sediment reflector and its spectra. The amplitude versus $p$ behavior of the reflection is relatively constant, and the frequency spectra do not show evident notches. In contrast, the sill reflection from CDP 14448, shown in Fig. 13, exhibits amplitude and phase characteristics that the synthetic sections showed to be diagnostic of an igneous sill layer and indicative of that layer's P-wave velocity, which we estimate to be $4.6 \mathrm{~km} / \mathrm{s}$. The spectra of this event show a notch near $40 \mathrm{~Hz}$ at small $p$ that we use, along with the estimated $V_{P}$, to estimate the sill thickness as $0.062 \mathrm{~km}$. Our estimates of P-wave velocity and layer thickness are sensitive to changes within $0.1 \mathrm{~km} / \mathrm{s}$ and $0.001 \mathrm{~km}$, respectively. The sill reflections and spectra for adjacent CDPs are shown in Fig. 14 to be similar to each other and similar to the synthetic response of a 62-m-thick sill.

\section{Discussion and Conclusions}

Igneous sill intrusion into sediments is increasingly being evoked as a mechanism to explain global-scale changes in climate and ocean chemistry observed to have occurred in the past [Svensen et al., 2004; Bralower, 2008; Turgeon and Creaser, 2008; Svensen et al., 2009; Aarnes et al., 2010; Sell et al., 2014]. This "mechanism" involves a spectrum of processes, from melt generation, transport, and emplacement, to hydrothermal circulation and associated thermo-chemical alteration of host sediments and the release of gases such as carbon dioxide and methane into the ocean. While aspects of the individual processes are well understood, our understanding of the sill-intrusion-into-sediments mechanism as a system is poor. A key reason for this is the existence of only a small number of observations that provide information about the outputs of this type of system, with a key output being the altered sediments within the metamorphic aureole of an intruded sill. Existing observations come from a limited number of drill cores and isolated outcrops of ancient systems, most of which lack sufficient context to enable inferences about the role of the many factors that can modulate the outputs of the system, i.e., the consequences of sill intrusion into sediments. The goal of the work presented in this thesis chapter is to demonstrate how MCS data can be used to provide quantitative 
observations of the consequences of sill intrusion into sediments. We present two types of seismic measurements, one a measure of the change in seismic properties of disturbed sediments above a sill, and the second an estimate of the seismic velocity and thickness of the sill beneath those disturbed sediments.

The MCS data from Guaymas Basin show images of what are interpreted to be igneous sills with disturbed sediments above them. That interpretation is a hypothesis with at least two implied tests: the visibly disturbed sediments above the sill should have higher seismic velocity than correlative undisturbed sediments, and the bright reflection underneath the disturbed sediments should be due to a discrete layer with seismic velocity consistent with an igneous sill. Prior to the work presented in this thesis chapter, this hypothesis had not been put to either of these tests, and the interpretation remained simply an interpretation. Here, however, we have shown that the hypothesis passes both of these tests. We show that visibly disturbed sediments above an igneous sill has experienced a compressional-velocity increase of $\sim 15 \%$. This increase is consistent with the changes in density, porosity, and composition experienced by sediments above and below igneous sills as observed in drill cores from DSDP Leg 64. This type of measurement can be used throughout Guaymas Basin and elsewhere to begin to understand the factors that influence sediment alteration due to sill intrusion. In Guaymas Basin, the influence of sediment type can be assessed with measurements to the southeast of the axial trough, where sediments are dominated by turbidites, and the influence of intrusion depth can be assessed with measurements from along Line 21 of the EW0210 cruise, where sills appear to have been recently intruded at great depth adjacent to the Sonoran margin.

We have also shown that the strong reflection beneath disturbed sediments, interpreted to be a sill, is almost certainly a sill. Analyses of the reflection's waveform and frequency spectra as a function of ray parameter provide compelling evidence that the reflection arises from a 62-m-thick layer with high shear strength, an estimated $V_{P}=4.6 \mathrm{~km} / \mathrm{s}$, and a return to sediment-like seismic properties beneath the layer. Providing strong support to the sill interpretation gives further confidence to other such interpretations. The development of a method for estimating sill thickness enables seismic-velocity proxies for sediment alteration to be coupled with estimates of sill 
thickness, perhaps the dominant factor controlling sill-driven alteration. For example, alteration intensity can now be compared between sills with different measured thicknesses that intruded similar sediments at similar depths.

The approach of modeling frequency notches as a function of ray parameter appears to be novel and may have much wider applicability, as it seems to be an approach that fills an obvious gap in the current tool kit used in the analysis of thin beds. The analysis of seismically thin beds has been a focus of research for decades, beginning on a sound theoretical footing with Widess [1973], and a number of threads have evolved out of this focus. Three threads are closely related to our approach. The first is time-domain forward modeling of amplitude versus angle, which was used by Peron-Pinvidic et al. [2010] to estimate the properties of sills intruded into sediments off of Newfoundland. This approach does not take advantage of the spectral properties of sill reflections to reduce the number of degrees of freedom in the problem. The second is spectral inversion [e.g., Puryear and Castagna, 2008; Puryear et al., 2012], an approach that sharpens the response of post-stack seismic data by (essentially) using spectral notches in stacked normal-incidence traces to invert for components of the reflectivity series at intervals less than the 1/8 wavelength resolution limit (as described by Widess [1973]) of seismic data. This approach can effectively estimate the thickness of thin beds, but because it is formulated specifically for normal incidence, it cannot reveal anything about absolute layer velocities. The third thread is nonlinear inversion of pre-stack data. This approach can in principle find all of the characteristics of a high-velocity thin bed. However, with the slightest amount of noise, this approach will find numerous parameter sets that explain the data and will have no basis for identifying the correct set out of the large number of possible sets. Our approach is premised on the notion that the frequency spectra provide additional information for such a distinction and that, moreover, this information is so diagnostic that a trained Monte Carlo search is unnecessary. Rubino and Velis [2009] incorporate frequency spectra into the cost function for a simulatedannealing, nonlinear inversion approach targeting thin-bed properties. Their results extend the normal-incidence spectral inversion approaches to other angles and thus can provide constraints on seismic velocity. However, that method is highly sensitive to 
noise. Our approach is distinct in that we exclusively consider notch location in the spectra. 


\section{References}

Aarnes, I., Svensen, H., Connolly, J.A.D., and Podladchikov, Y.Y., 2010, How contact metamorphism can trigger global climate changes: Modeling gas generation around igneous sills in sedimentary basins: Geochimica et Cosomochimica Acta, v. 74, p. 7179-7195, doi:10.1016/j.gca.2010.09.011.

Agirrezabala, L.M., Permanyer, A., Suárez-Ruiz, I., and Dorronsoro, C., 2014, Contact metamorphism of organic-rich mudstones and carbon release around a magmatic sill in the Basque-Cantabrian Basin, western Pyrenees: Organic Geochemistry, v. 69, p. 26-35, doi:10.1016/j.orggeochem.2014.01.014.

Aki, K., and Richards, P.G., 1980, Quantitative Seismology, Theory and Methods, W.H. Freeman \& Co., San Francisco.

Bralower, T.J., 2008, Volcanic cause of catastrophe: Nature, v. 454, p. 285-287.

Chapman, C.H., 1978, A new method for computing synthetic seismograms: Geophysical Journal of the Royal Astronomical Society, v. 54, p. 481-518.

Cherrett, A., 2002, The seismic response of a thin basalt layer - relevance to full waveform inversion: Journal of Conference Abstracts, v. 7(2), p. 134-135.

Calvert, S.E., 1966, Accumulation of diatomaceous silica in the sediments of the Gulf of California: Geological Society of America Bulletin, v. 77, p. 569-596.

Coffin, M.F., and Eldholm, O., 1994, Large igneous provinces: Crustal structure, dimensions, and external consequences: AGU Reviews of Geophysics, v. 32, No. 1, p. 1-36.

Curray, J.R., and Moore, D.G., et al., 1982, Init. Repts. DSDP 64, U.S. Gov. Print. Off., Washington, D.C.

Diebold, J.B., and Stoffa, P.L., 1981, The traveltime equation, tau-p mapping, and inversion of common midpoint data: Geophysics, v. 46, No. 3, p. 238-254.

Dietrich, M., and Kormendi, F., 1990, Perturbation of the plane-wave reflectivity of a depth-dependent elastic medium by weak inhomogeneities: Geophysical Journal International, v. 100, p. 203-214.

Einsele, G., 1982, Pliocene and Quaternary mud turbidites in the Gulf of California: Sedimentology, mass physical properties, and significance, in Curray, J.R., Moore, D.G., et al., Init. Repts. DSDP, 64: Washington, p. 511-528.

Einsele, G., Gieskes, J.M., Curray, J., Moore, D.M., Aguayo, E., Aubry, M.-P., Fornari, D., Guerrero, J., Kastner, M., Kelts, K., Lyle, M., Matoba, Y., Molina-Cruz, A., 
Niemitz, J., Rueda, J., Saunders, A., Schrader, H., Simoneit, B., and Vacquier, V., 1980, Intrusion of basaltic sills into highly porous sediments, and resulting hydrothermal activity: Nature, v. 283, p. 4411-445.

Fisher, A.T., and Becker, K., 1991, Heat flow, hydrothermal circulation, and basalt intrusions in the Guaymas Basin, Gulf of California: Earth and Planetary Science Letters, v. 103, p. 84-99.

Fisher, A.T., and Narasimhan, T.N., 1991, Numerical simulations of hydrothermal circulation resulting from basalt intrusions in a buried spreading center: Earth and Planetary Science Letters, v. 103, p. 100-115.

Henry, M., Orcutt, J.A., and Parker, R.L., 1980, A new method for slant stacking refraction data: Geophysical Research Letters, v. 7, No. 12, p. 1073-1076.

Hutnak, M., and Fisher, A.T., 2007, Influence of sedimentation, local and regional hydrothermal circulation, and thermal rebound on measurements of seafloor heat flux: Journal of Geophysical Research, v. 112, B12101, doi: 10.1029/2007JB005022.

Kastner, M., 1982, Evidence for two distinct hydrothermal systems in the Guaymas Basin, in Curray, J.R., Moore, D.G., et al., Init. Repts. DSDP, 64: Washington, p. 1143-1157.

Kennett, B.L.N, and Kerry, N.J., 1979, Seismic waves in a stratified half-space: Geophysical Journal of the Royal Astronomical Society, v. 57, p. 557-583.

Kluesner, J., Lonsdale, P., and González-Fernández, A., 2014, Late Pleistocene cyclicity of sedimentation and spreading-center structure in the Central Gulf of California: Marine Geology, v. 347, p. 58-68.

Korenaga, J., Holbrook, W.S., Singh, S.C., and Minshull, T.A., 1997, Natural gas hydrates on the southeast U.S. margin: Constraints from full waveform and travel time inversions of wide-angle seismic data: Journal of Geophysical Research, v. 102, No. B7, p. 15345-15365.

Kormendi, F., and Dietrich, M., 1991, Nonlinear waveform inversion of plane-wave seismograms in stratified elastic media: Geophysics, v. 56, p. 664-674.

Larson, R.L., 1991, Latest pulse of Earth: Evidence for a mid-Cretaceous superplume: Geology, v. 19, p 547-550.

Lerman, A., Wu, L., Mackenzie, F.T., 2007, CO2 and H2SO4 consumption in weathering and material transport to the ocean, and their role in the global carbon balance: Marine Chemistry, v. 106, p. 326-350. 
Lizarralde, D., Axen, G.J., Brown, H.E., Fletcher, J.M., González-Fernández, A., Harding, A.J., Holbrook, W.S., Kent, G.M., Paramo, P., Sutherland, F., and Umhoefer, P.J., 2007, Variation in styles of rifting in the Gulf of California: Nature, v. 448, p. 466-469, doi: 10.1038/nature06035.

Lizarralde, D., Soule, S.A., Seewald, J.S., and Proskurowski, G., 2010, Carbon release by off-axis magmatism in a young sedimented spreading centre: Nature Geoscience, doi: 10.1038/NGEO1006.

Ludwig, W.F., Nafe, J.E., and Drake, C.L., 1970, Seismic refraction, in Maxwell, A.E., eds., The Sea, v. 4, Wiley-Interscience: New York, p. 53-84.

Maclennan, J., Hulme, T., and Singh, S.C., 2004, Thermal models of oceanic crustal accretion: Linking geophysical, geological, and petrological observations: Geochemistry, Geophysics, Geosystems, v. 5, No. 2, doi: 10.1029/2003GC000605.

Mavko, G., Mukerji, T., and Dvorkin, J., 2009, The Rock Physics Handbook: Tools for Seismic Analysis of Porous Media, New York: Cambridge University Press, 524 p.

McNutt, M.K., and Fischer, K.M., 1987, The South Pacific Superswell, in Keating, B.H., Fryer, P., Batiza, R., and Boehlert, G.W., eds., Seamounts, Islands, and Atolls, American Geophysical Union Geophysical Monograph 43, p. 25-34.

Miller, N.C., and Lizarralde, D., 2012, Thick evaporites and early rifting in the Guaymas Basin, Gulf of California: Geology, v. 41, p. 283-286.

Olsen, P.E., 1997, Stratigraphic record of the Early Mesozoic breakup of Pangea in the Laurasia-Gondwana rift system: Annual Reviews of Earth and Planetary Science Letters, v. 25, p. 337-401.

Partyka, G., Gridley, J., and Lopez, J., 1999, Interpretational applications of spectral decomposition in reservoir characterization: The Leading Edge, v. 18, p. 353-360.

Partyka, G., 2005, Spectral decomposition and spectral inversion: SEG Spring 2005 Distinguished Lecture.

Peron-Pinvidic, G., Shillington, D.J., and Tucholke, B., 2010, Characterization of sills associated with the $U$ reflection on the Newfoundland margin: evidence for widespread early post-rift magmatism on a magma-poor rifted margin: Geophysical Journal International, v. 182, p. 113-136, doi: 10.1111/j.1365246X.2010.04635.x. 
Press, W.H., Flannery, B.P., Teukolsky, S.A., and Vetterling, W.T., 1986, Numerical Recipes: The Art of Scientific Computing, New York: Cambridge University Press, $818 \mathrm{p}$.

Puryear, C.I., and Castagna, J.P., 2008, Layer-thickness determination and stratigraphic interpretation using spectral inversion: Theory and application: Geophysics, v. 73, No. 2, p. R37-R48., doi: 10.1190/1.2838274.

Puryear, C.I., Portniaguine, O.N., Cobos, C.M., and Castagna, J.P., 2012, Constrained least-squares spectral analysis: Application to seismic data: Geophysics, v. 77, No. 5, p. V143-V167, doi: 10.1190/GEO2011-0210.1.

Raymond, A.C., and Murchison, D.G., 1988, Development of organic maturation in the thermal aureoles of sills and its relation to sediment compaction: FUEL, v. 67, p. 1599-1608.

Rubino, J.G., and Velis, D., 2009, Thin-bed prestack spectral inversion: Geophysics, v. 74, no. 4, p. R49-R57, doi: 10.1190/1.3148002.

Schrader, H., 1982, Diatom biostratigraphy and laminated diatomaceous sediments from the Gulf of California, in Curray, J.R., Moore, D.G., et al., Init. Repts. DSDP, 64: Washington, p. 973-981.

Seewald, J.S., Seyfried, W.E., and Thornton, E.C., 1990, Organic-rich sediment alteration: an experimental and theoretical study at elevated temperatures and pressures: Applied Geochemistry, v. 5, p. 193-209.

Sell, B., Ovtcharova, M., Guex, J., Bartolini, A., Jourdan, F., Spangenberg, J.E., Vicente, J.-C., and Schaltegger, U., 2014, Evaluating the temporal link between the Karoo LIP and climatic-biologic events of the Toarcian Stage with high-precision $\mathrm{U}-\mathrm{Pb}$ geochronology: Earth and Planetary Science Letters, v. 408, p. 48-56.

Simoneit, B.R.T., and Bode, GW., 1982, Carbon/carbonate and nitrogen analyses, Leg 64, Gulf of California, in Curray, J.R., Moore, D.G., et al., Init. Repts. DSDP, 64: Washington, p. 1303-1305.

Stock, J.M., and Lee, J., 1994, Do microplates in subduction zones leave a geological record?: Tectonophysics, v. 13, No. 6, p. 1472-1487.

Stoffa, P.L., Buhl, P., Diebold, J.B., and Wenzel, F., 1981, Direct mapping of seismic data to the domain of intercept time and ray parameter - A plane-wave decomposition: Geophysics, v. 46, No. 3, p. 255-267.

Stork, C., 1992, Singular value decomposition of the velocity-reflector depth tradeoff, Part 1: Introduction to using a two-parameter model: Geophysics, v. 57, p 927932. 
Svensen, H., Planke, S., Chevallier, L., Malthe- Sørenssen, A., Corfu, F., and Jamtveit, B., 2007, Hydrothermal venting of greenhouse gases triggering Early Jurassic global warming: Earth and Planetary Science Letters, v. 256, p. 554-566, doi: 10.1016/j.eps1.2007.02.013.

Svensen, H., Planke, S., Malthe-Sørenssen, A., Jamtveit, B., Myklebust, R., Eidem, T.R., and Rey, S.S., 2004, Release of methane from a volcanic basin as a mechanism for initial Eocene global warming: Nature, v. 429, p. 542-545.

Svensen, H., Planke, S., Polozov, A.G., Schmidbauer, N., Corfu, F., Podladchikov, Y.Y., and Jamtveit, B., 2009, Siberian gas venting and the end-Permian environmental crisis: Earth and Planetary Science Letters, v. 277, p. 490-500, doi: 10.1016/j.eps1.2008.11.015.

Turgeon, S.C., and Creaser, R.A., 2008, Cretaceous oceanic anoxic event 2 triggered by a massive magmatic episode: Nature, v. 454, p. 323-326, doi: 10.1038/nature07076.

Widess, M., 1973, How thin is a thin bed?: Geophysics, v. 38, p. 1176-1180.

Zelt, C.A., and Smith, R.B., 1992, Seismic traveltime inversion for 2-D crustal velocity structure: Geophysical Journal International, v. 108, p. 16-34.

Zhang, R., and Castagna, J., 2011, Seismic sparse-layer reflectivity inversion using basis pursuit decomposition: Geophysics, v. 76, No. 6, p. R147-R158., doi: 10.1190/GEO2011-0103.1. 


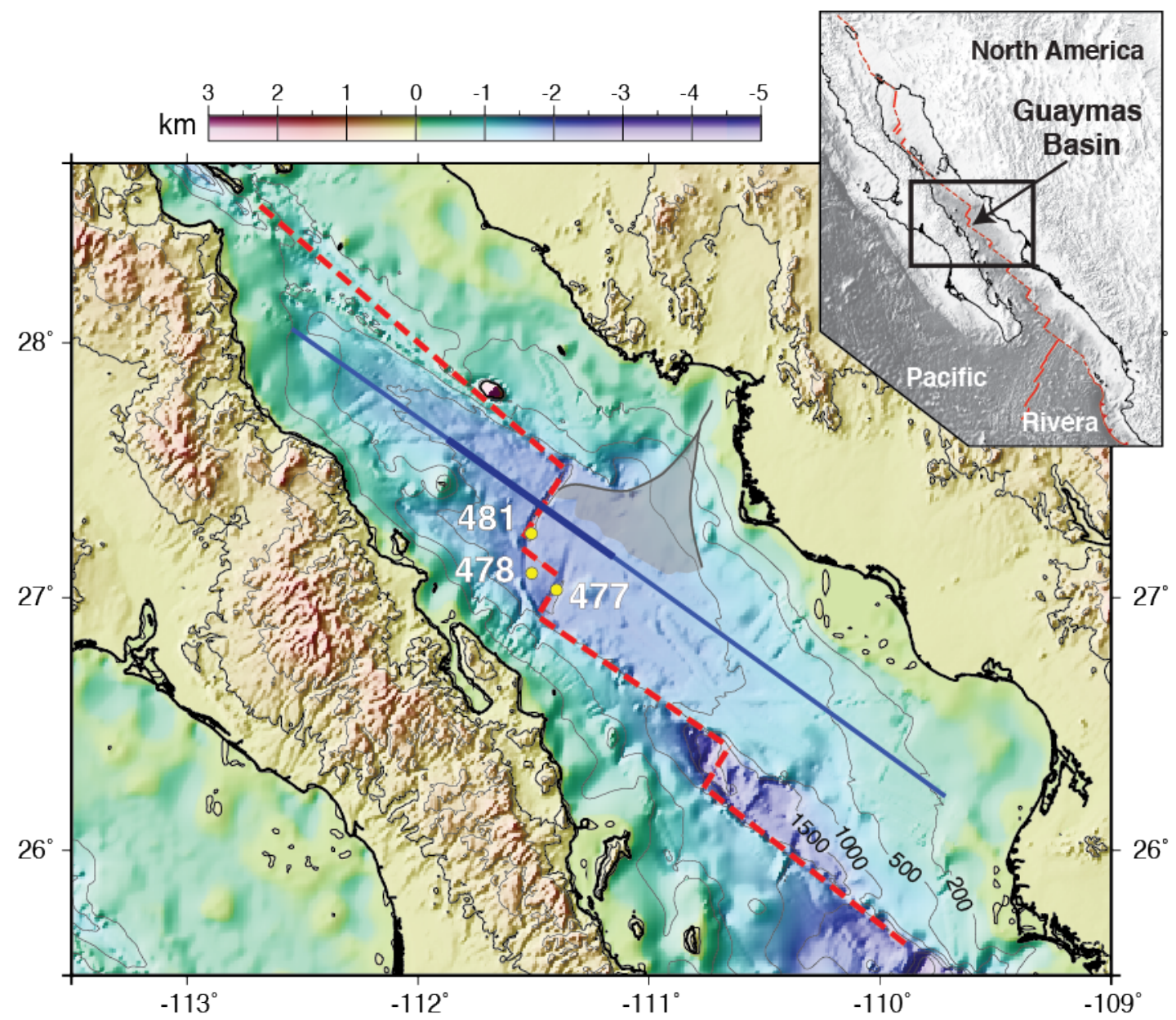

Figure 1. Bathymetry of Guaymas Basin as located within the Gulf of California (inset). Oblique rifting between the Pacific and North American plates is accommodated by seafloor spreading in the Gulf of California, with approximate plate boundaries represented by the dashed red lines. Transect 3 from the PESCADOR seismic experiment is denoted by the blue line, with a thickened segment in the center indicating the section of MCS data discussed in detail. DSDP Leg 64 drilling sites are numbered and located at the yellow circles. From Lizarralde et al. [2010]. 

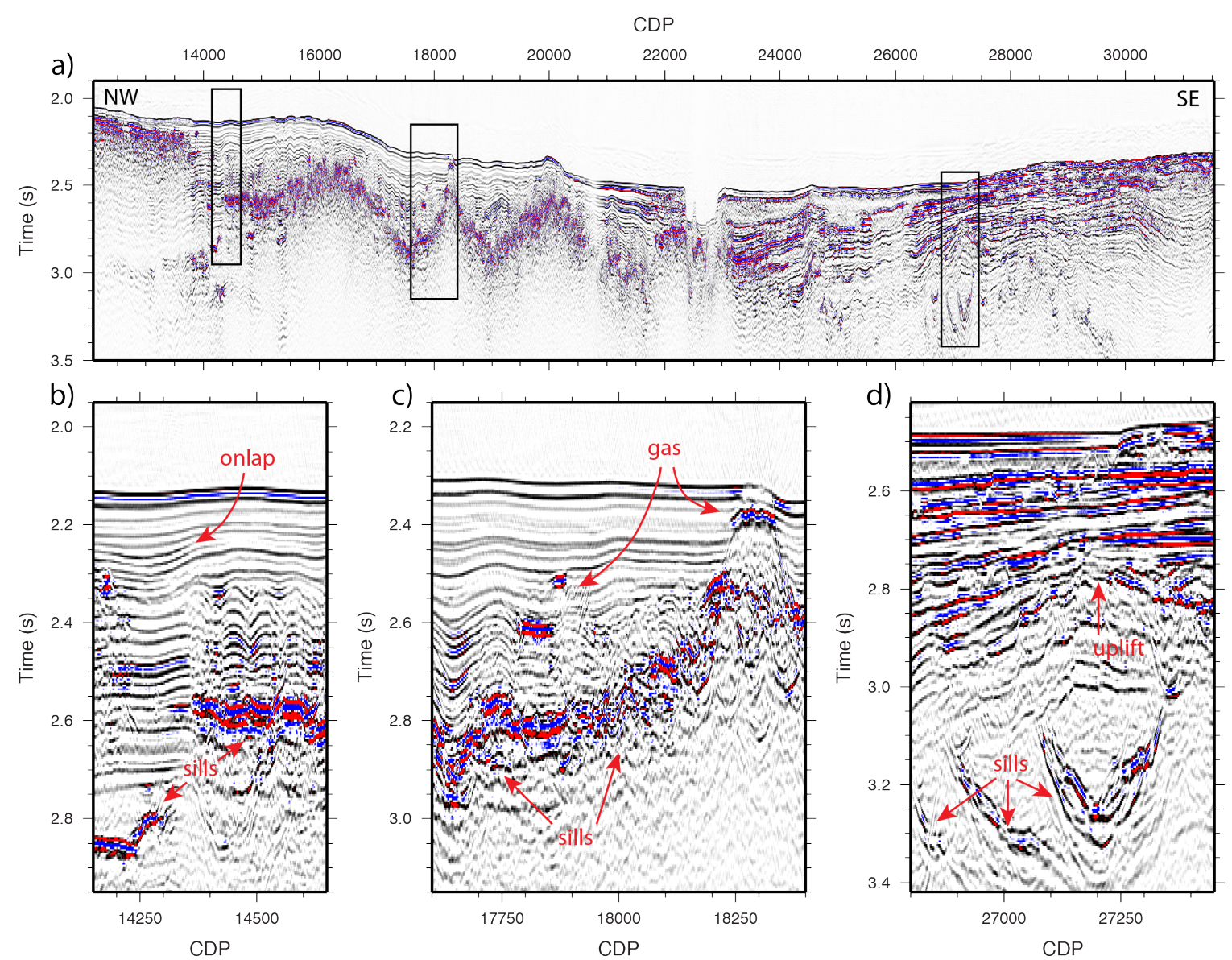

Figure 2. MCS images across Guaymas Basin along Transect 3. (a) Time-migrated stack with large amplitudes in red and blue, indicative of highly reflective strata such as igneous sill intrusions or compacted sediments. CDP gathers are spaced at $\sim 6.25 \mathrm{~m}$, and the length of the MCS profile shown is $\sim 120 \mathrm{~km}$. A nearly continuous horizon of sills is seen northwest of the axial graben, which is located around CDP 22100. Turbidites southeast of the graben may obscure shallow magmatic activity, and sills observed in the southeast occur at greater depths. (b) Seismic stack showing disturbed sediments directly overlying a sill, with sediments adjacent to the sill appearing conformal and relatively undisturbed. Onlap of younger sedimentary strata above the deformed sediments provides age constraints on the emplacement of the sill. (c) Seismic stack showing probable accumulations of shallow gas beneath the seafloor, likely originating from sediments disturbed by sills. (d) Seismic stack showing bowl-shaped sills at depth beneath turbiditic sediments, with resulting sediment deformation and uplift above the sills. 
a)

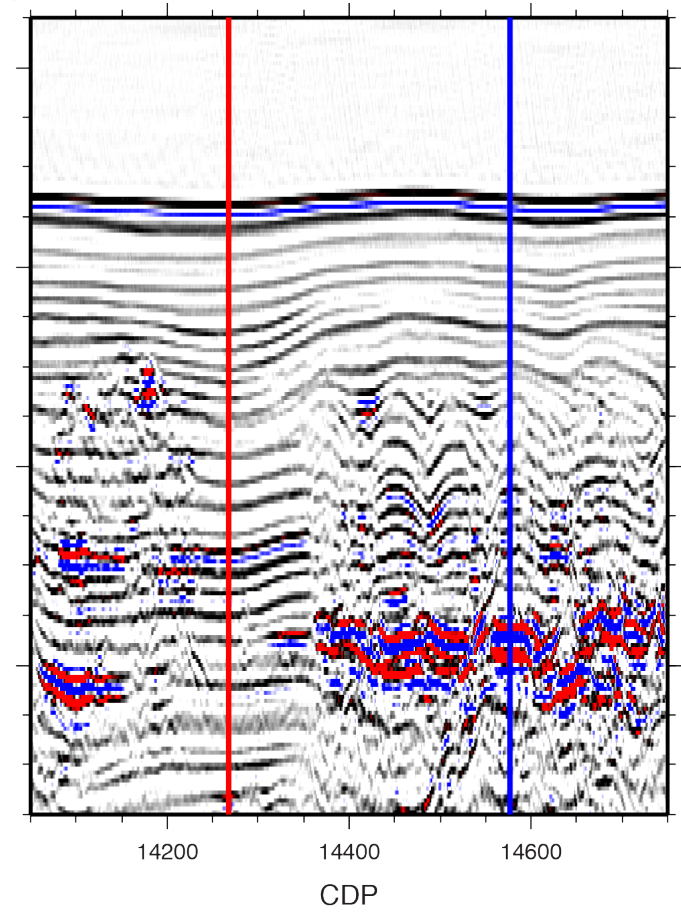

b)

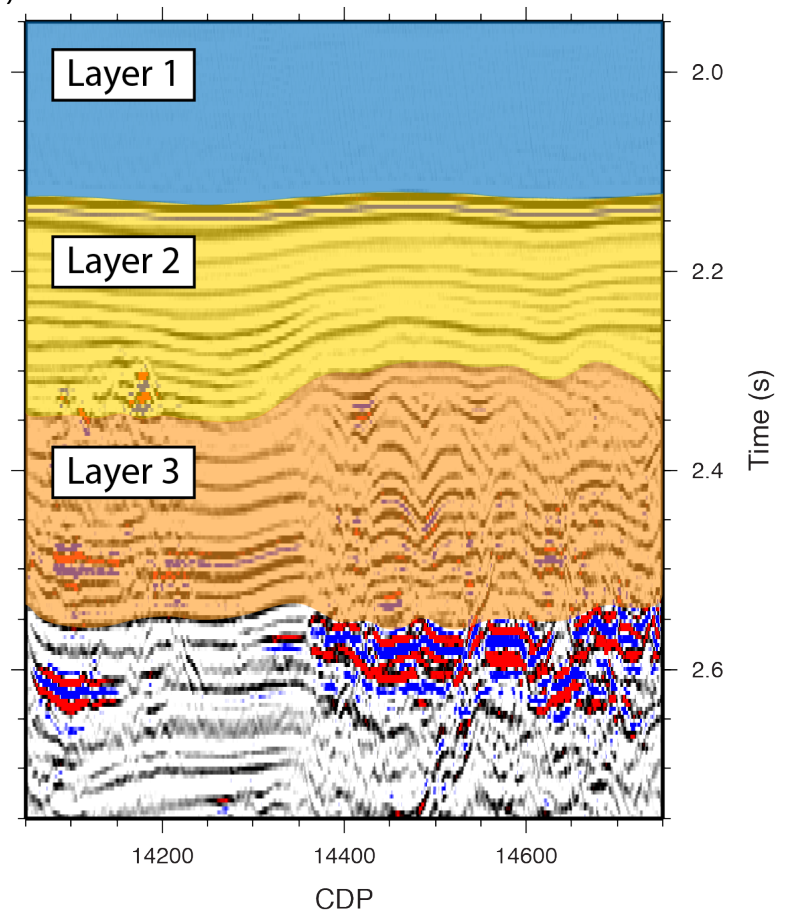

Figure 3. MCS images of sedimentary strata variably disturbed by sill intrusion. (a) Time-migrated stack with CDP gathers 14267 and 14576 indicated by the red and blue vertical lines, respectively. These sediments are found at the northwestern end of Transect 3, and this seismic section provides a reference baseline for estimating the effects of sill intrusion on sediments. (b) Seismic stack showing Layers 1, 2, and 3 used to parameterize the 1-D velocity model. The 3 layers correspond to water (shaded in blue), undisturbed sediments (shaded in yellow), and comparable sediments (shaded in orange). 

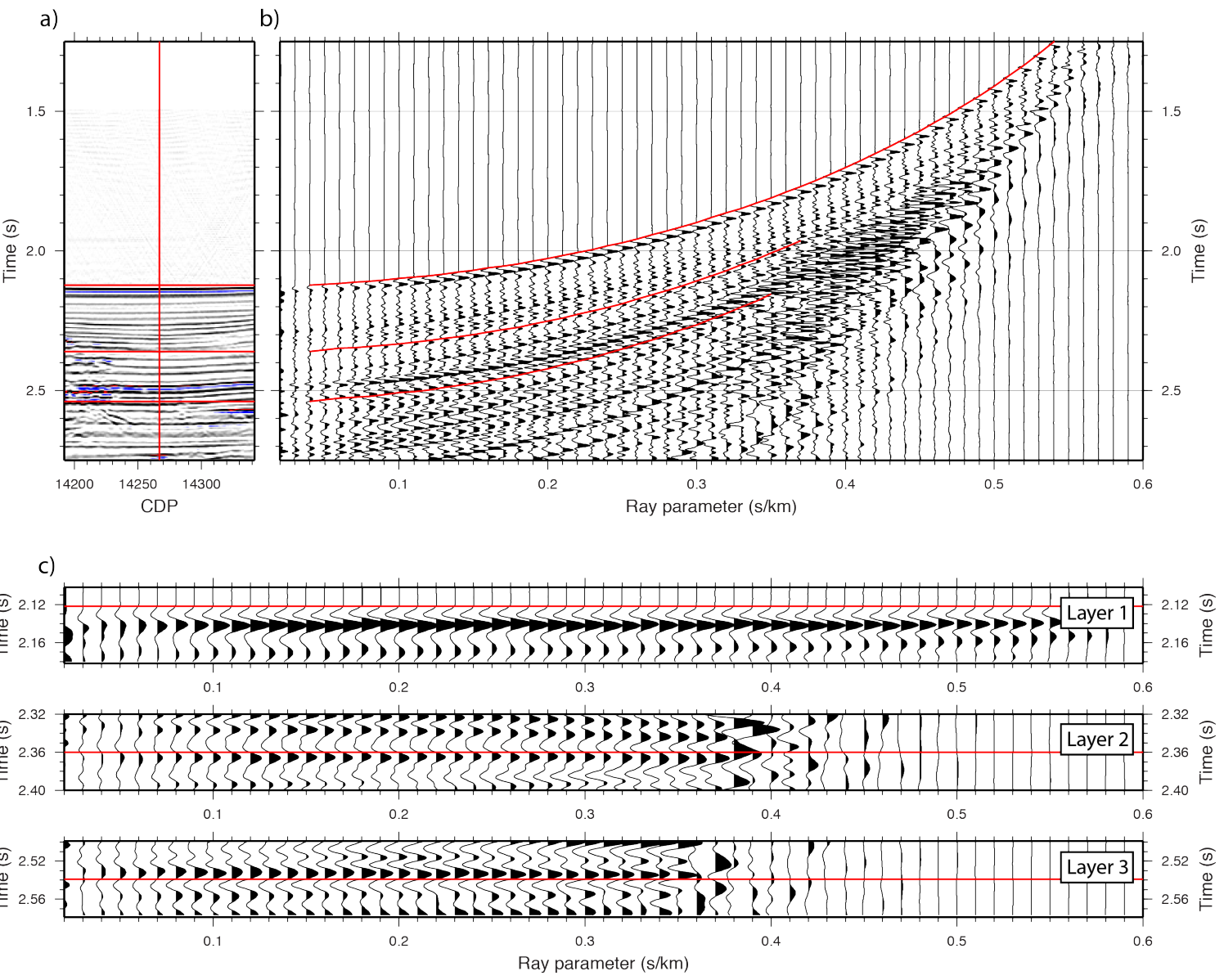

Figure 4. MCS data for CDP 14267 showing picked layer reflections used for travel time analysis. (a) Seismic stack showing sedimentary strata undisturbed by sills. These undisturbed sediments provide a reference for estimating the effects of sill intrusion on sediments. The location of the 1-D seismic velocity model is indicated by the vertical red line. Horizontal red lines correspond to chosen layer boundaries. (b) $\tau$-p transform of the pre-stack CDP gather with arrival times picked for reflections off of three layers. These travel time picks (red curves) are used in a grid search travel time inversion to produce a 1-D velocity model. (c) Reflections from Layers 1, 2, and 3 corresponding to the layer horizons in (a) and (b). Pre-stack CDP gather traces are time-shifted and flattened to picks indicated by the horizontal red lines. Layer reflections from CDP 14267 were selected for to be comparable with corresponding reflections from CDP 14576. 
a)

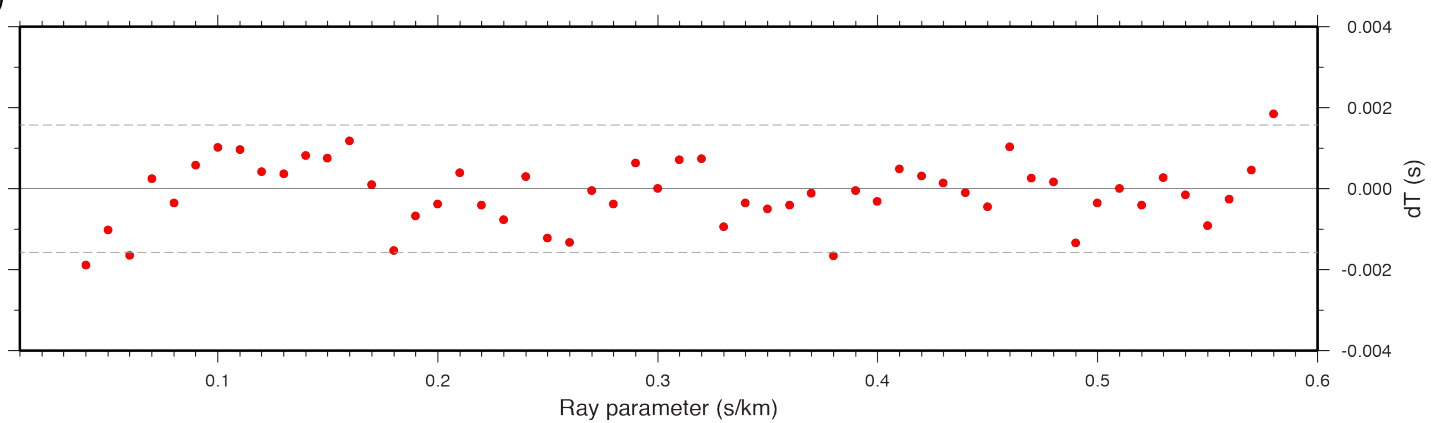

b)

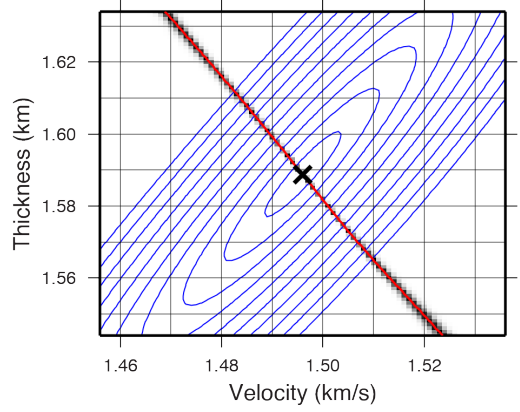

c)

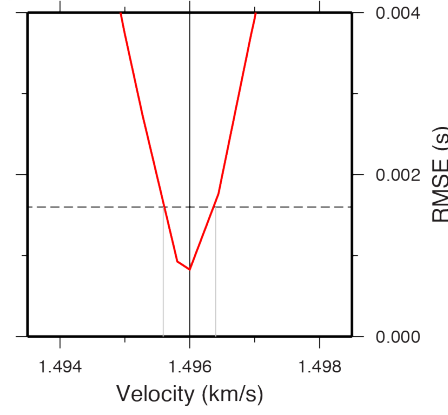

d)

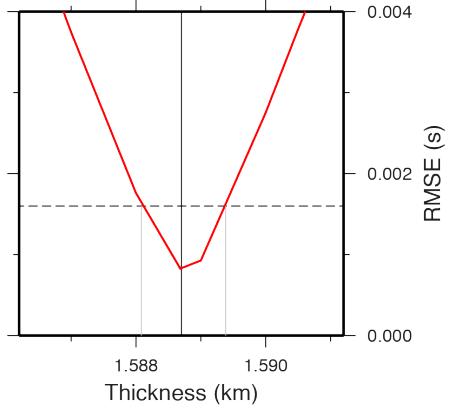

Figure 5. CDP 14267 travel time uncertainty analysis for Layer 1 reflection. (a) Residuals between travel time picks and travel time predictions based on the best-fit model. The dashed lines bound data ranging within two standard deviations. (b) Results of grid search-based travel time inversion. RMSE values (blue contours at $5 \mathrm{~ms}$ intervals) are minimized and coupled with the D-statistic (red line), providing the best-fit model velocity and thickness, which is marked by an $X$ at the center of the grid. (c) RMSE curve (red line) for varying velocities. Uncertainties (vertical grey lines) for the best-fit model parameters are constrained by finding the range of velocities within 2 standard deviations (horizontal dashed black line) of the residuals between the predicted and observed travel times. (d) RMSE curve (red line) for varying thicknesses. Uncertainties (vertical grey lines) for the best-fit model parameters are constrained by finding the range of thicknesses within 2 standard deviations (horizontal dashed black line) of the residuals between the predicted and observed travel times. 

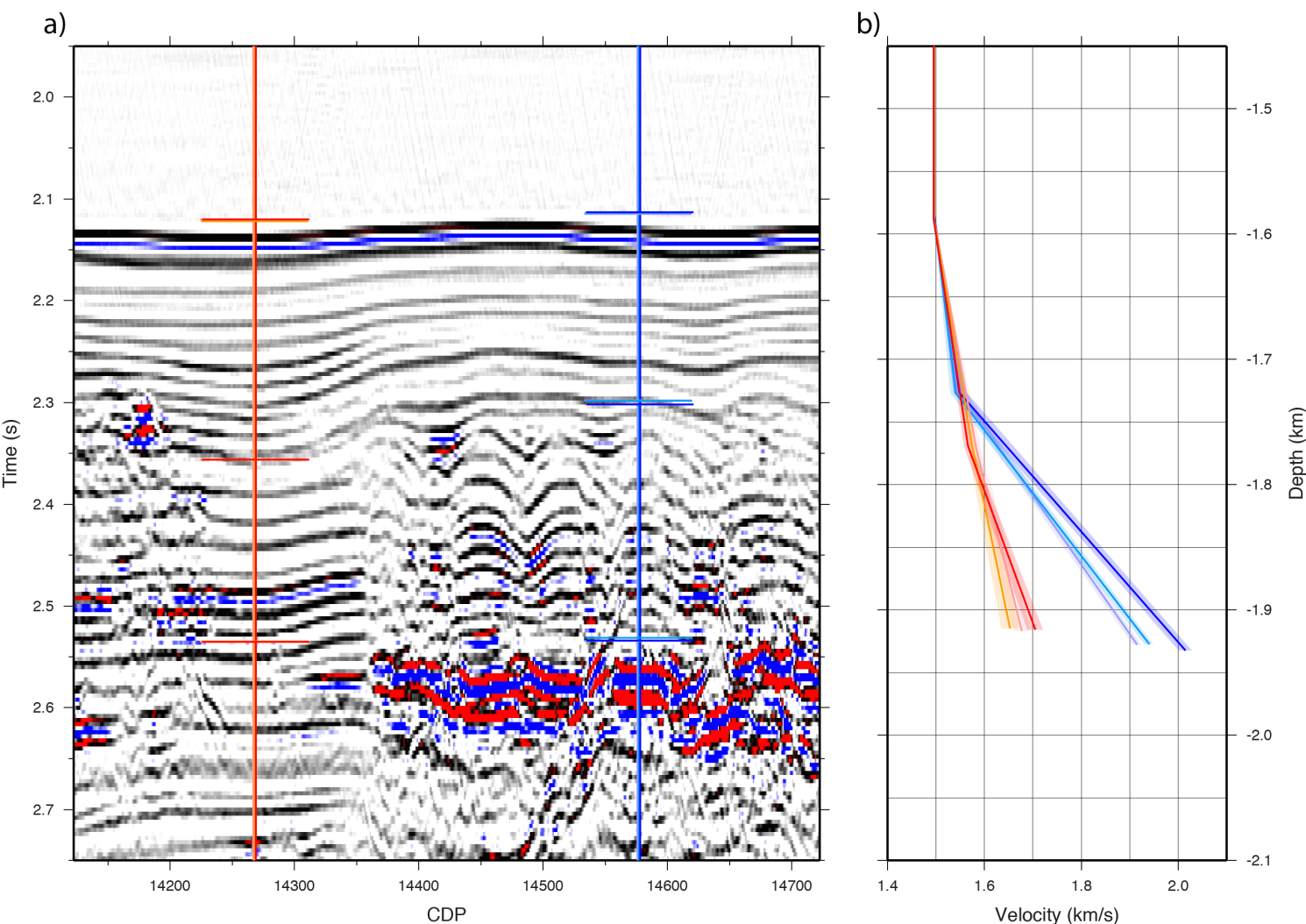

Figure 6. Comparison of sediment velocities around CDPs 14267 and 14576. (a) Timemigrated stack showing locations of CDPs 14267-14269 (vertical lines in shades of red) and 14576-14578 (vertical lines in shades of blue). (b) Velocity models from travel time analysis for CDPs 14267, 14268, 14269, 14576, 14577, and 14578. For all CDPs, velocities are almost indistinguishable within Layers 1 and 2. The increase in Layer 3 velocity from CDPs 14267-14269 to 14576-14578 is attributed to the presence of the sill directly underlying and altering the sediments in CDPs 14576-14578. Uncertainties for the best-fit model parameters are indicated by red and blue shading around the linear velocity gradients. 


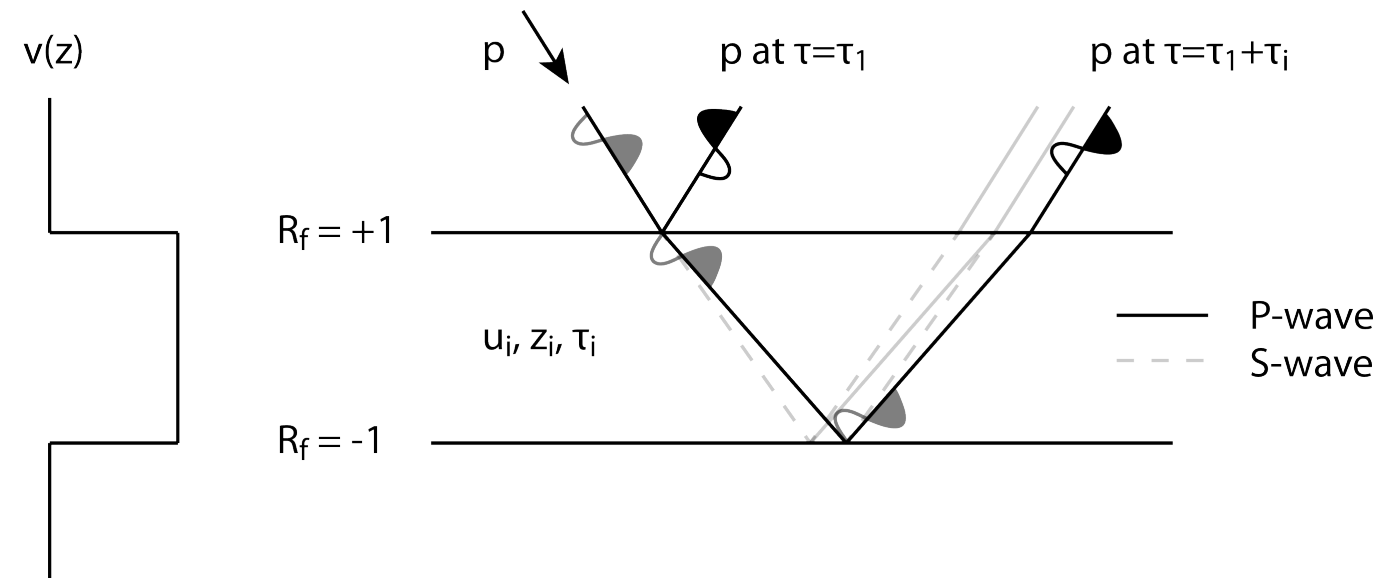

Figure 7. Ray reflections from the top and bottom of a sill layer intruded into sedimentary layers, for a given ray parameter $p$. Velocity as a function of depth is shown to the left. At the top of the sill layer, the downgoing ray indicated by $p$ reflects back up with a positive phase. Reflections from $p$ at the bottom of the sill travel upwards with the opposite phase, due to reflection coefficients at the sill interfaces that are equal or close in magnitude and opposite in sign. The time associated with the ray traveling through the sill layer is $\tau_{\mathrm{i}}$, and the thickness of the sill can be derived from $\tau_{\mathrm{i}}$ at vertical offset. For a specific frequency as a function of the ray indicated by $p$, reflections off the top and bottom of the sill result in destructive interference, which is dependent on the thickness of the sill layer. 

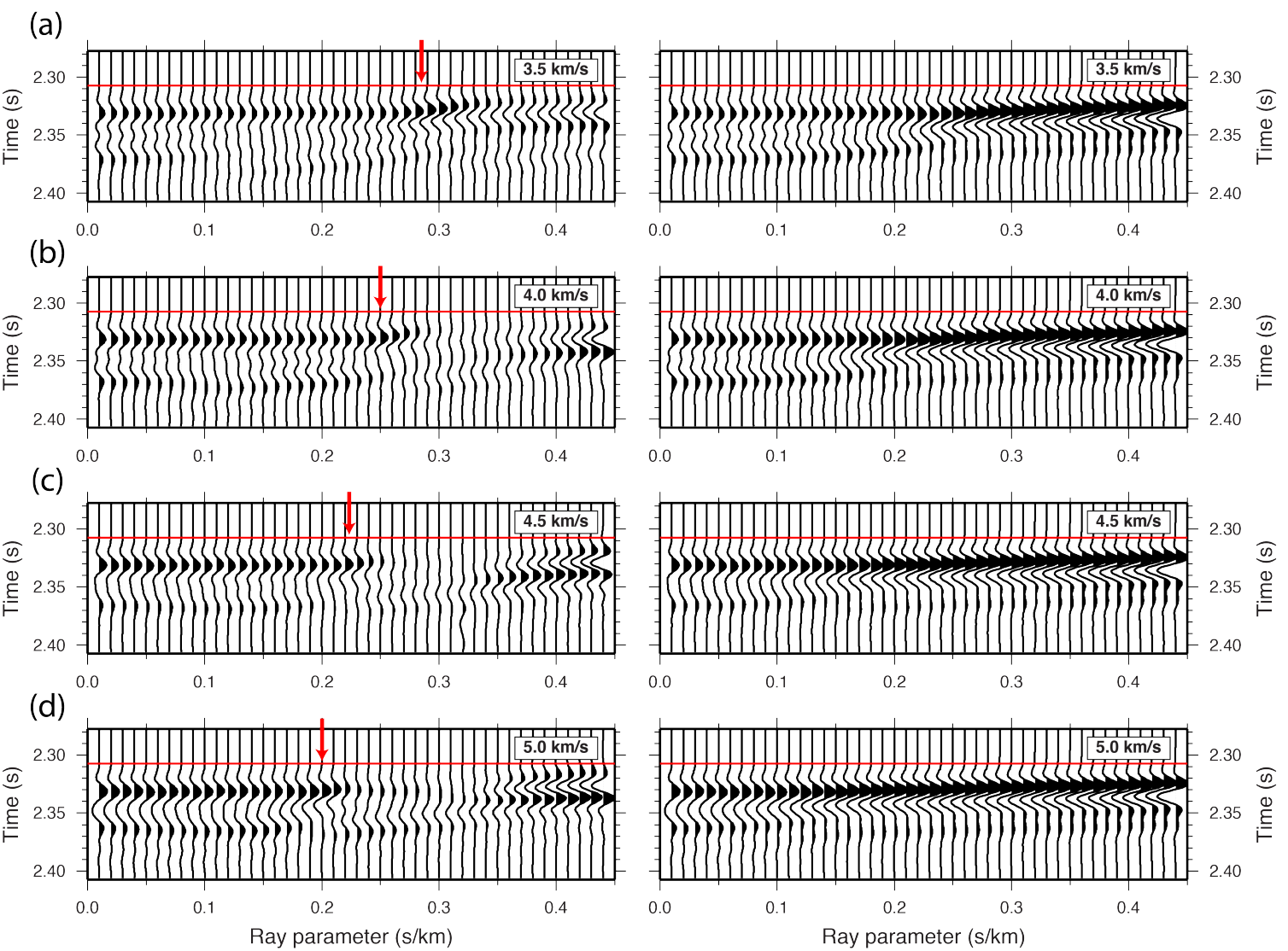

Figure 8. Synthetic waveforms for sill reflections of varying sill P-wave velocity, with sill thickness held constant at $50 \mathrm{~m}$. On the left, S-wave velocity is calculated as a function of P-wave velocity according to Brocher [2005], and on the right, S-wave velocity is set to a negligibly small value $(0.001 \mathrm{~km} / \mathrm{s})$. The horizontal red lines are calculated travel times from the top of the sill reflections, to which the data are flattened. Notably, the P-wave velocity of the sill controls the critical angle and the associated decrease in amplitude versus offset (AVO) and phase change observed as a function of the ray parameter, as indicated by the red arrows. (a) Synthetic waveforms for sills with a P-wave velocity of $3.5 \mathrm{~km} / \mathrm{s}$. (b) Synthetic waveforms for sills with a P-wave velocity of $4.0 \mathrm{~km} / \mathrm{s}$. (c) Synthetic waveforms for sills with a P-wave velocity of $4.5 \mathrm{~km} / \mathrm{s}$. (d) Synthetic waveforms for sills with a P-wave velocity of $5.0 \mathrm{~km} / \mathrm{s}$. 

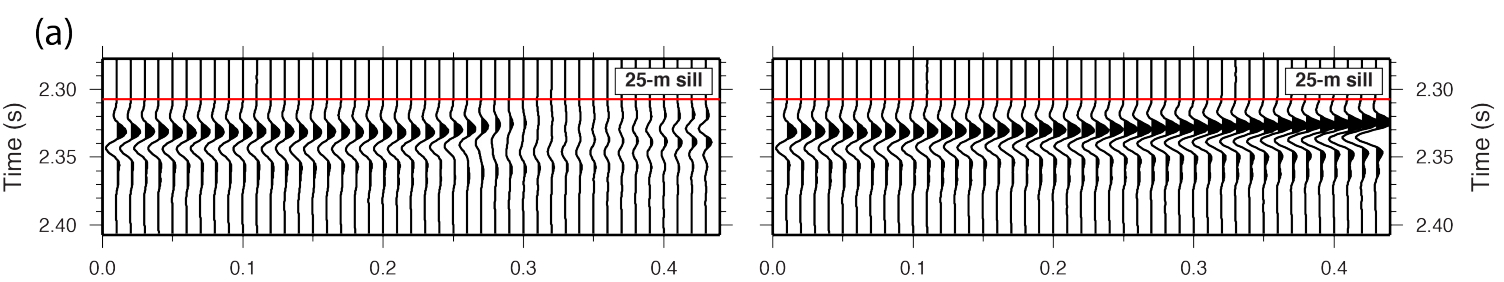

(b)
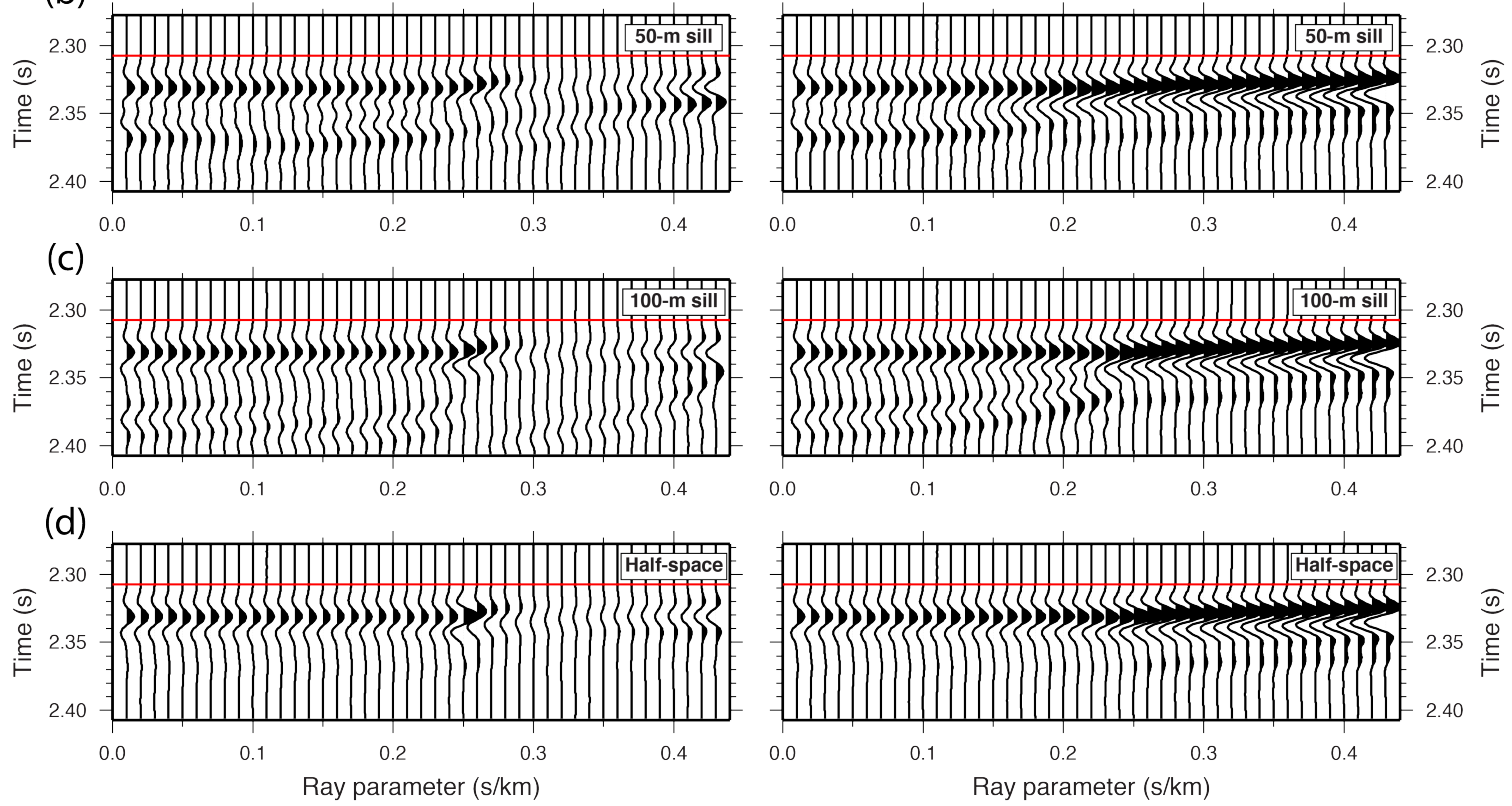

Figure 9. Synthetic waveforms for sill reflections of varying sill thickness, with P-wave velocity held constant at $4.0 \mathrm{~km} / \mathrm{s}$. On the left, S-wave velocity is calculated as a function of P-wave velocity according to Brocher [2005], and on the right, S-wave velocity is set to a negligibly small value $(0.001 \mathrm{~km} / \mathrm{s})$. The horizontal red lines are calculated travel times from the top of the sill reflections, to which the data are flattened. Slight differences in the waveforms are visible with changing sill thickness, including larger delays in P- and S-wave conversions with increasing sill thickness. The conversions do not show up for the half-space case. (a) Synthetic waveforms from 25-m-thick sills. (b) Synthetic waveforms from 50-m-thick sills. (c) Synthetic waveforms from 100-m-thick sills. (d) Synthetic waveforms from half-space reflections. 

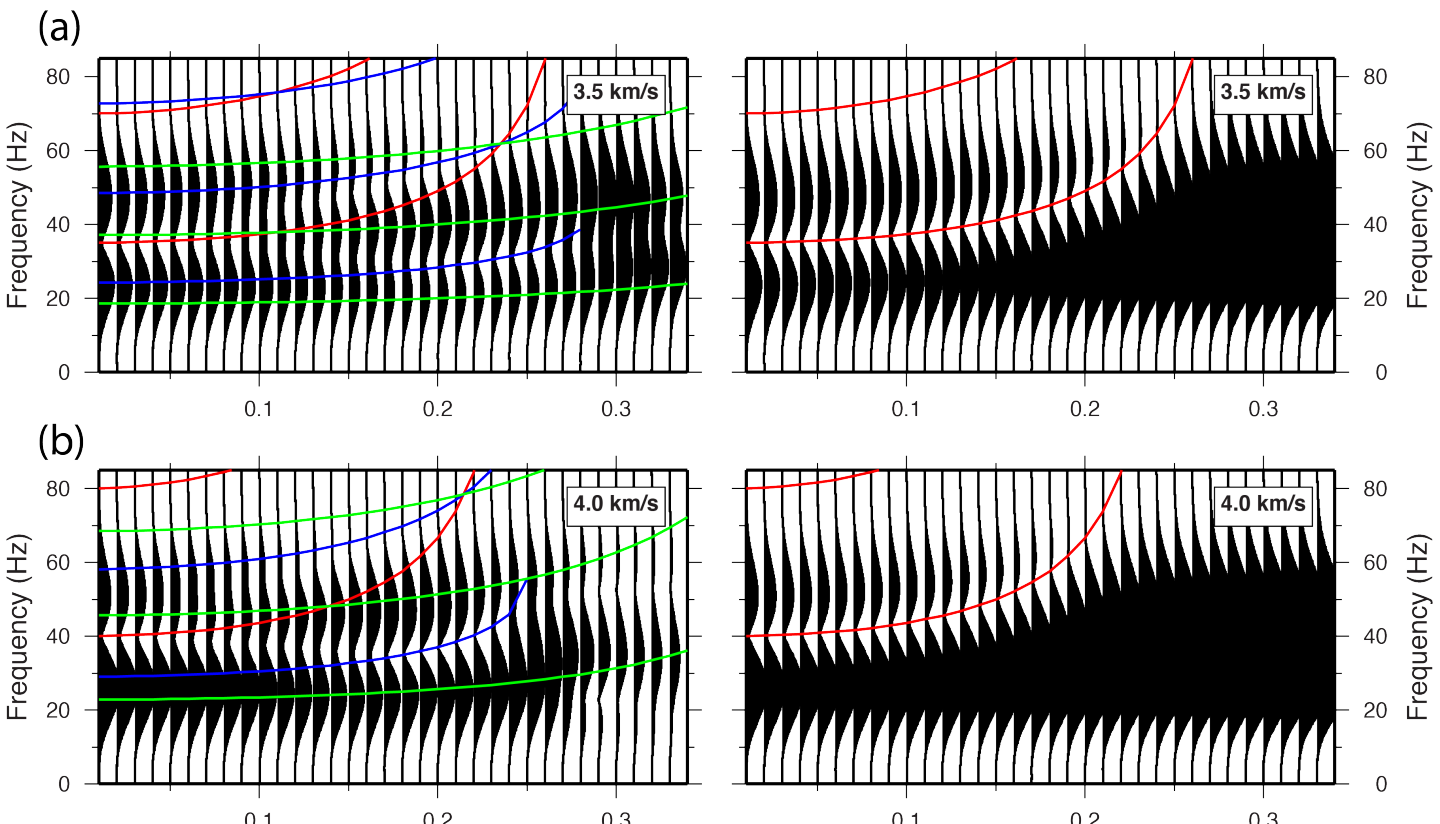

(c)
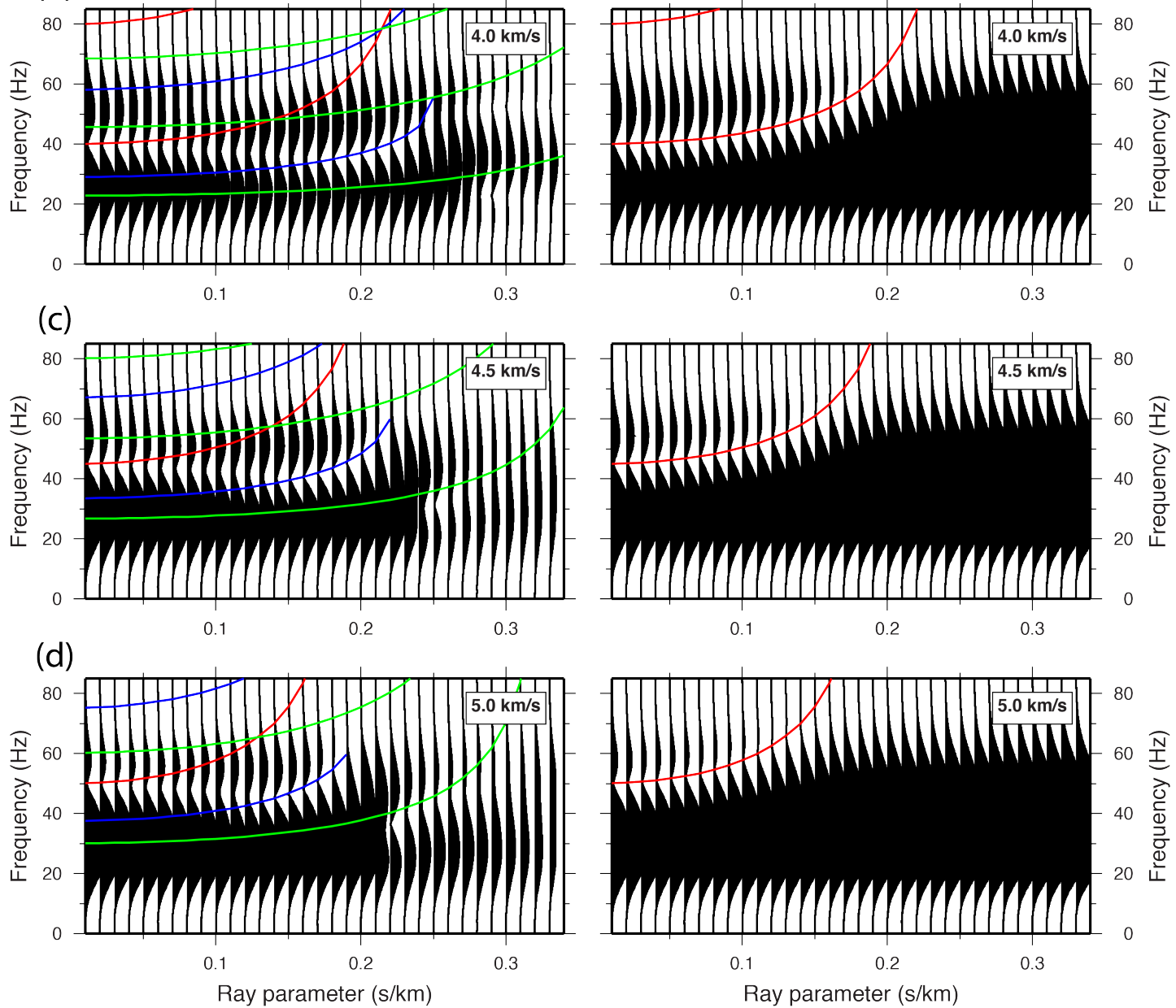

Figure 10. Frequency spectra of synthetic waveforms for sill reflections of varying sill Pwave velocity, with sill thickness held constant at $50 \mathrm{~m}$. On the left, S-wave velocity is calculated as a function of P-wave according to Brocher [2005], and on the right, S-wave velocity is set to a negligibly small value $(0.001 \mathrm{~km} / \mathrm{s})$. Red curves follow notches calculated for PP-waves and multiples, blue curves follow notches calculated for PSwaves and multiples, and green curves follow notches calculated for SS-waves and multiples. The P-wave velocity of the sill is the primary control on the changes in amplitude as a function of the ray parameter. (a) Frequency spectra for sills with a Pwave velocity of $3.5 \mathrm{~km} / \mathrm{s}$. (b) Frequency spectra for sills with a P-wave velocity of 4.0 $\mathrm{km} / \mathrm{s}$. (c) Frequency spectra for sills with a P-wave velocity of $4.5 \mathrm{~km} / \mathrm{s}$. (d) Frequency spectra for sills with a P-wave velocity of $5.0 \mathrm{~km} / \mathrm{s}$. 

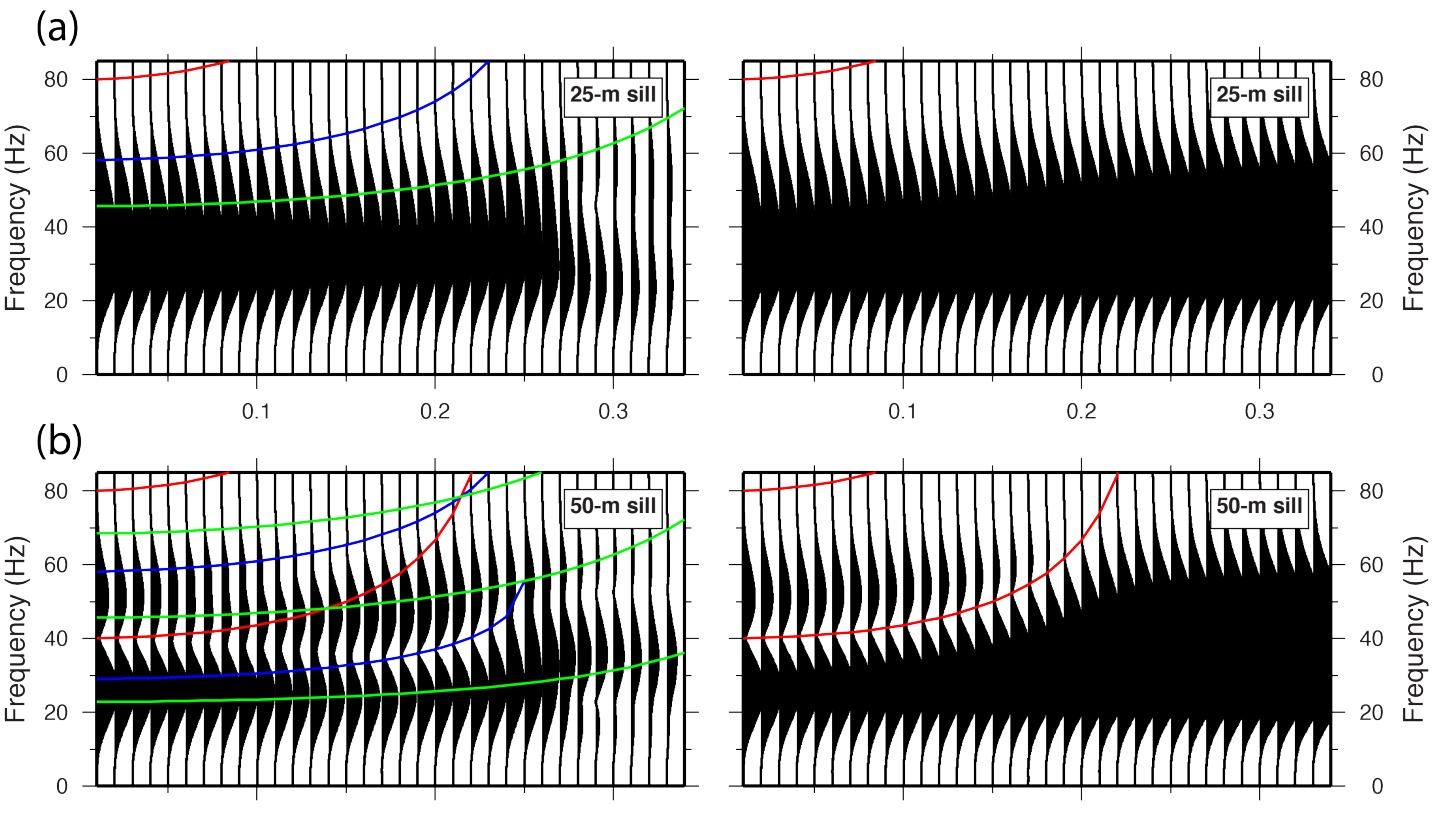

(c)
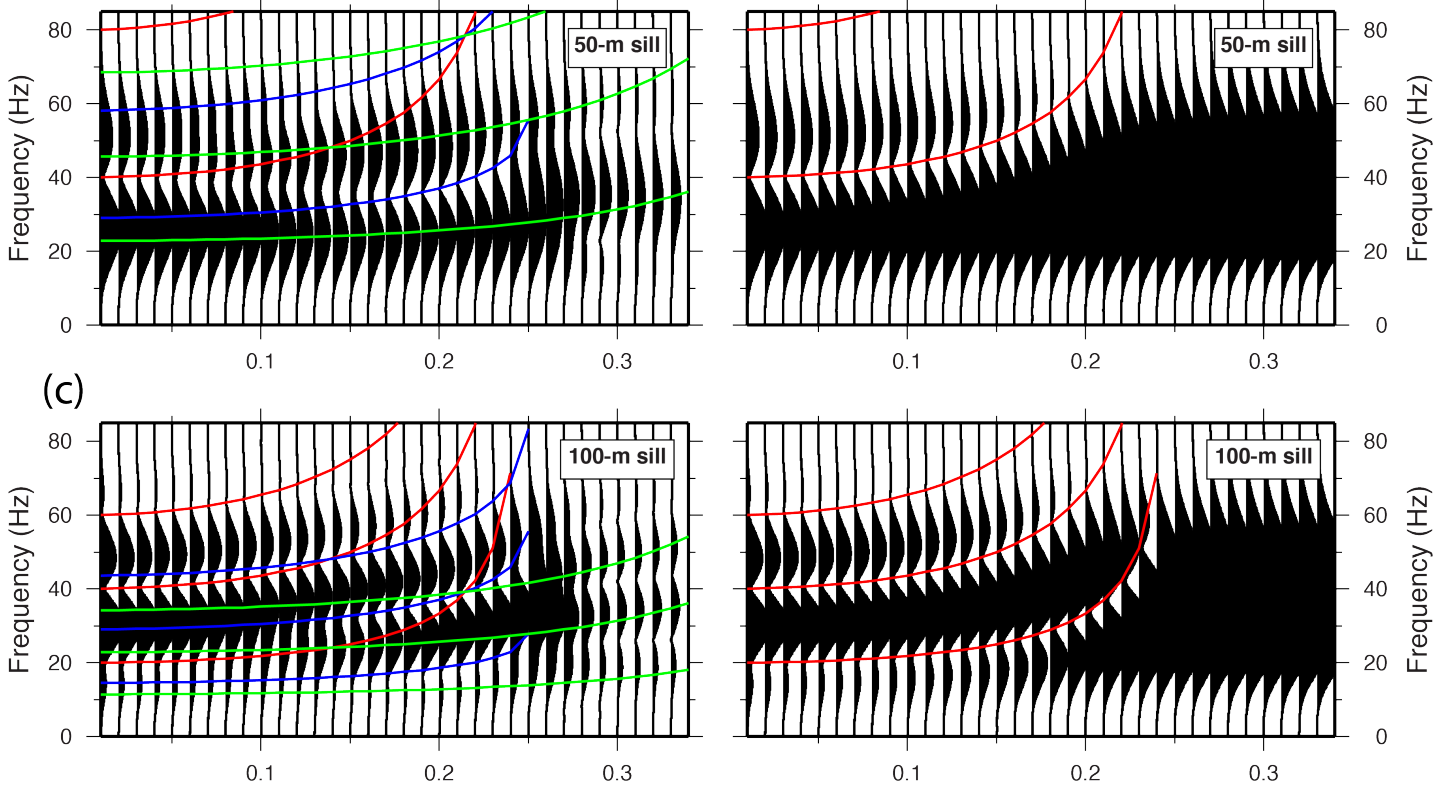

(d)
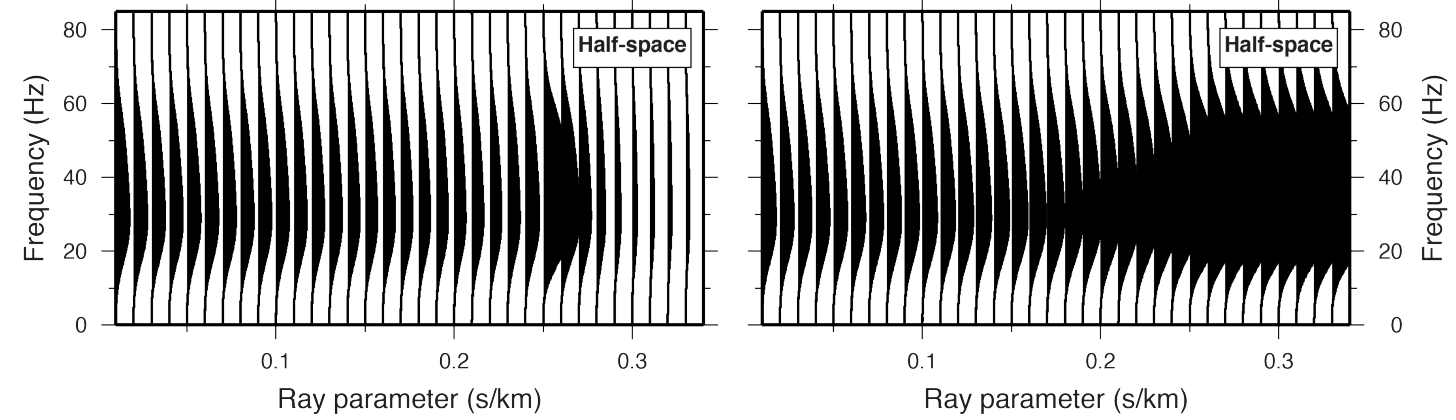

Figure 11. Frequency spectra of synthetic waveforms for sill reflections of varying sill thickness, with P-wave velocity held constant at $4.0 \mathrm{~km} / \mathrm{s}$. On the left, S-wave velocity is calculated as a function of P-wave according to Brocher [2005], and on the right, S-wave velocity is set to a negligibly small value $(0.001 \mathrm{~km} / \mathrm{s})$. Red curves follow notches calculated for PP-waves and multiples, blue curves follow notches calculated for PSwaves and multiples, and green curves follow notches calculated for SS-waves and multiples. Notches are clearly identifiable in the frequency spectra of sills that are 50and 100-m-thick. (a) Frequency spectra for 25-m-thick sills. (b) Frequency spectra for 50-m-thick sills. (c) Frequency spectra for 100-m-thick sills. (d) Frequency spectra for half-space reflections. 
(a)

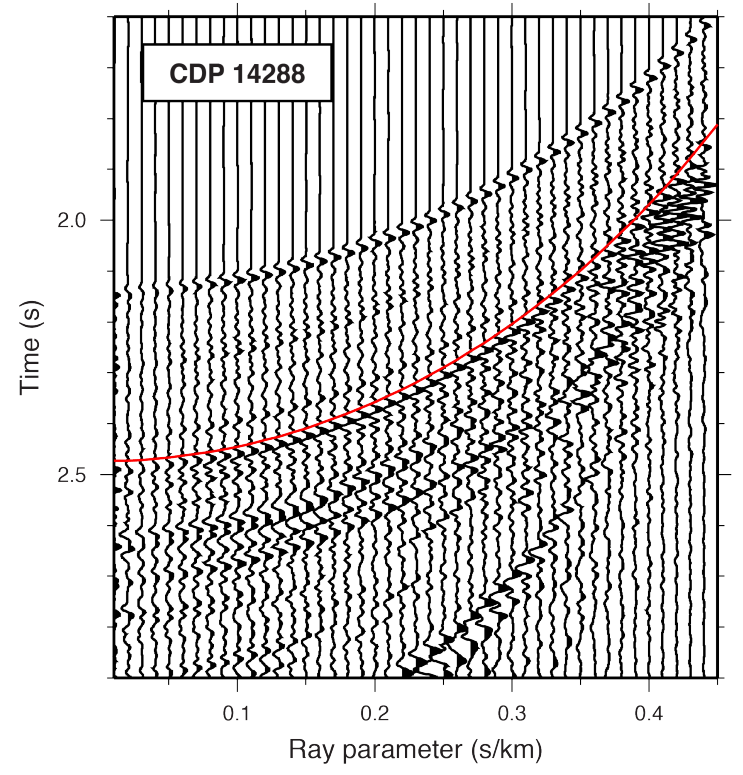

(b)

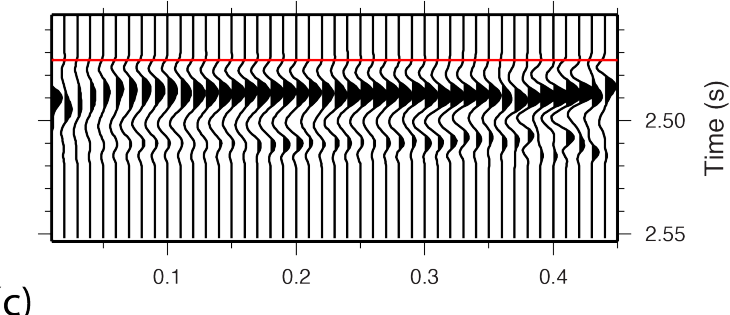

(c)

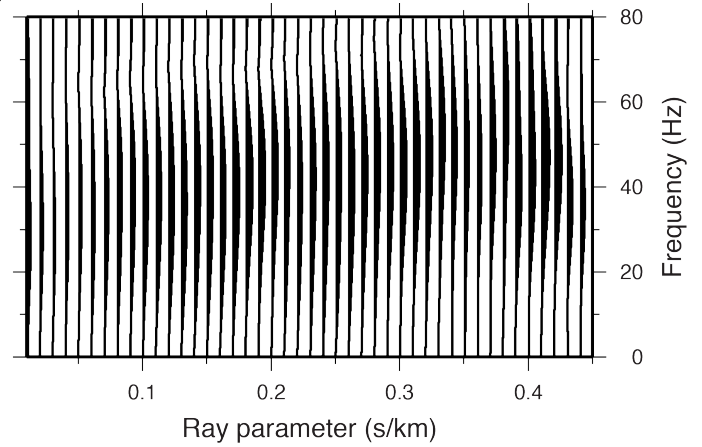

Figure 12. Seismic data from Guaymas Basin at the location of CDP 14288, where the presence of a sill intrusion has not disturbed overlying sediments. (a) $\tau$-p section with travel times for reflections from the top of a reflection calculated (red line). (b) Seismogram flattened to red line from (a) with the reflector windowed over $50 \mathrm{~ms}$. The event shows consistent AVO features, unlike reflections from a sill. (c) Frequency spectrum of the windowed event showing lack of characteristic notches. 
(a)

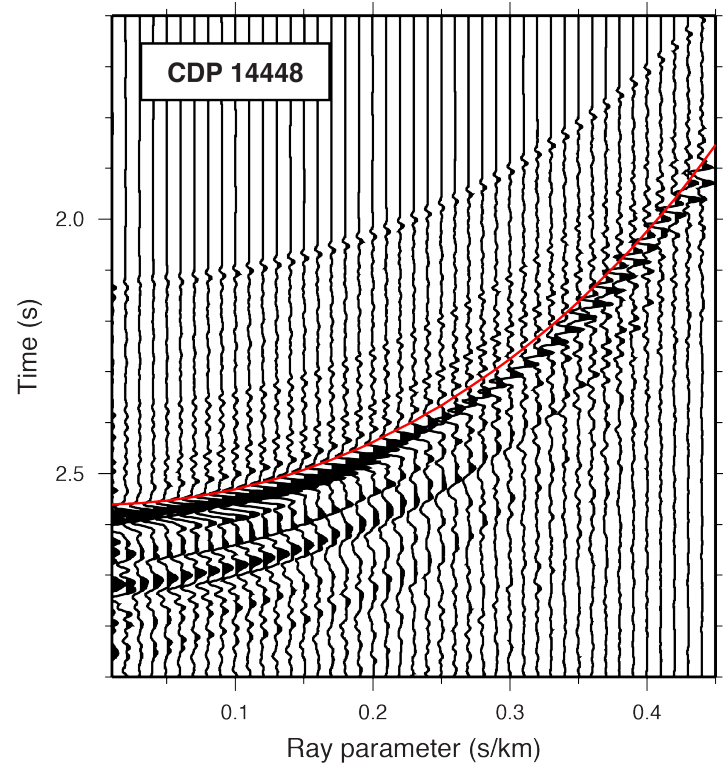

(b)

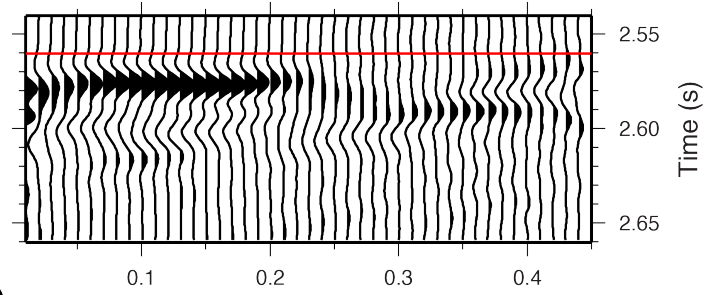

(c)

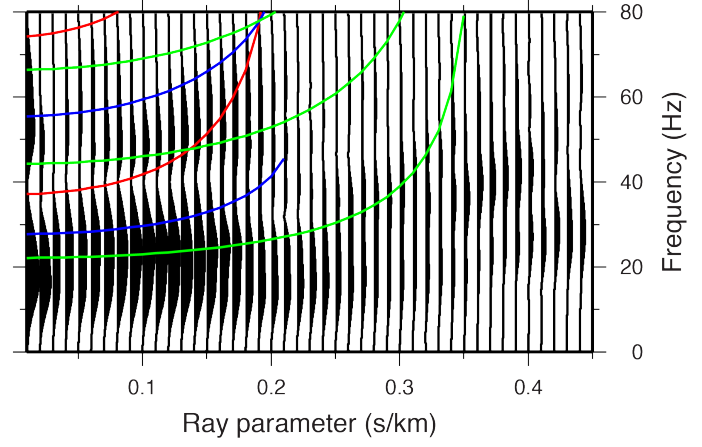

Figure 13. Seismic data from Guaymas Basin at the location of CDP 14448, where a sill intrusion has disrupted overlying sediments. (a) $\tau$-p section with travel times for reflections from the top of the sill calculated (red line). (b) Seismogram flattened to red line from (a) with the sill reflection windowed over $150 \mathrm{~ms}$. Diagnostic AVO features of the sill reflection can be seen, such as an amplitude and phase change at a $p$ of $\sim 0.22$ $\mathrm{s} / \mathrm{km}$. (c) Frequency spectrum of the windowed sill reflection. Red, blue, and green lines are notches calculated for PP-, PS-, and SS-waves from a 62-m-thick sill with a P-wave velocity of $4.6 \mathrm{~km} / \mathrm{s}$. 

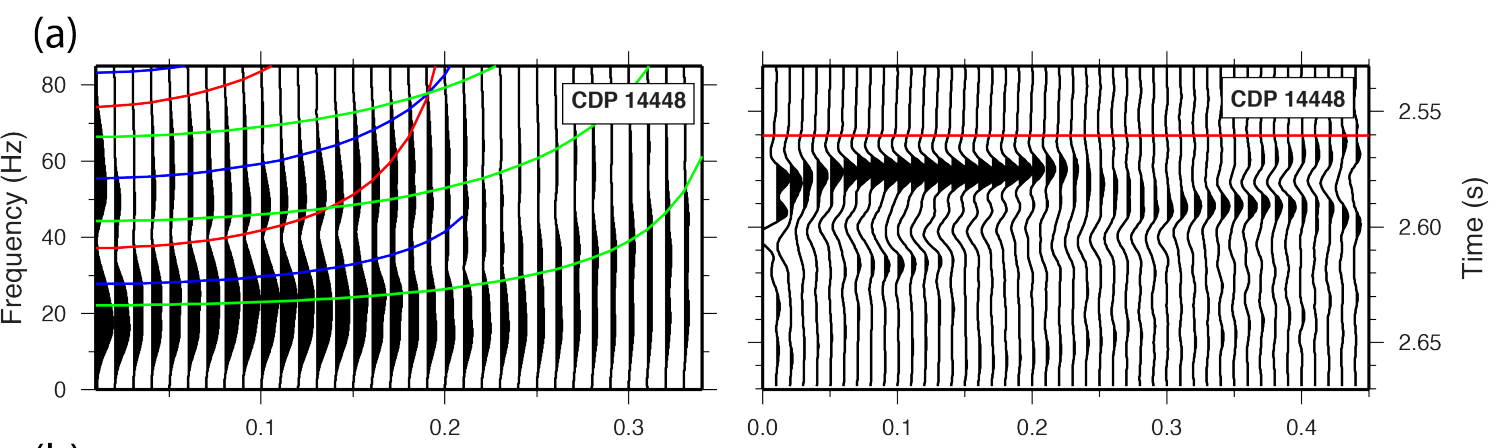

(b)
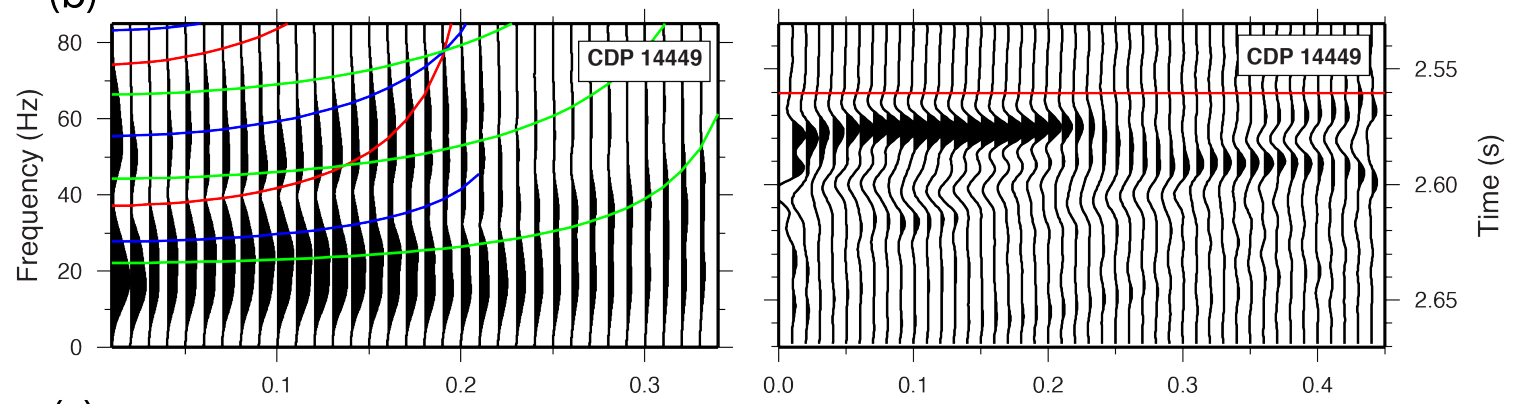

(c)
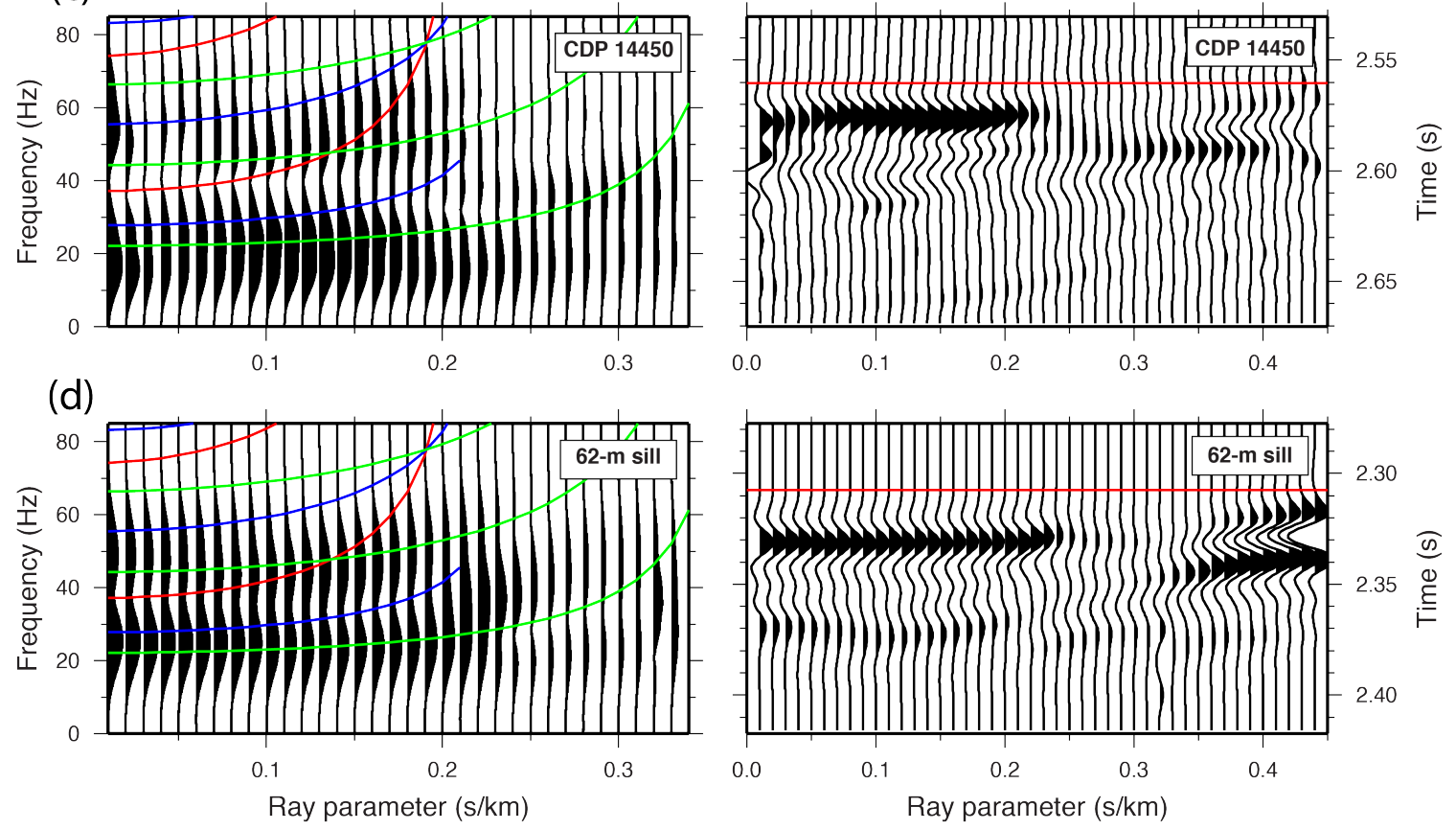

Figure 14. Comparison between CDP gathers 14448, 14449, 14450, and synthetic seismic data. On the left, frequency spectra shown with red, blue, and green lines are notches calculated for PP-, PS-, and SS-waves from a 62-m-thick sill with a P-wave velocity of $4.6 \mathrm{~km} / \mathrm{s}$. On the right, the corresponding flattened $\tau$-p sections are shown with red lines denoting the calculated travel times to which the data were flattened. (a) CDP gather 14448. (b) CDP gather 14449. (c) CDP gather 14450. (d) Synthetic data generated from a $62-\mathrm{m}$-thick sill with a P-wave velocity of $4.6 \mathrm{~km} / \mathrm{s}$. 


\title{
Chapter 3:
}

\section{Extent and impact of Cretaceous magmatism on the evolution of Jurassic-age oceanic crust in the western Pacific}

\begin{abstract}
We model the structure of Jurassic-age oceanic crust affected by voluminous Cretaceous magmatism to study how crustal evolution occurs as a result of the transport and emplacement of a large distribution of melt through the lithosphere and into the crust. Multi-channel seismic (MCS) images and wide-angle sonobuoy data acquired during a 2011 cruise on the R/V Thomas G. Thompson (TN272) show widespread emplacement of igneous sills and broadly thickened oceanic Layer 2 through hundreds of kilometers of oceanic crust in one of the oldest ocean basins in the western Pacific, a region known as the Jurassic Quiet Zone (JQZ). We use seismic data to image heavily intruded and modified oceanic crust along an $800-\mathrm{km}$-long transect through the JQZ in order to examine how the structure of oceanic crust is modified during secondary crustal growth (distant from the plate boundary where the crust was originally formed) and what this structure might imply about the processes that transport melt through the lithosphere, emplace magma into the crust, and distribute lavas on the surface. Our observations suggest that western Pacific crust was modified via the following modes of emplacement: (1) intrusive seamount formation, (2) extrusive volcanism observed as flows, and (3) igneous sill intrusion into sediments. Emplacement modes (1) and (2) tend to imply a focused, pipe-like mechanism for melt transport through the lithosphere. Such a mechanism, however, does not explain the observed broadly distributed intrusive emplacement of mode (3), which may be related to our observation of significant $(\sim 50 \%)$ thickening of oceanic crust in Layer 2 along $\sim 400 \mathrm{~km}$ of our seismic line. A mechanism responsible for the thickening may entail successive sill emplacement within the igneous basement. This mode of crustal growth seems to require a largely unfocused, distributed mechanism of melt transport through the lithosphere and across the Moho.
\end{abstract}




\section{Introduction}

The crust of the oldest Pacific lithosphere, currently located in the western Pacific, has grown through at least two main magmatic phases. It was formed by midocean ridge processes in the Jurassic at $\sim 170$ Ma [Handschumacher et al., 1988; Nakanishi et al., 1992a; Gradstein et al., 2012], and then $~ 45-95$ My later [e.g., Ozima et al., 1983; Koppers et al., 2003b; Clouard and Bonneville, 2005], it was modified by a substantial Cretaceous magmatic event that affected crust over a vast region. Crustal formation in the first phase is a well-understood process in which melt beneath a midocean ridge is extracted from a partial-melt domain of decompressing mantle into a focused zone of crustal accretion [e.g., Perfit et al., 1994], resulting in crust that, on average, has remarkably uniform structure throughout the oceans [e.g., White et al., 1992]. The second phase of western Pacific crustal evolution involves the transport of asthenospheric melt through existing lithosphere and the emplacement of this melt as igneous additions to the top, bottom, and/or middle of pre-existing crust. These processes that modify oceanic crust are not well understood. The abundance of seamounts observed in seafloor bathymetry [Dietz, 1954; Wessel and Lyons, 1997] indicates that localized, focused volcanic emplacement is an important process of secondary crustal growth. In addition, Cretaceous-age igneous flows and sills sampled in drill cores from Ocean Drilling Program (ODP) Legs 129 and 185 [Lancelot and Larson, 1990; Koppers et al., 2003b] provide physical evidence of other modes of magmatic emplacement. Seismic observations suggest that the sills and flows extend throughout hundreds of thousands of square kilometers of western Pacific lithosphere [Abrams et al., 1993; Kaneda et al., 2010], significantly modifying the structure of the crust.

In this study, we analyze multi-channel reflection and wide-angle refraction seismic data that were acquired along a NE-SW trending, 800-km-long transect crossing Middle-Jurassic to Early Cretaceous lithosphere (Fig. 1) and model the structure of modified Pacific crust. Seafloor depths range between $\sim 5$ and $6 \mathrm{~km}$ along the line, and regional bathymetry is influenced by the Marcus-Wake Seamount Chain and other volcanic features. The transect extends from relatively undisturbed crust within the Hawaiian Lineation Set into the substantially modified crust of the JQZ. Crust within the 
JQZ ranges between $\sim 150$ and $170 \mathrm{My}$ in age and becomes progressively younger towards the northeast in the Hawaiian Lineation Set [Nakanishi et al., 1992a]. The transition from the Hawaiian Lineation Set into the JQZ provides a means to evaluate the impact of Cretaceous magmatic activity on Jurassic-age crust. ODP Site 801 is also located on Jurassic-age crust that was modified by Cretaceous magmatism, $\sim 600 \mathrm{~km}$ away from the southwestern end of our seismic transect, and thus provides drill core samples and data relevant to the interpretation of our seismic results. Similarly, the seismic studies described in Abrams et al. [1993] and Kaneda et al. [2010], which discuss modified Pacific crust in the Pigafetta Basin and provide the most relevant seismic results for comparison with our study, occurred several hundred kilometers away from our seismic line. Our results show widespread emplacement of igneous sills and thickened oceanic crustal Layer 2 over hundreds of kilometers. These regionally distributed features seem to require mechanisms of melt transport through the lithosphere and across the Moho that are less focused than the mechanisms needed to form localized features such as seamounts. Developing a more comprehensive view of the magmatic processes associated with the Cretaceous magmatic event will lead to a better understanding of the history and evolution of Pacific oceanic lithosphere and of the effects and consequences of large-igneous province formation generally.

\section{Background}

The Pacific plate is the largest tectonic plate on Earth, and it contains some of the world's oldest in situ oceanic crust [e.g., Larson and Chase, 1972; Larson, 1976; Sager et al., 1988; Koppers et al., 2003a], providing a long-lived record of dynamic geological processes. In the western Pacific, Mesozoic magnetic anomaly lineations reveal the spreading history of the plate (Fig. 1). Plate reconstruction models place the nascent Pacific microplate at the center of a ridge-ridge-ridge triple junction between the Phoenix, Izanagi, and Farallon plates at $\sim 170$ Ma [Handschumacher et al., 1988; Nakanishi et al., 1992; Gradstein et al., 2012]. The subsequent growth of the Pacific

plate and its interaction with underlying mantle processes have produced many prominent, yet poorly understood, crustal features. The well-defined Japanese, Hawaiian, and Phoenix magnetic lineation sets converge around a region of low-amplitude, short- 
wavelength magnetic anomalies known as the Jurassic Quiet Zone (JQZ). Recent and ongoing studies in the region have correlated seafloor magnetic anomalies as far back as 170 Ma [Sager et al., 1988; Tivey et al., 2006; Tominaga et al., 2008], but the cause of the anomalous nature of the JQZ (i.e., low-amplitude magnetic anomalies combined with rapid field fluctuations) remains unresolved. Cretaceous intraplate volcanism may play a role in obscuring seafloor magnetic records, due to the widespread emplacement of large volumes of igneous material into pre-existing Jurassic crust, and the relationship between seafloor volcanic features and JQZ magnetic anomalies has been considered in previous studies [Kent and Gradstein, 1985; Tivey et al., 2006].

The Cretaceous magmatic event was regionally extensive and long in duration, affecting millions of square kilometers of oceanic crust over the course of tens of millions of years. Major features in the western Pacific, including the Ontong Java Plateau [Janney and Castillo, 1996], Mid Pacific Mountains [Hamilton, 1956], Marshall-Gilbert Islands [Morgan, 1972], Magellan Seamounts [Smith et al., 1989], and Marcus-Wake Seamounts [Heezen et al., 1973; Sager et al., 1993], are associated with the Cretaceous event, and the seafloor in between is marked by numerous guyots, seamounts, and volcanic flows. Absolute ${ }^{40} \mathrm{Ar} /{ }^{39} \mathrm{Ar}$ dating places age constraints on western Pacific intraplate volcanism between 75 and 125 Ma [e.g., Ozima et al., 1983; Clouard and Bonneville, 2005]. The nonsystematic spatial and age distributions of these igneous features [e.g., Larson, 1991; Winterer et al., 1993; Koppers et al., 2003b] suggest a magma source present contemporaneously beneath a very large region, possibly disqualifying more localized sources such as spreading centers or long-lived, stationary hotspots. To account for the voluminous Cretaceous event, models involving an anomalously large magma source have proposed the existence of mantle convectioninduced "superswell" activity [McNutt and Fisher, 1987; McNutt, 1998] or multiple closely spaced, short-lived mantle "plumelets" [Koppers et al., 2003a] originating from a deeper "superplume" [Menard, 1964; Larson, 1991].

While the geodynamic origin of the Cretaceous magmatic event remains uncertain, it is clear that this and other similar periods of voluminous intraplate volcanism can have global-scale impacts. Numerous studies have linked the formation of large igneous provinces (i.e., voluminous outpourings of magma over short periods of time) to 
increases in greenhouse gas emission, changes in atmospheric and oceanic chemistry, and mass biological extinction events [Tarduno et al., 1991; Bowring et al., 1998; Svensen et al., 2004; Svensen et al., 2008; Reichow et al., 2009]. Thousands of gigatons of greenhouse gases may be generated when large igneous intrusions are emplaced into sedimentary basins [Aarnes et al., 2010]. In an oceanic setting, $\mathrm{CO}_{2}$ emitted as a consequence of widespread magmatic activity may not directly lead to global warming due to complex interactions with oceanic chemical and biological feedback mechanisms, but nevertheless, the impacts are important in other ways. Notably, a massive episode of magmatism dated at 93 Ma has been suspected of triggering a major oceanic anoxic event (OAE) and subsequent global-scale mass extinctions of deep-sea organisms, based on osmium isotope signals used as a proxy for carbon isotope ratios [Turgeon and Creaser, 2008; Bralower, 2008]. Such catastrophic consequences call for a better understanding of large magmatic events, especially the processes concerning their formation and possible impacts on their surroundings.

Our knowledge of the structure of modified Pacific crust is based on dredge samples, scientific drilling results, and previous seismic studies in the western Pacific. Cretaceous volcanics are commonly encountered throughout the region, as evidenced by the material sampled from numerous dredging expeditions since the 1950s and eight scientific drilling sites from ODP and Deep Sea Drilling Program (DSDP) legs dating back to 1969 [Abrams et al., 1993]. ODP Leg 129 Hole $801 \mathrm{C}$ (located at $18^{\circ} 38.538^{\prime} \mathrm{N}$, $156^{\circ} 21.588^{\prime}$ E) resulted in the first successful recovery of Jurassic-age material in 1989, providing a detailed stratigraphic record of crustal sediments and locating the basement at $493.7 \mathrm{~m}$ below the seafloor [Lancelot and Larson, 1990]. Basement basalts at Site 801 have features consistent with typical mid-ocean ridge basalt (MORB) tholeiites generated at a spreading center. The MORB tholeiites are overlain by an upper sequence of younger ocean island basalts [Floyd and Castillo, 1992], providing stratigraphic evidence of the relationship between spreading ridge and intraplate magmatic processes. In addition to the drill-core results, regional seismic studies have inferred the presence of middle Cretaceous flows/sills overlying and within Jurassic and Early Cretaceous sediments and oceanic crust over hundreds of square kilometers in the East Mariana and Pigafetta Basins [Abrams et al., 1993]. High-amplitude seismic reflectors correlate with the 
occurrence of a massive igneous overburden modifying oceanic crust, with variations in the seismic horizon suggesting intermittent volcanic activity throughout the region. Kaneda et al. [2010] were able to image deeper lithospheric structures with a $\sim 900-\mathrm{km}-$ long seismic survey. Their crustal model suggests secondary crustal growth through volcanic and intrusive magmatic emplacement in the upper crust as well as lower-crustal underplating of up to $2 \mathrm{~km}$ beneath large seamounts. These results indicate that modified Pacific crust exists on a large scale and varies significantly in structure from that of typical oceanic crust.

\section{Methods}

Seismic reflection and refraction data were collected during the TN272 cruise on the R/V Thomas G. Thompson (Dec. 2011-Jan. 2012). The seismic source consisted of two 110-cubic-inch GI guns, with shots fired every $25 \mathrm{~m}$ from a depth of $4 \mathrm{~m}$ below the sea surface. MCS data were acquired with a 600-m-long, 48-channel streamer, while crustal refractions were recorded by 50 sonobuoys spanning $\sim 800 \mathrm{~km}$ of the survey (of which 42 successfully acquired data). Sonobuoys were deployed every $\sim 11-15 \mathrm{~km}$. Sonobuoy receiver depths were positioned between 30 and $122 \mathrm{~m}$ below the sea surface to optimize signal quality.

\section{Seismic Data Processing}

Multi-channel Seismic Reflection Images

MCS data were processed to provide detailed images of modified Pacific crust along the JQZ transect within a few hundred meters of the seafloor (Fig. 2). MCS processing involved bandpass filtering $(15-150 \mathrm{~Hz})$, trace editing, normal moveout correction, stacking, time migration, and automatic gain control (AGC), all of which were done at sea using the ProMax software package. The resulting MCS images depict shallow crustal features such as sedimentary strata, sections of relatively undeformed oceanic crust, igneous sill intrusions, volcanic seafloor flows, and seamount structures. The high-frequency MCS data provide detailed images of shallow crustal features, which complement the wide-angle sonobuoy data and aid in distinguishing between variably deformed sedimentary strata and reflections from igneous flows, intrusions and basement. 


\section{Sonobuoy Refraction Offset Correction}

Sonobuoys are disposable instruments consisting of a hydrophone suspended in the water column from a buoyant electronics package, which consists primarily of a radio transmitter, an antenna, and a board that controls limited functionality, such as releasing the hydrophone to a pre-set depth and scuttling the instrument after a period of time. Sonobuoys broadcast the hydrophone signal over a frequency-modulated radio band that is recorded onboard the ship, demodulated, and digitized. The maximum range that a sonobuoy's radio signal can be cleanly detected is limited by line of sight; this distance was $\sim 15 \mathrm{~km}$ during TN272, effectively limiting the maximum source-to-reciever offsets of the recorded wide-angle seismic data to that distance. In the JQZ region, offsets of 15 $\mathrm{km}$ are sufficient to record reflections through the sedimentary layer, the oceanic Layer $2 / 3$ triplication, and the Layer 3 "Pg" refraction phase. This combination of phases enables the thickness and velocity of the sedimentary layer and of oceanic Layer 2 to be measured.

The first step in analyzing sonobuoy data is estimating the position of the sonobuoy with time. Sonobuoys float freely once deployed, and even with a small drogue chute attached, they tend to drift with the wind and surface currents, with the result that this drift has a substantial impact on the interpretation of sonobuoy data. In principle, source/receiver offset could be measured using the direct wave and with knowledge of the water velocity structure with depth. In practice, however, the direct wave does not propagate with good signal strength to beyond a few $\mathrm{km}$ due to decreasing seismic velocity with depth in the water column. We thus use the travel times of the seafloor reflection observed in the sonobuoy records to estimate sonobuoy position. Determining sonobuoy position by predicting seafloor travel times requires an accurate velocity model for the water column and correspondingly accurate profile of seafloor depth. An accurate profile of the vertical-incidence two-way travel time (TWT) to the seafloor is provided by the seafloor reflection image in the migrated MCS data. We parameterized the seismic velocity structure of the water column along the transect such that these velocities, the TWT to the seafloor, and the corresponding bathymetry profile were consistent (Fig. 3). This velocity model was then used to calculate seafloor reflections for comparison with 
sonobuoy data (Fig. 4a) and estimate source/receiver offsets for the sonobuoy records (Fig. 4b-c).

An average water velocity profile for the JQZ transect was calculated using data from the Sentry autonomous underwater vehicle (AUV) dives 129, 131, 132, and 133 (Fig. 3a). A piecewise, linear parameterization of the water velocity profile provides a depth transformation for the bathymetry data, recorded by the shipboard multibeam system, that accurately predicts TWT to the seafloor image by the MCS data (Fig. 3b), and this internal consistency is all that is needed to model the sonobuoy data.

Seafloor reflection travel times were calculated using this velocity model and the two-dimensional (2-D) ray tracing program of Zelt and Smith [1992]. The seafloorreflection travel times predicted between known shot locations and stationary sonobuoy locations (their deployment positions) are not consistent with the observed data (Fig. 4a). The misfit between predicted and observed travel times worsens with increasing offset, consistent with current-driven sonobuoy displacement (i.e., "sonobuoy drift").

We corrected offsets in the sonobuoy data by assuming that the instruments drifted in line with the profile. This assumption is not likely to be correct, but it is necessary because bathymetry is only known to sufficient accuracy along the profile. Offset corrections made under this assumption result in estimated sonobuoy locations along the profile, enabling us to use 2-D ray tracing in a sensible way. The corrected offsets were made by modeling source/receiver separation as a quadratic function of time $t$,

$$
x_{\mathrm{offset}}(t)=a_{0}+a_{1} \cdot t+a_{2} \cdot t^{2}
$$

with the coefficients $a_{0}, a_{1}$, and $a_{2}$ representative of initial sonobuoy position, drift velocity, and change in drift velocity, respectively. The coefficients were determined for each sonobuoy by fitting predicted seafloor reflection travel time curves to the sonobuoy data in an iterative forward modeling scheme. The predicted and observed travel times fit to within $10 \mathrm{~ms}$ for most of the sonobuoys (Fig. 4b-c). Significant differences (>10 ms) between the predicted and observed seafloor-reflection travel times are observed for some instruments, and these misfits probably arise due to the sonobuoy drifting off line into a region where the bathymetry is substantially different than it is along-line at the 
same range. A comparison of sonobuoy position between the first and last seismic trace recorded for each instrument shows the change in sonobuoy drift along the transect (Fig. 5). Sonobuoy drift determined via the offset correction changes smoothly with time during the course of the experiment. This trend is probably due to changes in wind and sea-surface currents, which also vary smoothly.

\section{Modeling Crustal Structure}

We have created a velocity-depth model of the crust along the JQZ transect based on the MCS and sonobuoy datasets. The velocity model consists of five layers: water, 2 sedimentary layers, and 2 "igneous" layers corresponding to oceanic Layers 2 and 3 . The seafloor and the geometry and internal structure of the sedimentary layer are well imaged by the MCS reflection data. Sedimentary strata are clearly observable in the MCS images, and strong reflectors in the MCS data can be found in the corresponding sonobuoy seismograms (Fig. 6). The velocity structure and thickness of the sedimentary layer and the upper igneous layer (which we will refer to as Layer 2) are constrained by the travel times of basement reflections and refractions. The travel times of those phases were picked by hand for 42 sonobuoys and modeled using the ray-tracing program of Zelt and Smith [1992]. Layer velocities and depths were adjusted in a forward-modeling approach to minimize the misfit between the predicted and picked. In locations where the sonobuoy records are poor or absent, the velocity structure is interpolated using constraints on layer horizons from the MCS images.

\section{Results}

\section{MCS Profile}

The JQZ MCS survey is comprised of nine individual acquisition lines covering $\sim 800 \mathrm{~km}$ of Jurassic-age oceanic crust (Fig. 2). The 2-GI-gun source and short streamer length used in the MCS acquisition provides high-frequency reflections that resolve sedimentary structure to the basement or to the depth where the first substantial thickness of igneous material is encountered, though there are some instances where the data image structure beneath volcanic flows and sills. Overall from the northeast towards the southwest, we observe a transition from undisturbed volcanic crust to crust that is 
modified by seamounts and substantial igneous intrusion into sediments. At shorter wavelengths, the MCS profiles display variable morphologies within seafloor and subsurface formations that can be grouped into three distinct regions - North, Middle, and South - along the transect based on morphologic characteristics.

North (0-265 km, Sonobuoys 1-17): MCS images show seafloor topography with little variation over long distances, and sedimentary formations preserve undisturbed stratigraphy, except in the proximity of what we interpret, based on morphology and reflection amplitude, to be volcanic intrusions and flows (Fig. 7a). Some of the highamplitude reflectors have cuspate shapes and are very likely to be intrusive sills, whereas others are more flat-lying, extending over $2-10 \mathrm{~km}$, and are more likely to be volcanic flows. Uplifted sediments are often observed directly above these high-amplitude reflectors, indicative of intrusion. A few 2- to 3-km-wide pipe-like structures are observed in this region. These structures may be remnant expulsion features that accompanied sill intrusion. The features extend through sediments of much younger age than the presumably Cretaceous intrusion event, however, perhaps indicating that the original permeable pathways have been and may continue to be conduits for fluid flow.

Middle (265-485 km, Sonobuoys 18-31): The seafloor topography in the Middle region transitions into rough, uneven seafloor, and includes one of the most pronounced seamounts along the survey transect, located at $\sim 445 \mathrm{~km}$. A thin sedimentary cover lies atop the seamount. Short-wavelength topographical variations are exhibited by highamplitude reflectors on the seafloor, likely attributed to volcanic flows from localized volcanic centers (Fig. 7b). In some areas, the volcanic flows seem to pave new seafloor on top of older sedimentary layers. In the subsurface, volcanic intrusions of various shapes and sizes are commonly observed in within the sedimentary layer. The sedimentary layers adjacent to the seamounts appear to be folded, showing signs of compressional stress from what we infer to be lateral seamount growth via a diking mechanism (Fig. 7c).

South (485-800 km, Sonobuoys 32-50): Compared to the Middle region, the seafloor topography in the South region appears to be smoother and covered by a sedimentary blanket, similar to that of the North region. The sediments generally thicken 
towards the southwestern end of the line. On the seafloor, flows from several protruding seamounts are observed covering adjacent, older sediment basins (Fig. 7d). In the subsurface, volcanic sills and flows, as inferred by high-amplitude reflectors, are widely interspersed within crustal sediments.

\section{Sonobuoy Profiles}

There are distinct differences in the characteristics of the sedimentary and crustal reflections and refractions (Fig. 8) observed in records from the North region versus those from the South region. With fewer seafloor features in the northeast, the seafloor reflections are more coherent and consistent from sonobuoy to sonobuoy. Refractions from oceanic Layers 2 and 3 are sharper and easier to identify, and separation between the two phases is more apparent (Fig. 9). The Layer 3 refraction has a horizontal phase velocity greater than $6.5 \mathrm{~km} / \mathrm{s}$, which is typical for observations of this phase in oceanic crust and indicative of massive, plutonic gabbro. Layer 2 refractions observed in this region arrive as triplications after the Layer 3 refraction, which is also typical of oceanic crust and indicative of a thin Layer 2A with a strong velocity gradient. Strong sediment reflections are apparent in the North, indicating laterally coherent, stratified sedimentary layers. Along the southwestern half of the transect, the sonobuoys cover sections of oceanic crust that is more heavily modified by igneous intrusions and flows. The presence of seamounts distorts seafloor reflection curves in some sonobuoys, and reflections from off-axis features are often present. The distinction between Layer 2 and Layer 3 refractions becomes less obvious, as Layer 2 refractions arrive earlier than Layer 3 refractions in this region (Fig. 10). The onset of the Layer 2 refraction before that of Layer 3 indicates that Layer 2 is thicker in the southwestern half of the transect than in the northeast. Reflections within the second layer of sediments defined in our model also show more reverberations within the layer, which may be indicative of heavily intruded and altered sediments due to the increased distribution of seamounts and igneous structures along the southwestern half of the survey transect.

In the Middle region, seismic records from Sonobuoys 24 and 25 show no crustal refractions from oceanic Layers 2 and 3. Seafloor and sediment reflections are observed, consistent with adjacent sonobuoys, but the lack of seismic signals indicative of basement 
refractions is unexpected. It is unlikely that basement depths associated with the refracting phases have deepened significantly within the limited locality of Sonobuoys 24 and 25, as clear basement refractions can be seen in Sonobuoys 23, and to a lesser extent in Sonobuoy 26. As previously mentioned, seismic refractions from the northeastern end of the transect are generally more coherent compared to refracting phases of variable quality observed in the southwestern sonobuoy records, and the transition between the different records appears to be within the range of Sonobuoys 24 and 24.

The absence of basement refractions in Sonobuoys 24 and 25 may be associated with unaccounted crustal structure in our model, possibly affecting the velocity gradient within the crust. The presence of negative velocity gradients over a depth interval of $1 \mathrm{~km}$ or more could create a shadow zone for crustal refractions within the sonobuoy aperture. Such a zone would presumably involve high-velocity igneous material overlying lower velocity sediments; a sequence of flows and sediments, with the density of flows increasing upward, could result in a zone with seismic velocity decreasing with depth. We can only speculate that such a zone exists or how it might be created. Regional bathymetry data show small seamounts on either side of the seismic transect that may have introduced localized igneous additions to the crust near Sonobuoys 24 and 25. Additionally, the locations of the anomalous sonobuoys are centered within a region of gravitational lows profiled along the survey transect, which may be interrelated.

\section{Crustal Velocity Structure Model}

Seismic reflection and refraction data were used to construct a velocity model along the JQZ transect (Fig. 11). Average velocities for the two sedimentary layers are $\sim 2$ $\mathrm{km} / \mathrm{s}$ and $\sim 2.5-3.0 \mathrm{~km} / \mathrm{s}$, respectively. The fast sedimentary layer is likely composed of old, compacted sediments and may be heavily intruded with basalt flows and sills, as evidenced by the MCS images. Oceanic Layer 2 has an average velocity of $\sim 4.5-5.5$ $\mathrm{km} / \mathrm{s}$, over a large gradient. This layer is referred to as the top of the "basement," and it is inferred to be primarily composed of Jurassic basalts and dikes. The top of oceanic Layer 3 is constrained by our model, with average velocities of $\sim 6.8-7.0 \mathrm{~km} / \mathrm{s}$. A comparison of velocity profiles between the North, Middle, and South regions of our model indicate that velocity gradients are larger and more variable in the South than in the North, with 
intermediate features in the Middle. Oceanic Layer 2 is thicker and has higher velocities in the South as well.

Crustal structure varies significantly along the JQZ transect (Fig. 11). In the North, the sediment layers are $\sim 500 \mathrm{~m}$ thick, and oceanic Layer 2 is less than a kilometer thick. The relatively flat-lying sediments and basement in the model suggest that the crust along this section resembles "normal" oceanic crust with typical seismic velocities that are consistent with previous studies in the region [Abrams et al., 1993; Kaneda et al., 2010]. In the Middle and towards the South, seismic velocities generally increase along the transect. In these regions, seamounts become more prevalent, and sediment and "basement" depths show greater lateral variability. The high-velocity layer of sediments thickens and increases in velocity with proximity to seamount structures. At $\sim 445 \mathrm{~km}$ along the transect, the crust encompassing a large seamount feature has very little sedimentary cover within tens of meters of the seafloor, and instead appears to contain a core of basement-like ( $>4 \mathrm{~km} / \mathrm{s})$ material. Several seamounts at the southwestern end of the transect similarly show high-velocity core structures extending towards the seafloor, though not as pronounced as the central seamount structure. Oceanic Layer 2 is significantly thicker along the Middle and South regions, with the transition to thicker crust occurring at $\sim 400 \mathrm{~km}$, shortly before the emergence of the large seamount at $\sim 445$ $\mathrm{km}$. Large variations in "basement" depth along the JQZ transect may be partly attributable to the presence of igneous intrusions within sediments above the "basement," with higher-velocity "cooked" sediments surrounding the intrusions, rather than substantial deformation to the original basement. Sediments that have been heavily intruded by large quantities of igneous material may seismically resemble the upper section of oceanic Layer 2.

\section{Discussion}

The MCS images along the TN272 seismic transect reveal three modes of magmatic emplacement that have modified the oceanic crust: (1) intrusive seamount formation exhibiting lateral compression of sediments, (2) extrusive volcanism observed as flows, and (3) regionally extensive igneous sill intrusion into sediments. This volcanism is part of a Cretaceous Supervolcanism event [Larson, 1991] that modified 
Jurassic-age oceanic crust, creating numerous seamounts and igneous plateaus throughout the western Pacific [e.g., Koppers et al., 2003b; Kaneda et al., 2010; Stadler and Tominaga, 2015]. The geodynamic mechanism that gave rise to such a regionally extensive source of asthenospheric melt remains a topic of debate, but regardless of the source of the magma, the distribution and age of the volcanic features indicate that largescale transport of melt through the lithosphere occurred during the Cretaceous. As with the source of the volumetrically anomalous melt, the mechanisms that transported this melt through the lithosphere remain poorly understood. This transport may have been facilitated by lithospheric cracks due to tensional stresses of plate loading or thermal cooling [e.g., Sandwell et al., 1995; Korenaga, 2007], or more dramatic mechanisms akin to kimberlite pipe formation could have been involved, or perhaps the melt heated and cracked its way through the lithosphere via coalescing fracture networks [Keller et al., 2012]. Clues to the operative transport mechanisms ought to exist in the observed modes of magmatic emplacement. Isolated seamounts might suggest pipes, while linear chains of seamounts might suggest cracks. Large regions of modest but uniform intrusive crustal thickening would be difficult to explain with either of these localized transport mechanisms, however, and so the observation of this mode of magmatic emplacement dominant along half of the TN272 seismic transect seems to require a more diffuse mode of melt transport through the lithosphere.

A key finding of the seismic velocity model is the apparent thickening of oceanic Layer 2 over a $\sim 400-\mathrm{km}$-long span of the seismic transect. Our results show that Layer 2 thickness ranges from $0.8-1.0 \mathrm{~km}$ in the northeast, and that this layer is $\sim 50 \%$ thicker in the southwest, ranging from to $1.2-1.4 \mathrm{~km}$. There are two end-member explanations for the additional $\sim 400 \mathrm{~m}$ of relatively high-velocity $(5.1-5.5 \mathrm{~km} / \mathrm{s})$, presumably igneous, upper crust observed over the southern half of the transect: the thickness difference may reflect a change in crust-forming processes at the ridge during lithospheric formation, or the additional Layer 2 material may have been added tens of millions of years later during the Cretaceous magmatic event. Magnetic anomalies along this transect provide some constraints to these scenarios.

The latest analyses of the magnetic anomalies along the survey transect show that the crust preserves coherent Jurassic magnetic signatures and that there was no apparent 
change in spreading rate, or evidence for ridge jumps, over the period of time when the lithosphere along the transect was being formed [Tominaga et al., 2015]. The observed change in Layer 2 thickness thus cannot be ascribed to a spreading-rate change, which is perhaps the most likely parameter to result in an abrupt and then persistently constant change in volcanic effusiveness at the ridge. The capture of some volume of hot asthenospheric material by the spreading center could explain an increase in crustal production that would be partly expressed as a thickening of Layer 2. This mechanism might not be likely to result the observed abrupt, constant change in crustal production [e.g., Ito and Lin, 1995], however, unless the anomalous material were regionally extensive, in which case a similar change should be observed for in all western Pacific crust of this age. At present, there are not sufficient data throughout the region to test this notion and so it remains a possibility.

The alternative scenario, in which the change in Layer 2 thickness occurred as a post-formation modification, is supported by the observation of numerous other igneous features that obviously post-date crustal formation, including small $(<1 \mathrm{~km}$-tall $)$ seamounts, buried flows, and sills intruded into sediments. Given the scale and distribution of Cretaceous volcanism within the vicinity of the JQZ survey area [e.g., Wessel and Lyons, 1997; Larson, 1991; Stadler and Tominaga, 2015], the presence of these features and a general thickening of oceanic crust is not unexpected. Clearly, melt transport from an asthenospheric source through the lithosphere must have been widely distributed. However, a more or less uniform thickening of Layer 2 by $\sim 50 \%$ over a distance of $400 \mathrm{~km}$ requires a mechanism for melt transport through the lithosphere that has not yet been described - a mechanism for which the flux of melt across the Moho was nearly uniform along this distance. In addition, the mechanism of emplacement of this melt into the upper crust also needs to be special in that the emplacement mechanism would have to preserve most of the original magnetic signature of the crust.

Observations of igneous sills in this study and elsewhere in the western Pacific [e.g., Larson and Schlanger, 1981; Abrams et al., 1993; Kaneda et al., 2010] suggest that sills are a common feature in western Pacific oceanic crust. Our observation of thickened Layer 2 may have been facilitated by the accumulation of a dense complex of sills in the sediments above the original layer during the Cretaceous, with feeder dikes supplying 
magma through the preexisting layer. Sill development in this manner, over the relatively long timescale of Cretaceous Supervolcanism, may have enabled the preservation of Jurassic crustal magnetic anomalies, as it is unlikely that the piecewise formation of a sill complex over tens of millions of years would yield a coherent magnetic signature. It may be possible that sill emplacement occurred at greater depths within Layer 2, in which the sheeted dikes comprising Layer 2B may have formed extensive fracture networks [e.g., Dilek and Thy, 2009; Tominaga et al., 2009] easily penetrated by intruding sills and feeder dikes. The addition of igneous sills to the crust at greater depths may also minimize magnetic interference of the Jurassic signal. Over a lateral distance of $\sim 400 \mathrm{~km}$, thickening of Layer 2 via widespread sill emplacement would likely require a much more pervasive distribution of melt being transported through the lithosphere than previously inferred, possibly forming extensive sill networks and magma chambers at crustal depths [e.g., Cartwright and Hansen, 2006; Muirhead et al., 2012]. In addition to pipe-like structures facilitating the focused transport of melt through the lithosphere and across the Moho, we suggest that there exists a broad spectrum of fingering melt networks ascending from a volumetrically large asthenospheric source that transports melt through the lithosphere to produce a wide range of igneous crustal features, from extrusive seamounts and flows to sills embedded within the crust (Fig. 12).

Our inferences from the emplacement and distribution of igneous crustal additions along our seismic transect provide insight on the process of melt transport through the lithosphere, which may range between focused or diffuse modes depending on a multitude of factors regarding the mechanical, thermal, and chemical aspects of magma dynamics that control the pathways for buoyant magmatic material ascending towards the surface. Keller et al. [2013] use visco-elasto-plastic two-phase models to identify a continuum of modes for melt transport through the lithosphere. In these models, the influence of host rock viscosity and tensile rock strength determine the prevalent form of melt transport. Rheologically weak zones at the base of the lithosphere may give rise to melt diapirs, moving melt upwards from the asthenosphere. Within the lithosphere, decompaction channels formed from point sources driven by lithostatic pressure gradients likely transported melt into the upper mantle and crustal depths. A multitude of point sources supplied by melt from the Cretaceous magmatic event may have led to the 
formation of an interconnected, branching network of fluid-filled channels through the lithosphere. Depending on host rock properties, tensile fracturing may occur in the form of vertical dikes as well, contributing towards the development of sill complexes in the upper crust. The emplacement of sill intrusions within oceanic Layer 2 via decompaction channels or similar mechanisms of melt transport may be feasible since an initial occurrence of igneous intrusion makes it more likely that repeated intrusions will occur in the same area, as established thermal anomalies in the crust allow for easier remelting episodes [Annen and Sparks, 2002].

Seismically imaged thickening of the crust observed along the JQZ transect is very likely related to regional Cretaceous volcanism responsible for the formation of major seafloor features such as the Marcus-Wake Seamount Chain, as the southwestern end of the transect where thickening is observed runs through oceanic crust that has a higher density of seamounts. However, our data do not provide constraints that can help distinguish between the various hypotheses that have been proposed for the origin of the sub-lithospheric melt source of the Cretaceous volcanism. We interpret the vast regional extent of Cretaceous magmatism to imply the existence of widespread melt at the base of the lithosphere that provided a common source for seamount formation and crustal thickening. In addition, we interpret distinct modes of emplacement, including seamount formation, igneous flows, and sill intrusion into both the sediments and igneous crust, to be indicative of different modes of melt transport from this common asthenospheric source through the lithosphere. In this interpretation, seamounts along the Marcus-Wake chain represent a mode of emplacement associated with focused, high-flux melt transport through the lithosphere. Crustal thickening observed along the TN272 transect represents another mode of emplacement that is suggestive of a more diffuse, low-flux mode of melt transport through the lithosphere. It is possible that the network of melt channels through the lithosphere feeding these two regimes are related in some way, but we have no constraints on details of those possible relationships. Our seismic results show widespread thickening of oceanic Layer 2, but it is unlikely that melt supplying seamount formation was diverted laterally to form regionally extensive sill intrusions within our crustal-scale depth resolution. 
Additional work may provide a more complete image of the structure of Jurassicage oceanic crust, as the limitations of our seismic dataset prevent an estimate of total crustal thickness. By modeling gravity anomalies along the seismic transect, we can estimate crustal densities and thicknesses that may provide additional constraints on the structure of the modified crust. Satellite gravity measurements show a gravity low near the center of our seismic transect, which coincides with the surficial expression of a quasi-linear cluster of seamounts perpendicular to the transect. Plate loading due to the emplacement of high-density igneous material would typically be expected to produce a gravity high, but the off-axis distance between the seismic transect and actual seamount locations may have affected the observed signal. As previously noted, our seismic transect had been designed to purposefully avoid large bathymetric features. Igneous features along our seismic transect are small in size compared to other western Pacific seafloor structures and may represent the early formative stages of seamount structures. Relatively few seismic studies focus on determining the structure of old oceanic crust in the western Pacific, but as further progress is made in the form of seismic observations and models, we can gain a better understanding of how the processes of magmatic transport, emplacement, and distribution affect the evolution of oceanic lithosphere.

\section{Conclusion}

Our model of the structure of modified Pacific crust in the JQZ indicates that secondary crustal growth through the Cretaceous magmatic event played an important role in the evolution of the crust. The addition of immense amounts of igneous material 45-95 My after the formation of the crust can be attributed to poorly understood processes of intraplate volcanism involving the emplacement, transport, and distribution of igneous material in the crust. From our seismic observations, we identify three modes of magmatic emplacement: (1) intrusive seamount formation, (2) extrusive volcanism observed as flows, and (3) igneous sill intrusion into sediments. The distributions of these igneous features have various implications for the transport of melt through the lithosphere. Our constraints on the boundary between oceanic Layers 2 and 3, and thus changes in Layer 2 thickness, suggest that the broadly distributed intrusive emplacement of igneous sills in modified Pacific crust may be largely responsible for the thickening 
(up to $50 \%$ ) of oceanic Layer 2 along $\sim 400 \mathrm{~km}$ of our seismic line. Emplacement of the melt within Layer 2 may have occurred through the accumulation of sill complexes within sediments directly above Layer 2 or the formation of sills within the fracture networks of sheeted dikes comprising the bottom of the layer, thus preserving the magnetic signature of the original Jurassic crust. Crustal thickening within Layer 2 over the hundreds of kilometers observed along our survey transect likely require a much more pervasive distribution of melt being transported through the lithosphere than previously inferred. 


\section{References}

Aarnes, I., Svensen, H., Connolly, J.A.D., and Podladchikov, Y.Y., 2010, How contact metamorphism can trigger global climate changes: Modeling gas generation around igneous sills in sedimentary basins: Geochimica et Cosomochimica Acta, v. 74, p. 7179-7195, doi:10.1016/j.gca.2010.09.011.

Abrams, L.J., Larson, R.L., Shipley, T.H., and Lancelot, Y., 1993, Cretaceous volcanic sequences in Jurassic oceanic crust in the East Mariana and Pigafetta Basins of the western Pacific, in Pringle, M.S., and Sager, W.W., eds., The Mesozoic Pacific: Geology, tectonics, and volcanism, American Geophysical Union Geophysical Monograph 77, p. 77-101.

Annen, C., and Sparks, R.S.J., 2002, Effects of repetitive emplacement of basaltic intrusions on thermal evolution and melt generation in the crust: Earth and Planetary Science Letters, v. 203, p. 937-955.

Bowring, S.A., Erwin, D.H., Jin, Y.G., Martin, M.W., Davidek, K., and Wang, W., 1998, $\mathrm{U} / \mathrm{Pb}$ zircon geochronology and tempo of the end-Permian mass extinction: Science, v. 280, p. 1039-1045.

Bralower, T.J., 2008, Volcanic cause of catastrophe: Nature, v. 454, p. 285-287.

Cartwright, J., and Hansen, D.M., 2006, Magma transport through the crust via interconnected sill complexes: Geology, v. 34, No. 11, p. 929-932, doi: 10.1130/G22758A.1.

Clouard, V., and Bonneville, A., 2005, Ages of seamounts, islands, and plateaus on the Pacific plate, in Foulger, G.R., Natland, J.H., Presnall, D.C., and Anderson, D.L., Plates, plumes, and paradigms: Geological Society of America Special Paper 388, p. 71-90, doi: 10.1130/2005.2388(06).

Dietz, R.S., 1954, Marine Geology of northwestern Pacific: Description of Japanese bathymetry Chart 6901: Bulletin of the Geological Society of America, v. 65, p. 1199-1224.

Dilek, Y., and Thy, P., 2009, Island arc tholeiite to boninitic melt evolution of the Cretaceous Kizildag (Turkey) ophiolite: Model for multi-stage early arc-forearc magmatism in Tethyan subduction factories: Lithos, v. 113, p. 68-87.

Floyd, P.A., and Castillo, P.R., 1992, Geochemistry and petrogenesis of Jurassic ocean crust basalts, Site 801, in Larson, R.L., Lancelot, Y., et al., 1992, Proc. ODP, Sci. Results, 129: College Station, TX (Ocean Drilling Program).

Gradstein, F.M., Ogg, J.G., Schmitz, M.D., and Ogg, G.M., 2012, The Geologic Time Scale, Elsevier Publishing, p. 731-792. 
Hamilton, E.L., 1956, Sunken Islands of the Mid-Pacific Mountains: Geological Society of America Bulletin, v. 64, 97 p.

Handschumacher, D.W., Sager, W.S., Hilde, T.W.C., and Bracey, D.R., 1988, PreCretaceous tectonic evolution of the Pacific plate and extension of the geomagnetic polarity reversal timescale with implications for the origin of the Jurassic "Quiet Zone": Tectonophysics, v. 155, p. 365-380, doi: 10.1016/00401951(88)90275-2.

Heezen, B.C., Matthews, J.L., Catalano, R., Natland, J., Coogan, A., Tharp, M., and Rawson, M., 1973, Western Pacific Guyots, in Heezen, B.C., MacGregor, I.D., 1973, Init. Repts. DSDP, 20: Washington, p. 653-723.

Ito, G., and Lin, J., 1995, Oceanic spreading center-hotspot interactions: Constraints from along-isochron bathymetric and gravity anomalies: Geology, v. 23, p. 657-660, doi: $10.1130 / 0091-7613$.

Janney, P.E., and Castillo, P.R., 1996, Basalts from the Central Pacific Basin: Evidence for the origin of Cretaceous igneous complexes in the Jurassic western Pacific: Journal of Geophysical Research, v. 101, No. B2, p. 2875-2893.

Kaneda, K., Kodaira, S., Nishizawa, A, Morishita, T, and Takahashi, N., 2010, Structural evolution of preexisting oceanic crust through intraplate igneous activities in the Marcus-Wake seamount chain: Geochemistry, Geophysics, Geosystems, v. 11, No. 10, doi: 10.1029/2010GC003231.

Keller, T., May, D.A., and Kaus, B.J.P., 2013, Numerical modeling of magma dynamics coupled to tectonic deformation of lithosphere and crust: Geophysical Journal International, doi: 10.1093/gji/ggt306.

Kent, D.V., and Gradstein, F.M., 1985, A Cretaceous and Jurassic geochronology, Geological Society of America Bulletin, v. 96, p. 1419-1427.

Koppers, A.A.P., Staudigel, H., Pringle, M.S., and Wijbrans, J.R., 2003a, Short-lived and discontinuous intraplate volcanism in the South Pacific: Hot spots or extensional volcanism?: Geochemistry, Geophysics, Geosystems, v. 4, No. 10, doi: 10.1029/2003GC000533.

Koppers, A.A.P., Staudigel, H., and Duncan, R.A., 2003b, High-resolution ${ }^{40} \mathrm{Ar} /{ }^{39} \mathrm{Ar}$ dating of the oldest oceanic basement basalts in the western Pacific basin: Geochemistry, Geophysics, Geosystems, v. 4, No. 11, doi: 10.1029/2003GC000574. 
Korenaga, J., 2007, Thermal cracking and the deep hydration of oceanic lithosphere: A key to the generation of plate tectonics?: Journal of Geophysical Research, v. 112, doi: $10.1029 / 2006 J B 004502$.

Lancelot, Y., Larson, R.L., and Leg 129 Shipboard Scientific Party, 1990, Proceedings of the Ocean Drilling Program, Initial Reports, Volume 129: College Station, Texas, Ocean Drilling Program, 499 p.

Larson, R.L., 1976, Late Jurassic and Early Cretaceous evolution of the western Central Pacific Ocean: Journal of Geomagnetism and Geoelectricity, v. 28, p. 219-236.

Larson, R.L., 1991, Latest pulse of Earth: Evidence for a mid-Cretaceous superplume: Geology, v. 19, p 547-550.

Larson, R.L., and Chase, C.G., 1972, Late Mesozoic evolution of the western Pacific Ocean: Geological Society of America Bulletin, v. 83, p. 3627-3644.

Larson, R.L., and Hilde, T.W.C., 1975, A revised timescale of magnetic reversals for the Early Cretaceous and Late Jurassic: Journal of Geophysical Research, v. 80, p. 2586-2594.

Larson, R.L., and Schlanger, S.O., 1981, Geological evolution of the Nauru basin and regional implications, Initial Repts. Deep Sea Drill. Proj. 61, p. 841-862.

McNutt, M.K., and Fischer, K.M., 1987, The South Pacific Superswell, in Keating, B.H., Fryer, P., Batiza, R., and Boehlert, G.W., eds., Seamounts, Islands, and Atolls, American Geophysical Union Geophysical Monograph 43, p. 25-34.

McNutt, M.K., 1998, Superswells: Reviews of Geophysics, v. 36, 2, p. 211-244.

Menard, H.W., 1964, Marine geology of the Pacific: New York, McGraw-Hill, 271 p.

Morgan, W.J., 1972, Deep mantle convection plumes and plate motions: The American Association of Petroleum Geologists Bulletin, v. 56, No. 2, p. 203-213.

Muirhead, J.D., Airoldi, G., Rowland, J.V., and White, J.D.L., 2012, Interconnected sills and inclined sheet intrusions control shallow magma transport in the Ferrar large igneous province: Bulletin of the Geological Society of America, v. 124, no. 1/2, p. 162-180, doi: 10.1130/B30455.1.

Nakanishi, M., Tamaki, K., and Kobayashi, K., 1992a, Magnetic anomaly lineations from Late Jurassic to Early Cretaceous in the west-central Pacific Ocean: Geophysical Journal International, v. 109, p. 701-719. 
Nakanishi, M., Tamaki, K., and Kobayashi, K., 1992b, A new Mesozoic isochron chart of the northwestern Pacific Ocean: Paleomagnetic and tectonic implications: Geophysical Research Letters, v. 19, No. 7, p. 693-696.

Ogg, J.G., Karl, S.M., and Behl, R.J., 1992, Jurassic through Early Cretaceous sedimentation history of the central equatorial Pacific and of Sites 800 and 801, in Larson, R.L., Lancelot, Y., et al., 1992, Proc. ODP, Sci. Results, 129: College Station, TX (Ocean Drilling Program).

Ogg, J.G., and Hinnov, L.A., 2012, Jurassic, in Gradstein, F.M., Ogg, J.G., Schmitz, M.D., and Ogg, G.M., eds., The Geologic Time Scale, Elsevier Publishing, p. 731-792.

Ozima, M., Kaneoka, I., Saito, K., Honda, M., Yanagisawa, M., and Takigami, Y., 1983, Summary of geochronological studies of submarine rocks from the Western Pacific Ocean, in Hilde, T.W.C., and Uyeda, S., eds., Geodynamics of the Western Pacific-Indonesian Region, v. 11, p. 137-142.

Perfit, M.R., Fornari, D.J., Smith, M.C., Bender, J.F., Langmuir, C.H., and Haymon, R.M., 1994, Small-scale spatial and temporal variations in mid-ocean ridge crest magmatic processes: Geology, v. 22, p. 375-379.

Reichow, M.K., Pringle, M.S., Al'Mukhamedov, A.I., Allen, M.B., Andreichev, V.L., Buslov, M.M., Davies, C.E., Fedoseev, G.S., Fitton, J.G., Inger, S., Medvedev, A.Ya., Mitchell, C., Puchkov, V.N., Safonova, I.Yu., Scott, R.A., and Saunders, A.D., 2009, The timing and extent of the eruption of the Siberian Traps large igneous province: Implications for the end-Permian environmental crisis: Earth and Planetary Science Letters, v. 277, p. 9-20, doi: 10.1016/j.epsl.2008.09.030.

Sager, W.W., Duncan, R.A., and Handschumacher, D.W., 1993, Paleomagnetism of the Japanese and Marcus-Wake Seamounts, Western Pacific Ocean, in Pringle, M.S., and Sager, W.W., eds., The Mesozoic Pacific: Geology, tectonics, and volcanism, American Geophysical Union Geophysical Monograph 77, p. 401-435.

Sager, W.W., Handschumacher, D.W., Hilde, T.W.C., and Bracey, D.R., 1988, Tectonic evolution of the northern Pacific plate and Pacific-Farallon-Izanagi triple junction in the Late Jurassic and Early Cretaceous (M21-M10): Tectonophysics, v. 155, p. 345-364.

Sandwell, D.T., Müller, R.D., Smith, W.H.F., Garcia, E., and Francis, R., 2014, New global marine gravity model from CryoSat-2 and Jason-1 reveals buried tectonic structure: Science, v. 346, pp. 65-67, doi: 10.1126/science.1258213.

Sandwell, D.T., and Smith, W.H.F., 2009, Global marine gravity from retracked Geosat and ERS-1 altimetry: Ridge segmentation versus spreading rate: Journal of Geophysical Research, v. 113, B01411, doi: 10.1029/2008JB006008. 
Sandwell, D.T., Winterer, E.L., Mammerickx, J., Duncan, R.A., Lynch, M.A., Levitt, D.A., and Johnson, C.L., 1995, Evidence for diffuse extension of the Pacific plate from Pukapuka ridges and cross-grain gravity lineations: Journal of Geophysical Research, v. 100, No. B8, p. 15087-15099.

Shipley, T.H., Abrams, L.J., Lancelot, Y., and Larson, R.L., 1993, Late Jurassic-Early Cretaceous oceanic crust and Early Cretaceous volcanic sequences of the Nauru Basin, Western Pacific, in Pringle, M.S., and Sager, W.W., eds., The Mesozoic Pacific: Geology, tectonics, and volcanism, American Geophysical Union Geophysical Monograph 77, p. 103-119.

Smith, W.H.F., Staudigel, H., Watts, A.B., and Pringle, M.S., 1989, The Magellan Seamounts: Early Cretaceous record of the South Pacific Isotopic and Thermal Anomaly: Journal of Geophysical Research, v. 94, No. B8, p. 10501-10523.

Stadler, T.J., and Tominaga, M., 2015, Intraplate volcanism of the western Pacific: New insights from geological and geophysical observations in the Pigafetta Basin: Geochemistry, Geophysics, Geosystems, v. 16, No. 9, p. 3015-3030.

Svensen, H., Planke, S., Polozov, A.G., Schmidbauer, N., Corfu, F., Podladchikov, Y.Y., and Jamtveit, B., 2008, Siberian gas venting and the end-Permian environmental crisis: Earth and Planetary Science Letters, v. 277, p. 490-500, doi: 10.1016/j.epsl.2008.11.015.

Svensen, H., Planke, S., Malthe-Sørenssen, A., Jamtveit, B., Myklebust, R., Eidem, T.R., and Rey, S.S., 2004, Release of methane from a volcanic basin as a mechanism for initial Eocene global warming: Nature, v. 429, p. 542-545.

Tarduno, J.A., Sliter, W.V., Kroenke, L., Leckie, M., Mayer, H., Mahoney, J.J., Musgrave, R., Storey, M., and Winterer, E.L., 1991, Rapid formation of Ontong Java Plateau by Aptian mantle plume volcanism: Science, v. 254, p. 399-403.

Tivey, M.A., Larson, R.L., Pockalny, R., and Schouten, H., 2005, Downhole magnetic measurements of ODP Hole 801C: Implications for Pacific oceanic crust and magnetic field behavior in the Middle Jurassic: Geochemistry, Geophysics, Geosystems, v. 6, doi: 10.1029/2004GC000754.

Tivey, M.A., Sager, W.W., Lee, S.-M., and Tominaga, M., 2006, Origin of the Pacific Jurassic quiet zone: Geology, v. 34, no. 9, p. 789-792, doi: 10.1130/G22894.1.

Tominaga, M., Sager, W.W., Tivey, M.A., and Lee, S.-M., 2008, Deep-tow magnetic anomaly study of the Pacific Jurassic Quiet Zone and implications for the geomagnetic polarity reversal timescale and geomagnetic field behavior: Journal of Geophysical Research, v. 113, B07110, doi: 10.1029/2007JB005527. 
Tominaga, M., Teagle, D.A.H., Alt, J.C., and Umino, S., 2009, Determination of the volcanostratigraphy of oceanic crust formed at superfast spreading ridge: Electrofacies analyses of ODP/IODP Hole 1256D: Geochemistry, Geophysics, Geosystems, v. 10, No. 1, doi: 10.1029/2008GC002143.

Tominaga, M., Tivey, M.A., and Sager, W.W., 2015, Nature of the Jurassic Magnetic Quiet Zone: Geophysical Research Letters, v. 42, p. 8367-8372, doi: 10.1002/2015GL065394.

Turgeon, S.C., and Creaser, R.A., 2008, Cretaceous oceanic anoxic event 2 triggered by a massive magmatic episode: Nature, v. 454, p. 323-326, doi: 10.1038/nature07076.

Wessel, P., and Lyons, S., 1997, Distribution of large Pacific seamounts from Geosat/ERS-1: Implications for the history of intraplate volcanism: Journal of Geophysical Research, v. 102, No. B10, p. 22459-22475.

White, R.S., McKenzie, D., and O’Nions, R.K., 1992, Oceanic crustal thickness from seismic measurements and rare earth element inversions: Journal of Geophysical Research, v. 97, No. B13, p. 19683-19715.

Winterer, E.L., Natland, J.H., Van Waasbergen, R.J., Duncan, R.A., McNutt, M.K., Wolfe, C.J., Premoli Silva, I., Sager, W.W., Sliter, W.V., 1993, Cretaceous guyots in the northwest Pacific: An overview of their geology and geophysics, in Pringle, M.S., and Sager, W.W., eds., The Mesozoic Pacific: Geology, tectonics, and volcanism, American Geophysical Union Geophysical Monograph 77, p. 307334.

Zelt, C.A., and Smith, R.B., 1992, Seismic traveltime inversion for 2-D crustal velocity structure: Geophysical Journal International, v. 108, p. 16-34. 

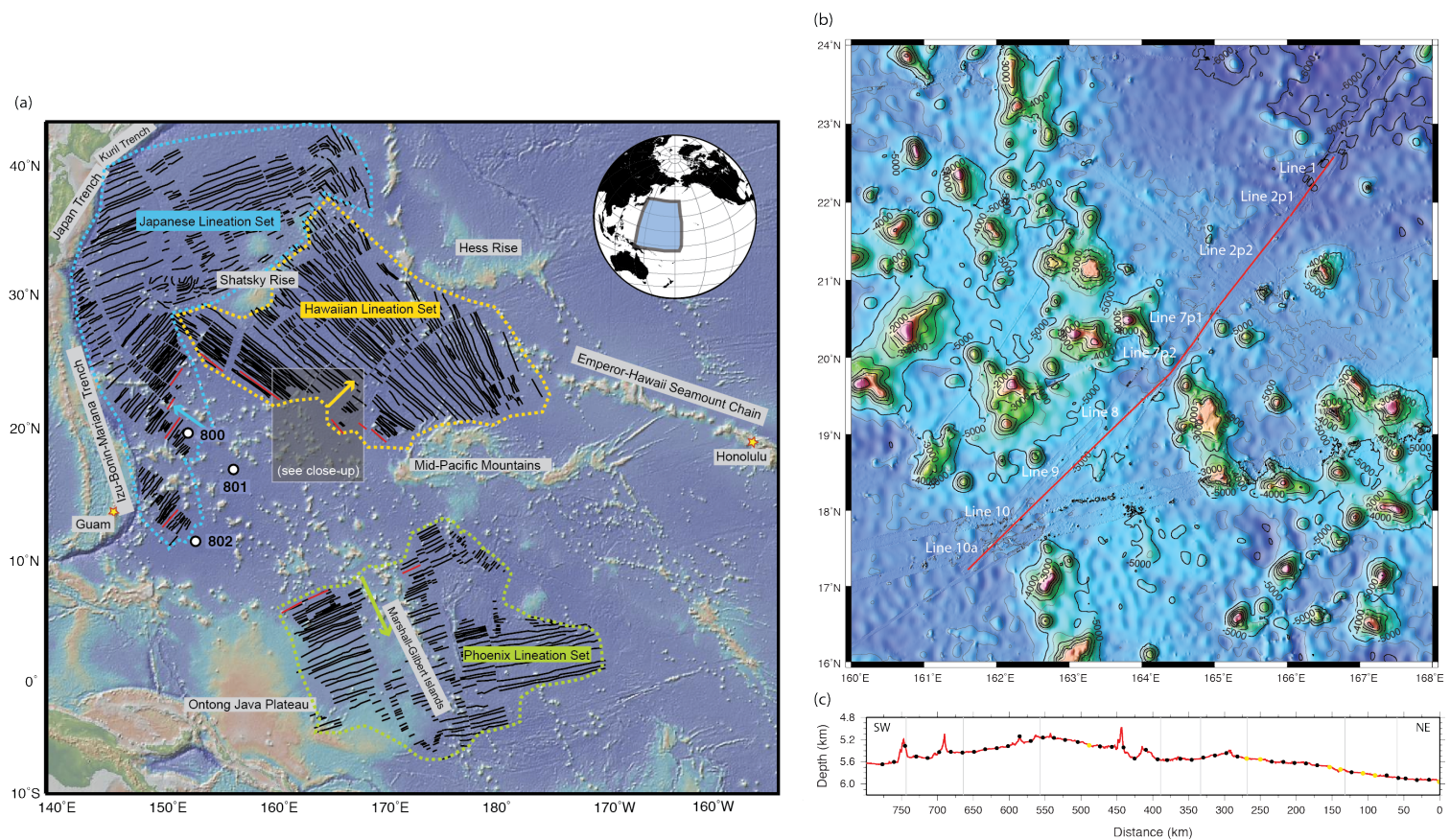

Figure 1. Map of the western Pacific showing the relative location of the JQZ survey area. (a) Western Pacific seafloor with major Mesozoic magnetic anomaly lineation sets. The Japanese, Hawaiian, and Phoenix lineations are bounded in blue, yellow, and green dots, respectively. The colored arrows indicate the approximate spreading directions of the Pacific-Farallon-Izanagi ridges. The study area for the JQZ magnetic and seismic survey lies within the shaded gray box. Red lines denote M29 ( 156 Ma), the widely accepted oldest seafloor chron. Ocean Drilling Program (ODP) Sites 800, 801, and 802 are labeled and represented by the white circles. Modified from Tominaga et al. [2015]. (b) Bathymetry of the JQZ survey area. (b) Nine MCS acquisition lines (Lines 1, 2p1, $2 \mathrm{p} 2,7 \mathrm{p} 1,7 \mathrm{p} 2,8,9,10$, and 10a) comprising the JQZ survey transect span a distance of $\sim 800 \mathrm{~km}$ and are represented by the nearly continuous red segments. (c) A depth profile of the survey transect shows sonobuoy deployment positions (represented by black dots) projected onto the seafloor. Fifty sonobuoys were used in the experiment, spaced at $\sim 16$ $\mathrm{km}$ intervals, with Sonobuoy 1 at the northeastern end and Sonobuoy 50 at the southwestern end of the transect. Yellow dots denote sonobuoys that provided unusable records with little or no data (Sonobuoys 1, 7, 8, 10,11, 17, 18, and 32). Gray vertical lines depict the locations of discontinuities between MCS lines. 


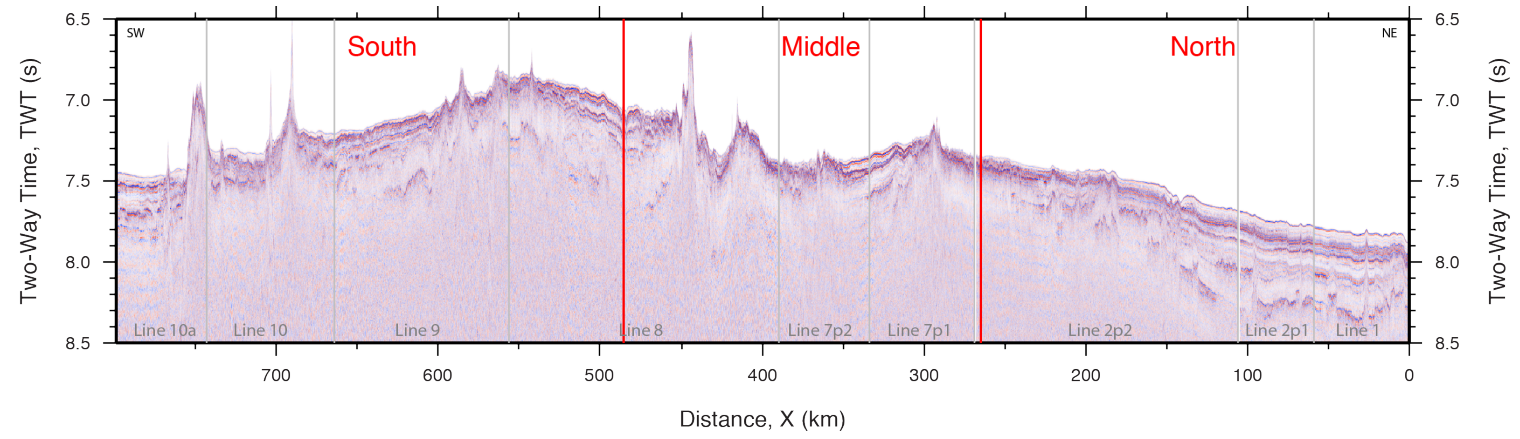

Figure 2. Multi-channel seismic (MCS) image along the JQZ transect. Nine MCS acquisition lines (Lines 1, 2p1, 2p2, 7p1, 7p2, 8, 9, 10, and 10a) comprising the survey transect span a distance of $\sim 800 \mathrm{~km}$. The transect is separated into three broadly defined regions: North, Middle, and South, as indicated by the red labels. 

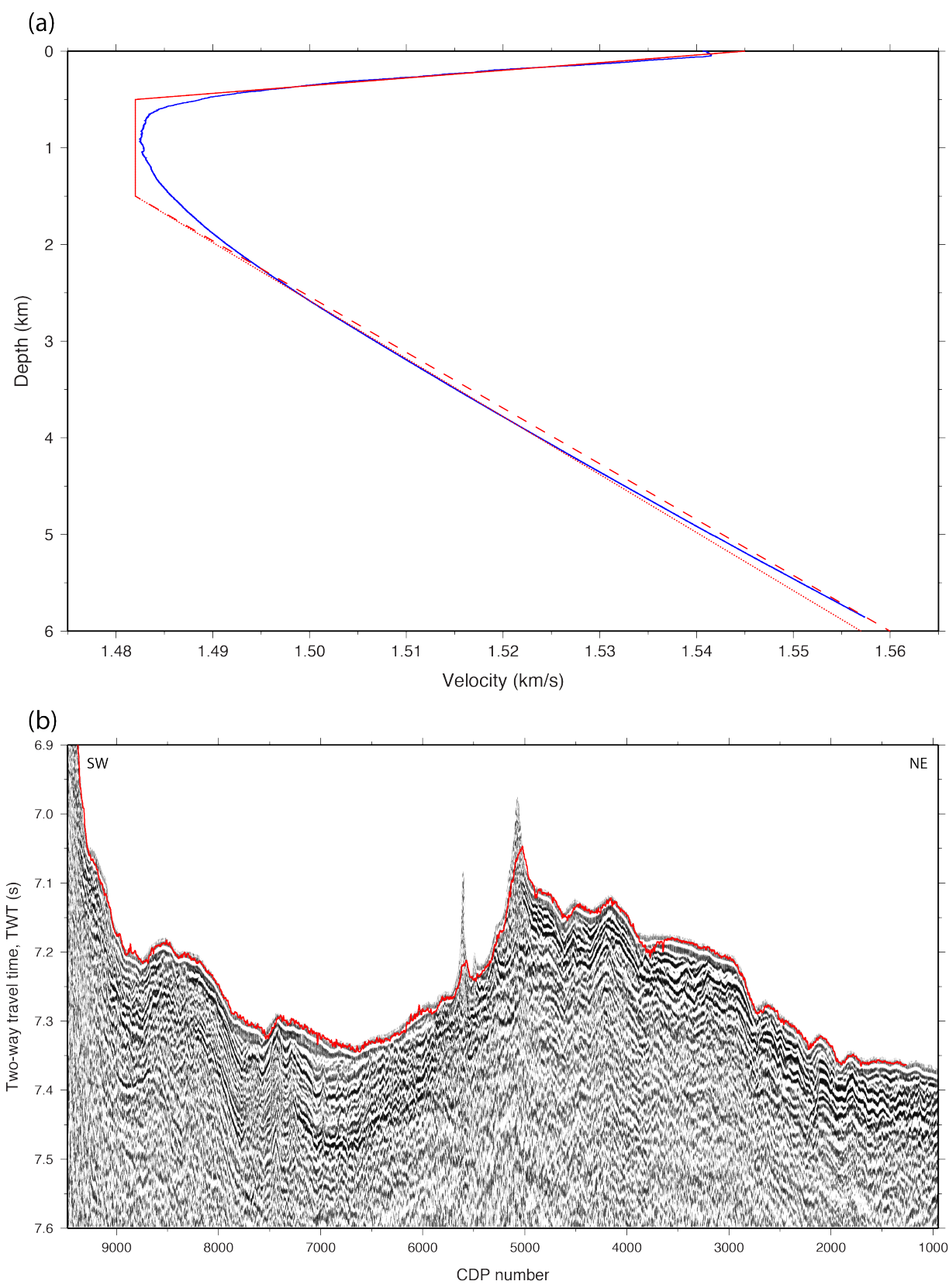

Figure 3. Seismic modeling of water velocity and seafloor depth. (a) Water velocity profiles along the JQZ transect. Measurements from Sentry AUV dives 129, 131, 132, and 133 were used to obtain an average water velocity profile (blue line), which was approximated with a piecewise, linear function (red lines). A slower velocity gradient was used at depths of 1.5-6.0 km for MCS Lines 1, 2p1, 2p2, 7p1, and 7p2 (stippled red line), whereas Lines $8,9,10$, and 10a used a slightly faster velocity gradient over the same depths (dashed red line). (b) MCS Line 8 section overlain with predicted seafloor arrival times. The predicted seafloor arrivals (red line) correlate with the MCS seafloor reflections, validating the water velocity approximation and multibeam bathymetry used in our model. The final results of our seismic interpretation are sensitive to the assumed velocity model, which makes this initial validation significant. 

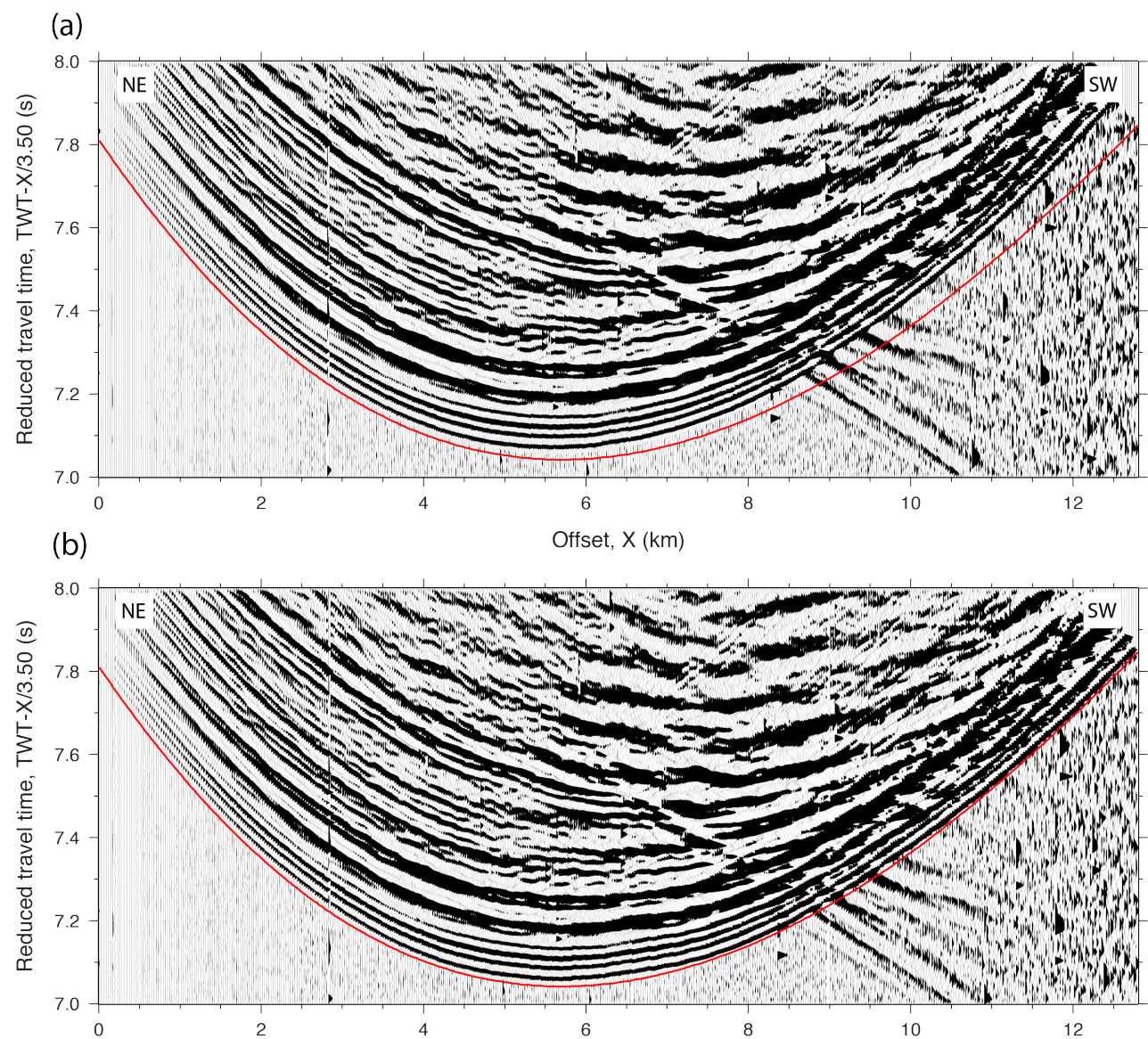

(c)

Offset, $X(\mathrm{~km})$

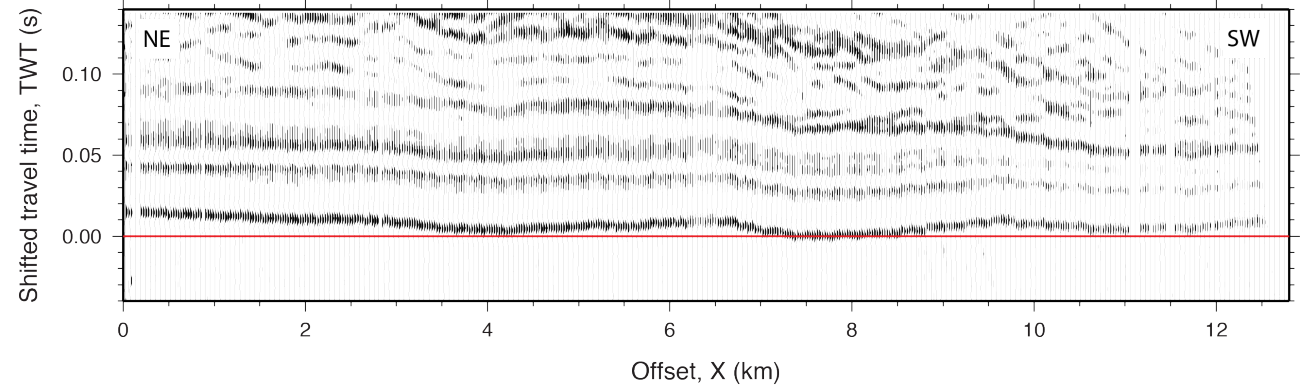

Figure 4. Sonobuoy 3 seismograms with predicted seafloor reflection arrival times. (a) Predicted seafloor arrival times (red line) and sonobuoy data with offsets determined from a fixed sonobuoy position show a poor fit, especially with increasing offset. Travel times are reduced at $3.5 \mathrm{~km} / \mathrm{s}$. (b) Predicted seafloor arrival times (red line) and sonobuoy data with an offset correction calculated as a polynomial function of shot time applied to sonobuoy source-receiver distances show a significantly improved fit. Travel times are reduced at $3.5 \mathrm{~km} / \mathrm{s}$. (c) Sonobuoy traces with an offset correction applied to sonobuoy source-receiver distances are time-shifted to predicted seafloor reflection arrival times (red line). The sonobuoy offset correction improves the fit between sonobuoy data and predicted arrival times to within a few milliseconds. 


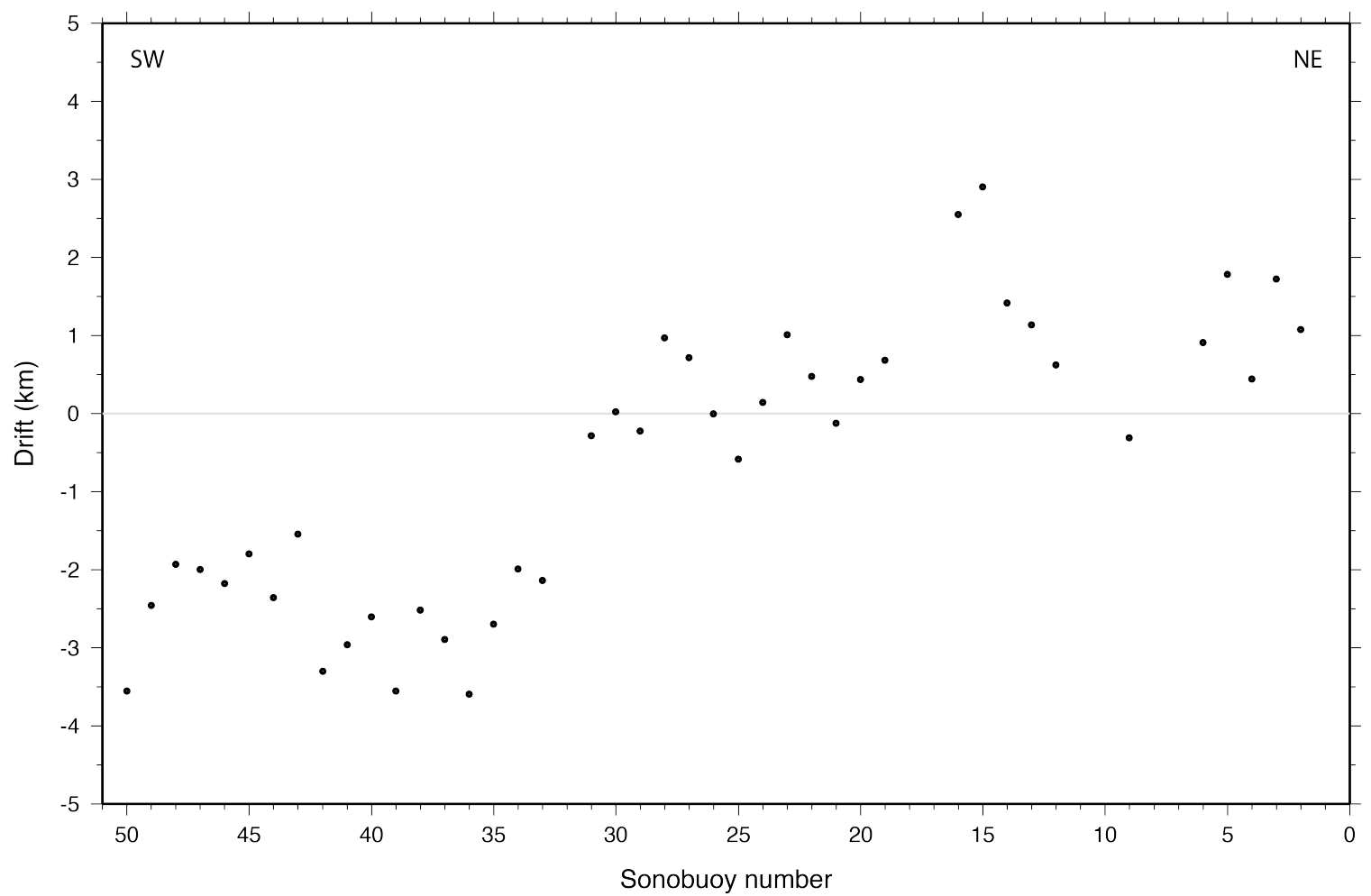

Figure 5. Total sonobuoy drift distances modeled for each instrument along the transect. Drifting instruments follow a general trend over the duration of the experiment, as sea surface currents gradually shifted towards the same direction as the ship's course. Positive values indicate sonobuoy drift away from the ship's course during seismic acquisition, and negative values indicate sonobuoy drift along with the ship's course during seismic acquisition. Eight sonobuoys not represented in this figure provided unusable records with little or no information (Sonobuoys 1, 7, 8, 10, 11, 17, 18, and 32). 

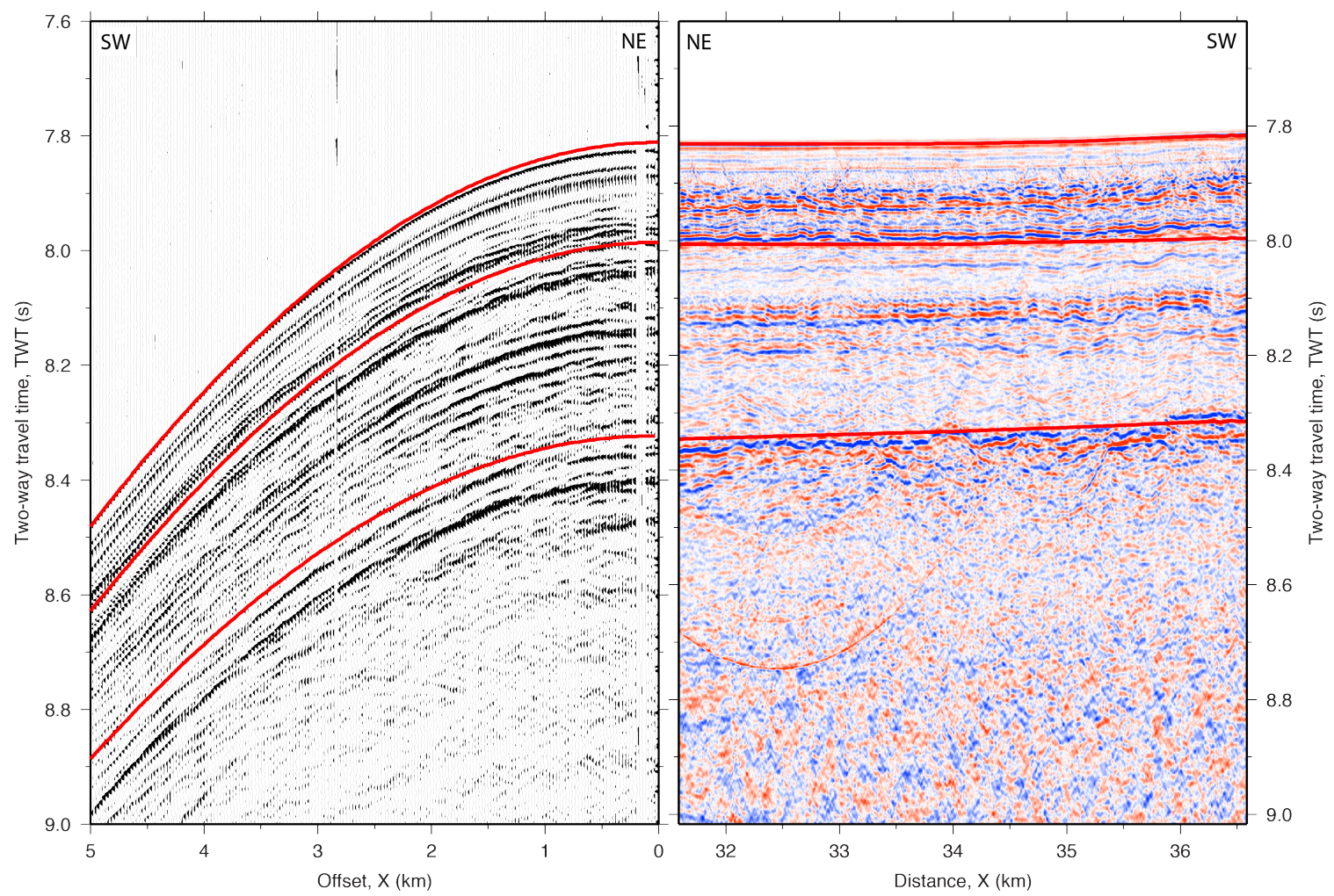

Figure 6. Sonobuoy 3 record and MCS image along the same survey section. Bright reflections in the MCS data (right) correspond to high amplitudes in the sonobuoy data at near offsets (left) at similar times. Slight differences between MCS and sonobuoy twoway travel times are due to different receiver depths in the water column. Red lines are positioned at model layer boundaries in the MCS image, corresponding to relatively strong reflections from the seafloor, sediments, and "basement" that are also observed in the sonobuoy record. 

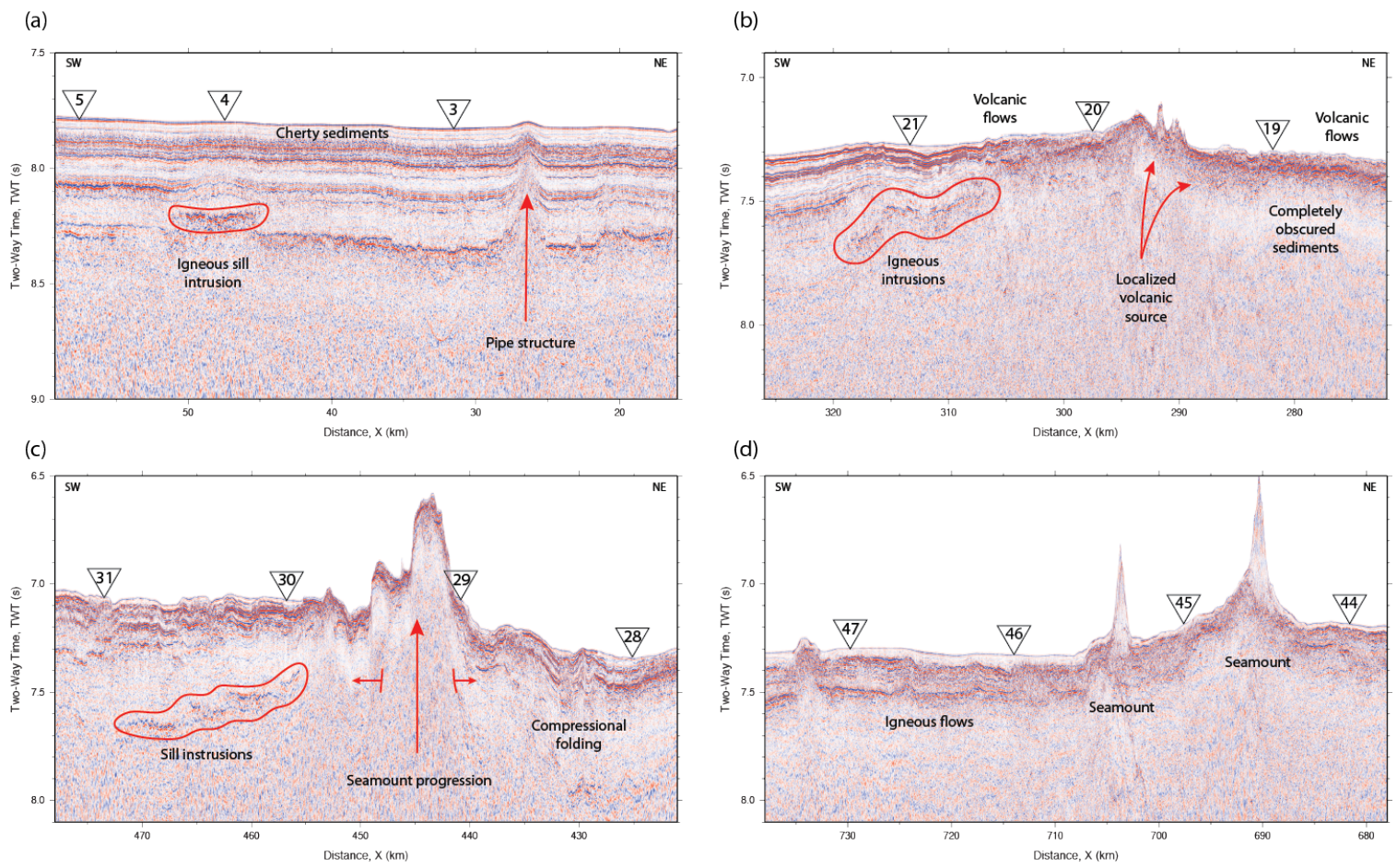

Figure 7. MCS images with notable crustal features. (a) MCS Line 1 sediments and igneous features. Oceanic crust from the North section of the JQZ transect generally lacks seafloor topography, although subsurface magmatism is intermittent throughout. Igneous sill horizons influence overlying sedimentary strata, resulting in deformational uplift and providing age constraints on the emplacement of igneous material into presumably Jurassic-age crust. Sonobuoys are represented by the numbered inverted triangles, projected onto the seafloor from their deployment locations at the sea surface. (b) MCS Line $7 \mathrm{p} 1$ seafloor and subsurface features. Magmatic activity increases along the Middle section towards the southwest and seafloor volcanics become more apparent. Rough seafloor basalt flows conceal reflections from the underlying material. (c) MCS Line 8 crustal features. The emplacement of large seamounts leads to apparent deformation in crustal sediments. Faults and folds are observed in the sediments adjacent to the flanks of the seamount, and sill intrusions that may or may not be related to the episodic volcanism are present. (d) MCS Line 10 shallow crustal features. Several localized seamounts appear in the South section of the transect. Away from the vicinity of the seamounts, the seafloor bathymetry is generally flat-lying, although variations in depth are occasionally associated with the structures (e.g., the seafloor northeast of Sonobuoy 44 is consistently shallower than the seafloor southwest of Sonobuoy 46). 


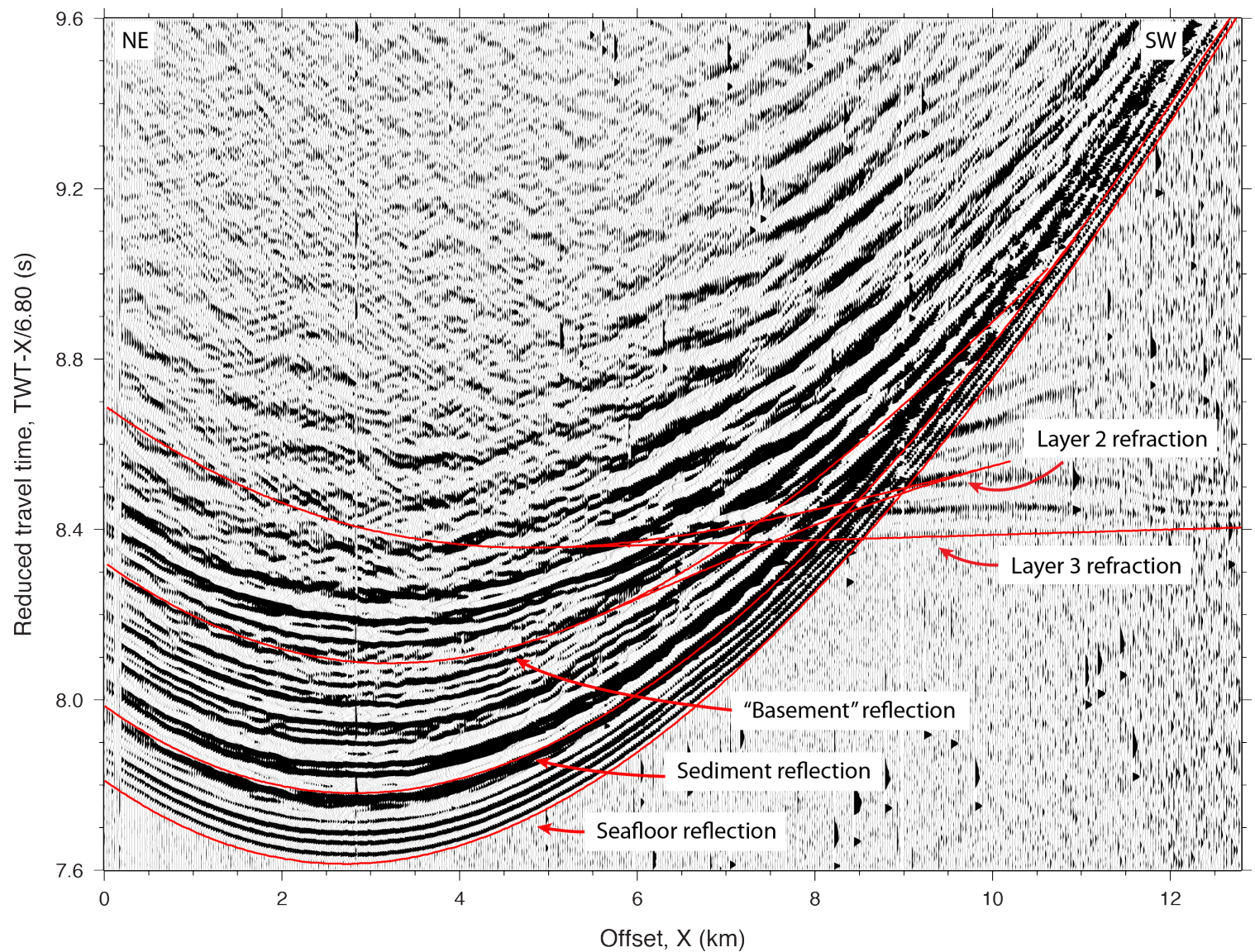

Figure 8. Sonobuoy 3 with predicted crustal reflections and refractions. Predicted seafloor arrival times, sediment reflections, and basement refractions (red lines) obtained from ray-traced waveforms based on our velocity model correspond with observed seismic phases in the sonobuoy data. Travel times are reduced at $6.8 \mathrm{~km} / \mathrm{s}$. 
(a)

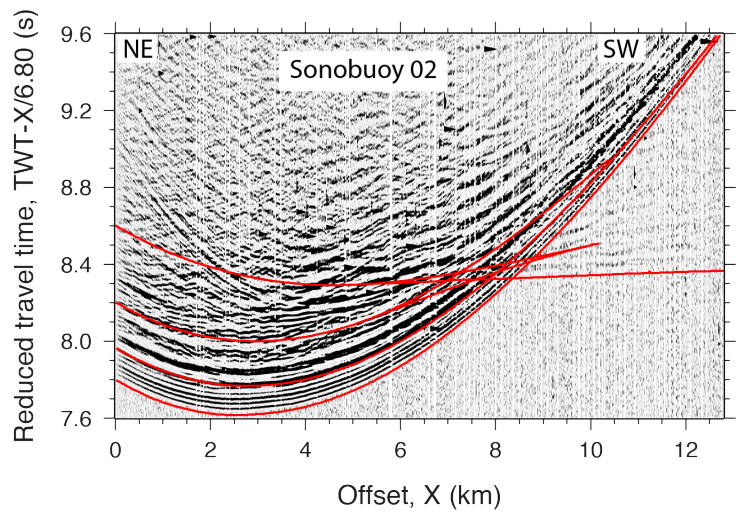

(c)

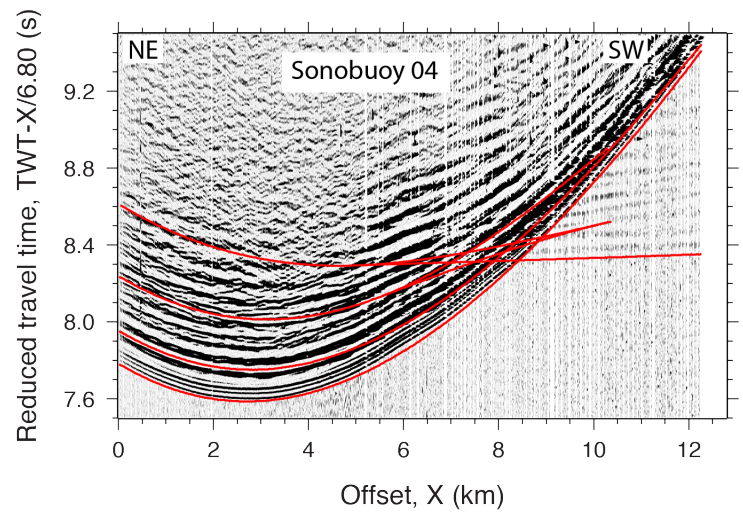

(b)

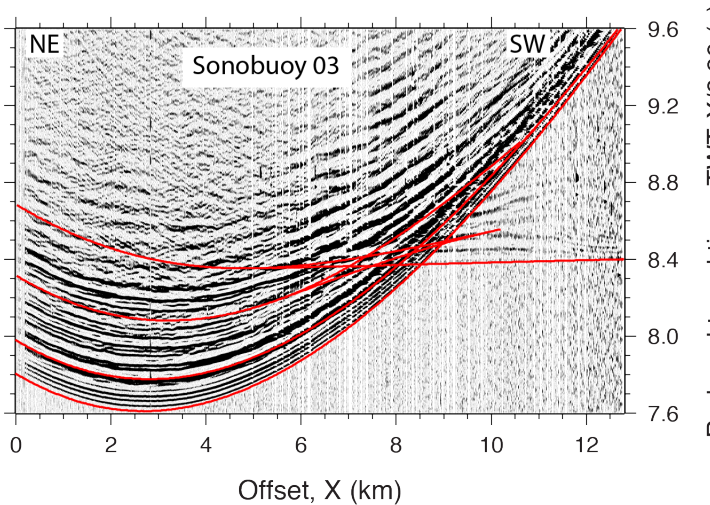

(d)

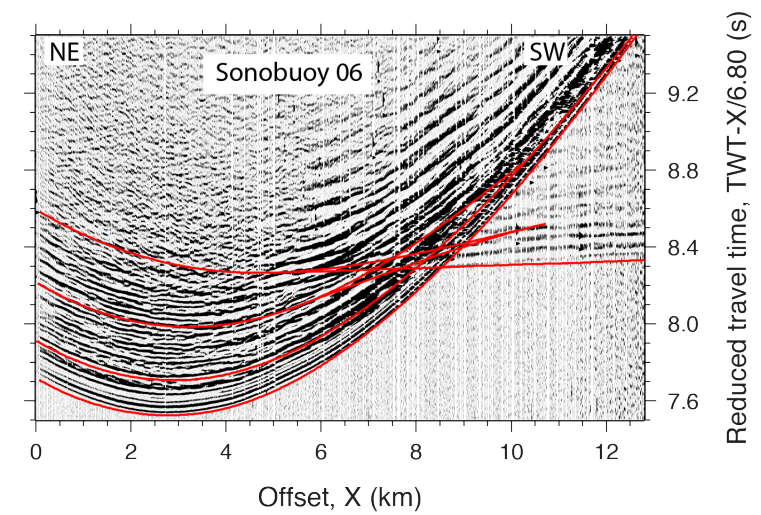

Figure 9. Sonobuoy records from the northeastern end of the JQZ survey transect. (a) Sonobuoy 2 provides relatively clean, coherent data clearly showing the Layer 2 and 3 refractions at offsets of $\sim 8 \mathrm{~km}$. (b) Sonobuoy 3 resembles adjacent records, and further supports the model of relatively unintruded, undisturbed oceanic crust. (c) Sonobuoy 4 has characteristically similar travel time curves to adjacent sonobuoy data. (d) Sonobuoy 6 similarly shows a strong Layer 2 refraction arriving later than the Layer 3 refraction. 
(a)

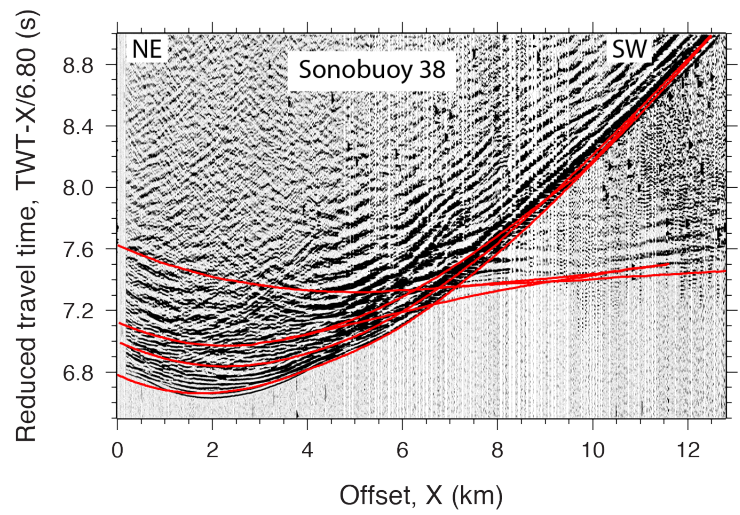

(c)

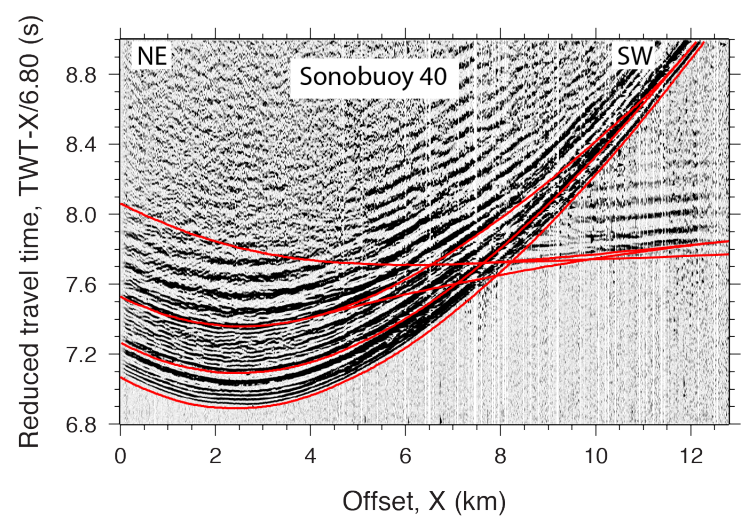

(b)

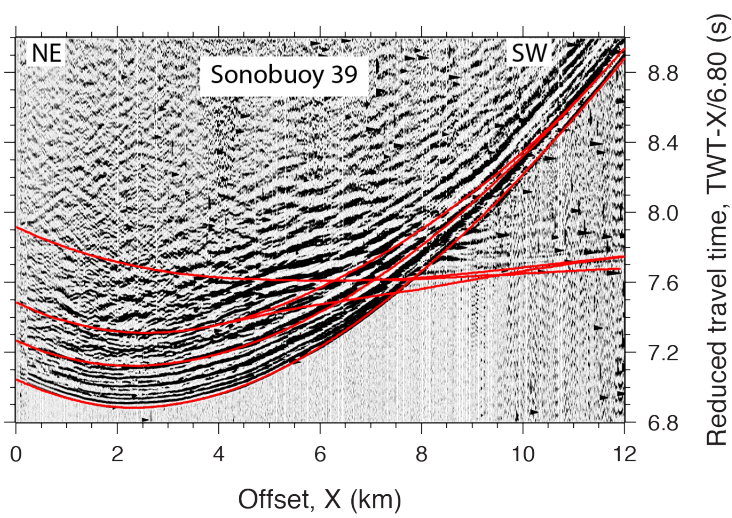

(d)

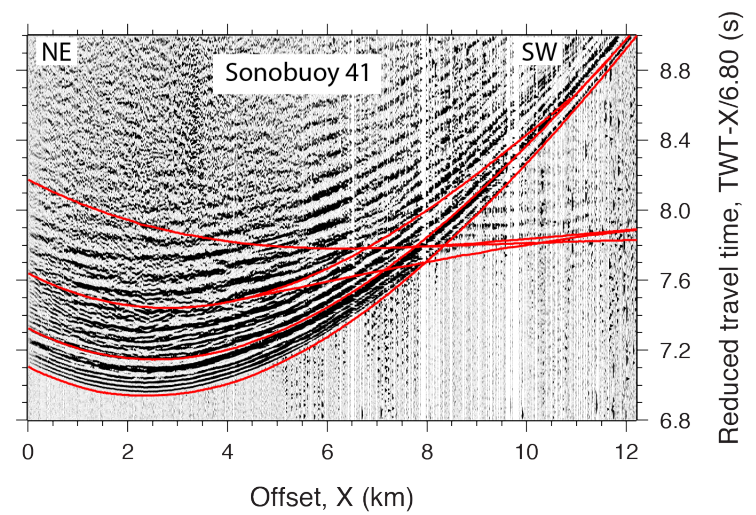

Figure 10. Sonobuoy records from the southwestern end of the JQZ survey transect. (a) Sonobuoy 38 is positioned over a $\sim 200$-m-tall seamount, contributing to a slightly uneven seafloor reflection. Noticeably different from northeastern sonobuoy records, Layer 2 refractions arrive earlier relative to Layer 3 refractions. (b) Sonobuoy 39 is generally representative of records from the southwestern end of the transect. (c) Sonobuoy 40 also has Layer 2 refractions arriving earlier than Layer 3 refractions. (d) Sonobuoy 41 is similar to adjacent sonobuoys, with Layer 2 refractions appearing before Layer 3 refractions, at offsets of $\sim 8 \mathrm{~km}$. 

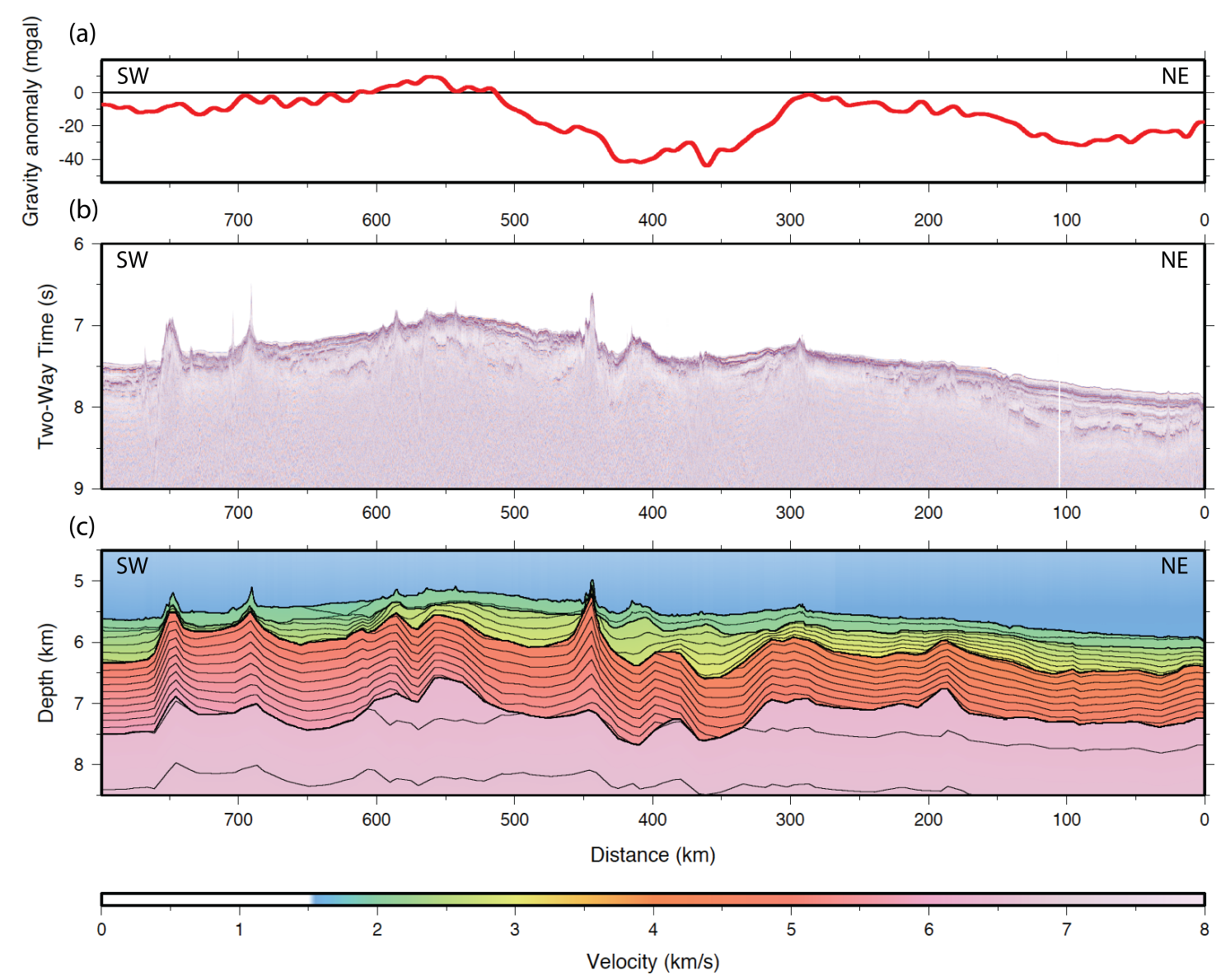

Figure 11. JQZ survey transect velocity model results based on gravity and seismic data. (a) Satellite gravity anomalies along the JQZ transect show significant trends, notably a low region at the center corresponding to the trace of the Marcus-Wake Seamount Chain and slight highs in the southwestern section. (b) The MCS profiles reveal subsurface sedimentary and igneous features, with a varying distribution of sills and flows across the transect. Surficial volcanics along the southwestern end of the line may obscure the identification of deeper intrusions. (c) The seismic velocity model is comprised of water, sediment, and "basement" layers. Low-velocity sediments are distinguishable from highvelocity, likely intruded, sediments. The boundary between oceanic crust Layers 2 and 3 is largely determined by crustal refractions modeled in the sonobuoy data. 

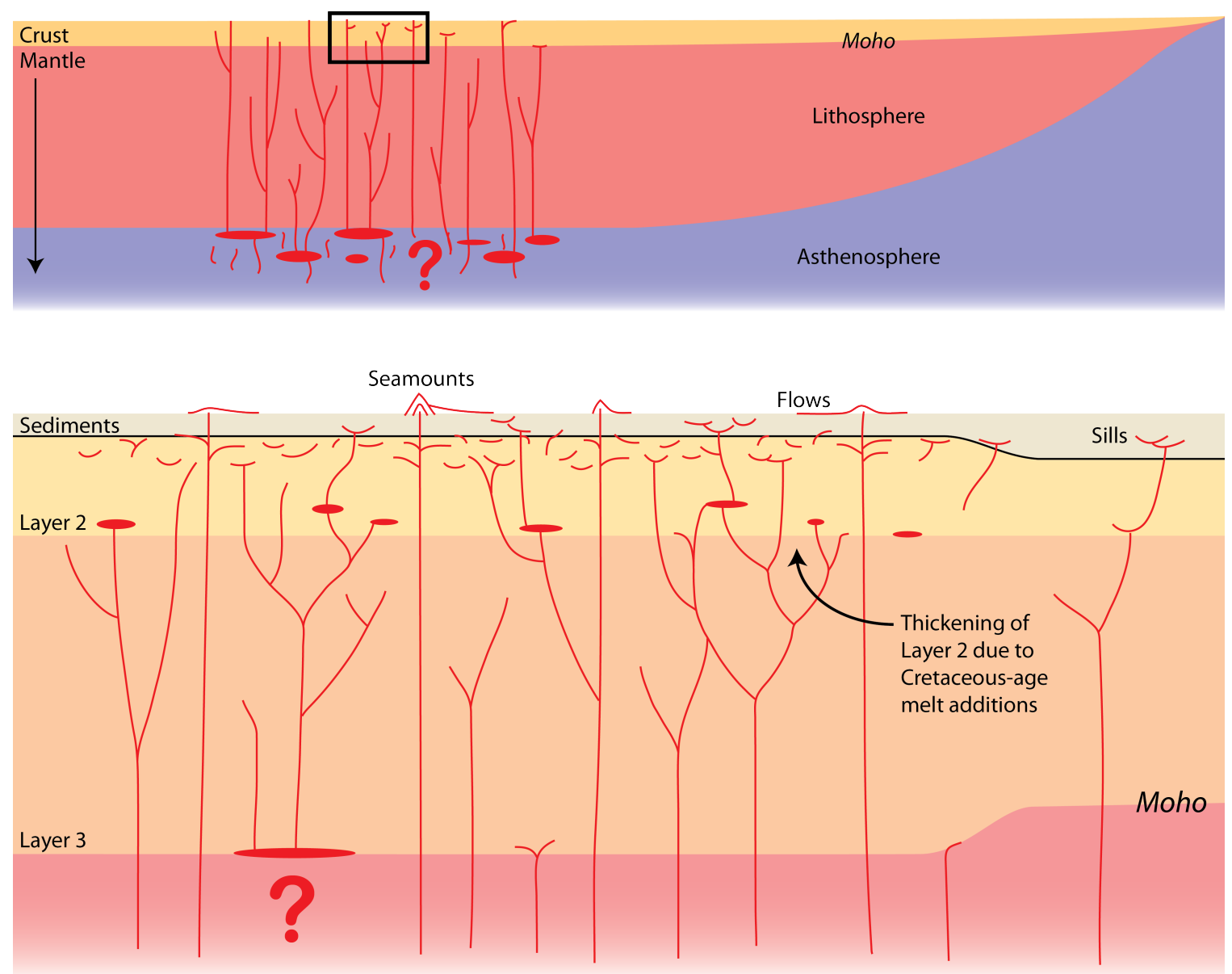

Figure 12. Possible modes of melt transport through the lithosphere. (top) Lithosphericscale schematic of melt ascending from an asthenospheric source attributed to the Cretaceous event. Direct, vertical conduits may facilitate the transport of melt over tens of kilometers, along with less robust veins that may or may not reach the seafloor. (bottom) Crustal-scale schematic of melt transport across the Moho and emplacement within the crust. Igneous seamounts, flows, and sills within the crust suggest widespread magmatic activity in the western Pacific, and results from our seismic velocity model indicate significant thickening of Layer 2 over $\sim 400 \mathrm{~km}$ of the survey transect that may be attributed to pervasive sill emplacement within sediments at the top of the "original" Layer 2 boundary. The emplacement of successive sills over a laterally extensive region may be facilitated by a dense, fingering network of melt through the lithosphere, in contrast to the focused, robust melt channels supplying nearby seamounts and flows. 


\title{
Chapter 4:
}

\section{Lithospheric-scale influence of magmatic activity on the subducting plate at the Mariana Trench}

\begin{abstract}
In this chapter, we model the structure of old ( $155 \mathrm{Ma})$, subducting lithosphere in the western Pacific that has been affected by voluminous magmatism and determine how magmatic additions are emplaced within the crust and upper mantle. As part of an experiment to investigate mantle hydration processes in the Marianas subduction system, several active-source wide-angle refraction lines were collected across the Pacific and Philippine Sea Plates. Data from ten ocean bottom seismometers (OBSs) were recovered from Line $\mathrm{E}$ of the experiment on the subducting plate, with the goal of providing a reference structure of subducting lithosphere to better understand the development of arc volcanism and tectonic history of the region. We determine the seismic velocity structure of the downgoing plate using P-wave travel time tomography. Our results indicate that widespread magmatic activity has resulted in significant crustal thickening beneath seamounts, likely via crustal underplating. Thickening of oceanic Layers 2 and 3 associated with seamounts along our line imply two distinct modes of melt transport within the lithosphere, either broadly pooling at the Moho or channeling through the crust to form extrusive additions. Additionally, our observation of a strong seismic reflector originating in the shallow upper mantle suggests that detailed upper mantle structures occur as a result of phase transitions under varying temperature and pressure conditions, namely the plagioclase-to-spinel transition at depths of $\sim 8-12 \mathrm{~km}$. This may have implications for our understanding of melt evolution from a pyrolite mantle composition and the effects of off-axis magmatism introducing basaltic components into an evolved mantle.
\end{abstract}




\section{Introduction}

Following the previous chapter in which western Pacific oceanic crust within the Jurassic Quiet Zone (JQZ) is examined in the context of post-formation crustal magmatism, we shift our focus westward approximately $1,500 \mathrm{~km}$ towards oceanic lithosphere that is part of the Mariana subduction system. Widespread magmatic activity during the Cretaceous produced extensive seamount chains that span hundreds of kilometers on the subducting Pacific plate [e.g., Koppers et al., 2003; Kaneda et al., 2010; Stadler and Tominaga, 2015] and presumably modified the structure of the original lithosphere. We use seismic records from ocean bottom seismometers (OBSs) to model the structure of old ( 155 Ma), subducting lithosphere in the western Pacific that has been affected by voluminous magmatism and determine how magmatic additions are emplaced within the crust and upper mantle. The use of OBSs in this seismic experiment enables us to probe deeper into the Earth and study igneous processes on a lithospheric scale, compared to shallower crustal depths limited by sonobuoy records in the JQZ study. Here, we use seismic tomography to model the crust and upper mantle produce a preferred P-wave velocity model of oceanic lithosphere. We find two main results: (1) large-scale crustal thickening associated with seamount formation and (2) the presence of a shallow upper mantle seismic discontinuity at $\sim 8 \mathrm{~km}$ beneath the Moho that may be associated with a solid-state phase transition from plagioclase to spinel in the upper mantle. Our seismic results suggest that crustal underplating may be a common feature associated with hotspot volcanism, and our understanding of lithospheric formation and evolution processes may be greatly improved with the collection and analysis of additional marine seismic datasets.

Widespread volcanism across the western Pacific Plate has affected hundreds of thousands of square kilometers of oceanic crust in the form of oceanic plateaus and seamount chains, but large volumes of igneous material associated with these features are embedded within the crust in poorly resolved quantities. Seismic surveys may provide valuable constraints on the structure of oceanic lithosphere, along with variations in structure attributable to post-formation crustal magmatic additions. Assuming "normal" oceanic crustal structure is exemplified by that of the Penrose ophiolite model [e.g., Raitt, 
1963; Christensen and Smewing, 1981; White, 1984], we can model western Pacific oceanic crust to ascertain how intraplate magmatic activity from the Cretaceous event has modified the crust. Although a significant range of crustal structures are formed due to differences in mid-ocean ridge spreading rates, Mesozoic magnetic anomaly lineations from the Japanese Lineation Set from our study area on the subducting Pacific plate reveal fast spreading rates up to $8 \mathrm{~cm} / \mathrm{yr}$ [Nakanishi et al., 1992] that are consistent with the fast spreading rates associated with oceanic crustal structure determined from the ophiolite model.

The Izu-Bonin-Mariana (IBM) arc system is an intraoceanic convergent margin with many unique features conducive to studying a wide-ranging suite of lithospheric processes. Our study focuses on lithosphere within the Mariana subduction zone (Fig. 1), the strongly arcuate segment of the IBM arc system south of the Ogasawara Plateau extending towards the deepest point on the planet, Challenger Deep. Since the initiation of subduction at $\sim 50 \mathrm{Ma}$ [Taylor, 1992], multiple episodes of crustal extension, rifting, and back-arc spreading have produced ridge, trough, arc, and trench features within the system [e.g., Stern et al., 2003; Calvert, 2011]. Some of the oldest remaining oceanic lithosphere in the western Pacific is subducted at the Mariana Trench, transporting crustal rocks, fluids, and igneous seamounts from the Pacific Plate beneath the overriding Philippine Sea Plate. Lithospheric flexure of the downgoing slab leads to extensional faulting and the formation of crustal-scale cracks that transfer fluids into the forearc and mantle [e.g., Bodine and Watts, 1979; Emry et al., 2014]. Thus, the structure and composition of the subducting lithosphere play a key role in the development of arc volcanism and the region's tectonic history.

As part of an experiment to investigate mantle hydration processes at the Mariana subduction zone, several active-source wide-angle refraction lines were collected across the Pacific and Philippine Sea Plates. This study focuses on Line E, an approximately N$\mathrm{S}$ trending refraction line oriented along-strike the trench at a distance of $\sim 150-180 \mathrm{~km}$ on the subducting Pacific Plate, near the western end of the Magellan Seamount Chain. Oceanic crust within our study area was formed between $\sim 150$ and $160 \mathrm{Ma}$ [Nakanishi et al., 1992]. Velocities modeled along Line $\mathrm{E}$ are oriented in the slow direction, perpendicular to the spreading direction established by Mesozoic seafloor magnetic 
anomaly lineations. The OBS array covers relatively flat seafloor, although small $(<1 \mathrm{~km}$ in height), irregularly shaped, seamount structures exist at the northern and southern ends of the line. Line $\mathrm{E}$ was designed to produce mantle velocities unaltered by cracks and serpentinization to be used for comparison with the results of cross-trench and forearc seismic lines studying faulting and fluid flux processes associated with the subduction zone. Seismic modeling of the Mariana subduction zone reveals crustal- and upper mantle-scale features (Fig. 2), providing structural context for the tectonic and igneous processes involved in the formation and evolution of oceanic lithosphere.

\section{Methods \& Results}

\section{Seismic Data Acquisition and Processing}

Active-source seismic data were collected with the 36-element, 6600 cubic inch air gun array of the R/V Marcus G. Langseth (cruise ID MGL1204), and the refraction experiment utilized a combination of short-period (SP) and broadband (BB) ocean bottom seismometers (OBSs). Coincident multi-channel seismic (MCS) data were acquired with airgun shots fired every $\sim 500 \mathrm{~m}$ from a depth of $9 \mathrm{~m}$ beneath the sea surface. Along Line E, data from ten four-channel (three-component seismometer and hydrophone) SP OBSs designed by Woods Hole Oceanographic Institution (WHOI) and Scripps Institution of Oceanography (SIO) from the Ocean Bottom Seismometer Instrument Pool (OBSIP) recorded crustal and upper mantle reflections and refractions over a distance of $\sim 260 \mathrm{~km}$. We designate the instruments numerically along our line, from OBS E01 in the north to OBS E12 at the southern end of the line (OBSs E04 and E05 were nonfunctional and result in a gap in ray coverage). OBSs were spaced $\sim 20 \mathrm{~km}$ apart and sat on the seafloor at depths ranging between $\sim 4,450 \mathrm{~m}$ and $\sim 5,460 \mathrm{~m}$.

High-quality data recorded on the SP OBSs were processed with routine seismic methods including OBS relocation, stacking of up to 3 co-located, band-pass filtering, and deconvolution. Compressional wave seismograms were obtained from the hydrophone and vertical component of the OBSs. The process of OBS relocation is necessary due to the extremely deep water column in the region, causing significant differences between original deployment positions at the sea surface and actual recording positions on the seafloor. In order to relocate OBS positions for seismic analysis, direct 
wave arrivals were picked and then modeled using the high-resolution bathymetric data collected during the cruise. A grid of root-mean-square (RMS) error contours provided new positions within a given uncertainty range, and we determined the relocated OBS position to be along the error contour with an RMS of $5 \mathrm{~ms}$ closest to the original deployment location. Relocated OBSs typically shifted $\sim 200 \mathrm{~m}$ from original deployment positions, with one exception being OBS E10, which moved $\sim 500 \mathrm{~m}$ due to the presence of a seamount flank altering its descent towards the seafloor. Airgun shots along Line $\mathrm{E}$ were recorded over several days, providing overlapping northbound and southbound segments that needed to be pieced together and stacked to maximize the signal-to-noise ratio in the data. A few segments along the line did not overlap and could not be stacked, resulting in shot coverage at intervals of $\sim 250 \mathrm{~m}$ instead of $\sim 500 \mathrm{~m}$. Noisy traces were removed from the records by zeroing out anomalously large amplitudes due to events such as earthquakes. Data were filtered between 4 and $15 \mathrm{~Hz}$ using a minimum phase band-pass filter, and predictive deconvolution was applied to reduce reverberations. Record sections were reduced to $8 \mathrm{~km} / \mathrm{s}$ for phase picking.

\section{Travel time picking}

First-arrival travel times were straightforward to identify in the majority of OBSs after seismic processing, with strong signals coming from the crust and upper mantle. Travel times were picked for compressional refractions through the crust (Pg) and mantle $(\mathrm{Pn})$ and reflections from the base of the crust $\left(\mathrm{P}_{\mathrm{M}} \mathrm{P}\right)$. Additionally, we were able to pick travel times for an upper mantle reflector/refractor that was observed in several instruments, which we refer to as Pd. The bathymetric profile of our line is relatively simple and flat, and local hilly structures due to off-axis seamounts at the northern (model offsets of 200-220 km) and southern (model offsets of 20-50 km) ends that were easily discernable in the seismograms did not significantly impede the picking process. We were unable to distinguish between phases from oceanic Layers 2 and 3 consistently, so crustal refractions were picked as a single phase, Pg. To ensure that picked phases were consistent across multiple stations, we used reciprocity to compare arrival times of phases that shared similar raypaths at reversed source/receiver locations. Uncertainties for travel time picks were conservatively estimated to be within $50 \mathrm{~ms}$. 
We picked first arrivals after identifying seismic phases $\left(\mathrm{Pg}, \mathrm{P}_{\mathrm{M}} \mathrm{P}, \mathrm{Pn}\right.$, and $\left.\mathrm{Pd}\right)$ in the OBS records reduced at $8 \mathrm{~km} / \mathrm{s}$ (panels (a) and (b) in Figs. 3-12). Crustal refractions, $\mathrm{Pg}$, were relatively simple to pick and showed up in all of the instruments, typically at source/receiver offsets between 5 and $40 \mathrm{~km}$. Moho reflections, $\mathrm{P}_{\mathrm{M}} \mathrm{P}$, were identified by large amplitudes characteristic of triplications with shallower absolute slopes (i.e., higher velocities) than adjacent $\mathrm{Pg}$ phases, at source/receiver offsets of $\sim 20-50 \mathrm{~km} . \mathrm{P}_{\mathrm{M}} \mathrm{P}$ travel times were pickable for all instruments, except for the negative (southbound) phase for OBS E08 due to weak signals from the hydrophone channel complicated by seafloor bathymetry. Upper-mantle refractions, $\mathrm{Pn}$, were observed in the seismograms as generally strong, horizontal seismic phases, from rays traveling at $\sim 8 \mathrm{~km} / \mathrm{s}$ in the uppermost mantle. First arrivals for Pn were visible from source/receiver offsets of $\sim 40$ until $>100 \mathrm{~km}$ in some instruments, although phase amplitudes weakened with increasing distances. For instruments E09 and E12, few or no picks could be made with confidence at positive source/receiver offsets (towards the north) due to anomalously weak phase arrivals. Reflections from the upper mantle, Pd, were observed in four OBSs: E02, E03, E10, and E11, at source/receiver offsets of $\sim 100-170 \mathrm{~km}$. Our ability to pick these bright reflections may be due to the geometry of the instruments' positions on the seafloor with respect to the raypaths traveling at depth through relatively uncomplex crustal structure in the middle of Line E. (Note: The tomographic model and figures in this chapter assume $\mathrm{Pd}$ to be an upper mantle refraction, but we refer to the phase as an upper mantle reflection upon further review. Subsequent inversions with the updated seismic phase may result in better velocity estimates, but the structural discontinuity in the velocity model is not likely to change significantly.)

\section{Seismic Tomography}

There are three main components to seismic tomography: creating an initial velocity model, tracing rays through the model, and running the tomographic inversion to update the model. The seismic tomography code used in this study was developed by $\mathrm{H}$. Van Avendonk [Van Avendonk et al., 1998; Van Avendonk et al., 2004] and updated by A. Harding at SIO. Our goal is to model seismic velocities within the crust and upper 
mantle based on our travel time picks of the four phases observed in the seismograms: $\mathrm{Pg}, \mathrm{P}_{\mathrm{M}} \mathrm{P}, \mathrm{Pn}$, and $\mathrm{Pd}$. The initial model should be set up such that a succession of small changes to update the model will be more effective than any large steps in the inversion process (i.e., a close approximation of the expected final result). In order to progress towards a smooth seismic velocity model, we alternate between ray tracing and linearized travel time inversions. Since the least squares travel time problem is underdetermined, regularization of the linear inversion allows us to balance the minimization of travel time residuals against a measure of model roughness to produce a preferred model of compressional velocities.

We create a two-dimensional (2-D) initial model by assigning slowness values to every node on a grid of model offsets and depths based on the velocity structure of typical oceanic crust. Five layers are designated in our model: water, sediments, crust, upper mantle above $\mathrm{Pd}$, and upper mantle below Pd. The first interface is defined by crustal topography at the sedimentary seafloor, which was obtained by extracting the bathymetric profile of our seismic line at regularly spaced model offsets. Deeper interfaces between the layers are input into the initial model using simple horizontal or isostatic depth estimates of lithospheric structure. In order to maximize the efficiency of the inversion process, we input initial slownesses derived from seismic velocity estimates of Pacific oceanic lithosphere [e.g., White et al., 1992; Kaneda et al., 2010]. Slowness values are associated with horizontal nodal values, whereas depths are independent and may be updated in the inversion process. This parameterization allows for interface locations and slowness jumps across interfaces to be updated with each iteration, as well as the slowness or slowness gradient within a given layer [Van Avendonk et al., 2004].

The graph method (or shortest path method) of ray tracing is used in the tomographic inversion process due to its ability to solve the forward problem efficiently and its suitability for marine refraction surveys. Using this method, raypaths are approximated through the model by using linear segments to connect adjacent grid points, with cumulative travel times calculated from each source location to all other points in space. The true path is determined to be the global minimum path time, following Fermat's principle. As in previous studies [Moser et al., 1992; Van Avendonk et al., 1998; Roland et al., 2012], the grid search is limited to the forward propagation 
direction, termed the forward star, which we limit at a minimum angle of $0.1^{\circ}$ between search directions. We consider 12 nodes in the $\mathrm{x}$-direction and 12 nodes in the z-direction during the graph method search, and choose a grid spacing of $100 \mathrm{~m}$ in both the vertical and horizontal directions. Rays are then traced from each instrument to the shot points.

We follow the same approach to tomographic inversion as described by Van Avendonk et al. [1998, 2004], which solves the damped least squares problem by using travel time residuals to minimize an objective function for the preferred model slowness perturbation. Our travel time picks are used to produce a set of linear equations that can be solved in the least squares inversion, as a solution to the matrix equation $d=G m$. In this equation, travel time differences between the picked phases and forward ray-traced arrivals make up the data vector $d$, the Frechét derivative matrix is denoted by $G$, and the normalized slowness perturbation vector is represented by $m$. Due to the underdetermined nature of the problem, functions of the first and second derivatives of the model slowness are incorporated by imposing roughness penalties, $F_{s 1}$ and $F_{s 2}$, and smoothing regularizations, $P_{1}$ and $P_{2}$, over smoothing length scales, $L_{H}$ and $L_{V}$, to arrive at a smooth model. The values of these parameters are determined empirically as we proceed through the inversion process, in attempts to limit nonphysical artifacts in the model without oversmoothing velocity perturbations along the raypaths.

The progression from initial to final model is guided by the model misfit, which is heavily influenced by the initial model. The inversion process is started with a limited set of travel times in order to restrict our model to shallow sedimentary and crustal depths, corresponding to the most well resolved portion of the model space. Through subsequent iterations of the ray-tracing scheme followed by tomographic inversion and model updates, we gradually extend the model to incorporate deeper layers. After each forward calculation, the total misfit between modeled and observed data is calculated as a $\chi^{2}$ value, the normalized sum of squared deviations between observed and predicted data. We use the $\chi^{2}$ value as a guide to adjusting the target misfit level for the following inversion. The inversion code then seeks a model perturbation that best satisfies the desired levels of data misfit and model roughness in a least-squared-error sense. We eventually arrive at our preferred slowness model by decreasing the target misfit level at 
small steps until an acceptable $\chi^{2}$ and an acceptable level of model roughness are achieved.

\section{Inversion Results}

The tomographic inversion of 4,129 first-arrival picks from 10 OBSs along our line resulted in a seismic velocity model fitting the data with a $\chi^{2}$ value of 0.90 after 32 iterations. Over the course of the inversion procedure, we closely monitored the output of each iteration of the forward-inverse problems for unphysical artifacts such as ray streaks or anomalous high- or low-velocity zones due to uneven ray coverage or the inversion process. If the model strayed too far from a realistic representation, we adjusted inversion parameters, model interfaces, or model slowness perturbations accordingly and re-ran the iteration. We began with an initial $\chi^{2}$ data misfit of 2.86 and gradually reduced the value to 0.91 for our preferred slowness model. Although a $\chi^{2}$ value of 1.00 is typically ideal, the trade-off between model roughness and data misfit is subjective. As such, the summed data misfit from the inversion process does not account for the importance in the spatial distribution of errors with respect to the seismic velocity model [Van Avendonk et al., 2004]. Additional improvements may be made to smooth out nonphysical artifacts and anomalous regions affected by low ray coverage, by redoing the tomographic inversion using a cleaned up version of our current slowness model as an initial model. This was not done due to time constraints, but the nominal improvement in our results would be unlikely to affect our broader interpretation of lithospheric structure and processes in the region.

Our final lithospheric model of preferred P-wave velocities is shown in Figure 2. The general structure of the crust and upper mantle resembles that of oceanic lithosphere with significant magmatic additions beneath observed seamounts. The relatively small initial $\chi^{2}$ data misfit indicates that the first iteration of layer interfaces and slownesses derived from past seismic velocity studies of Pacific oceanic lithosphere used in our initial model were not too far off from the eventual velocity model we produced for our study area. Differences in P-wave velocity between the initial and final models are generally small at $\pm 0.2 \mathrm{~km} / \mathrm{s}$ (Fig. 2b). Exceptions include a few locations around the Moho where the interface depth was adjusted. Beneath the seamounts at either end of the 
line (at model offsets $30 \mathrm{~km}$ and $210 \mathrm{~km}$ ), the Moho is slightly deeper than originally modeled. At the southern end of the line, lower crustal velocities are increased beneath the large seamount. Sediments in the upper crust also have higher-than-expected velocities. Regions of slower velocities in the final model are shown in red, mostly in the middle of the line within the lower crust.

Crustal thickness varies across the model (Fig. 13), with the southern end generally thicker (at a maximum thickness of $\sim 9.5 \mathrm{~km}$ ) than the northern end due to the presence of the large seamount (at a model offset of $30 \mathrm{~km}$ ). The small seamount at the northern end of the line (at a model offset of $210 \mathrm{~km}$ ) has a similar, less pronounced correlation with increased crustal thickness (at a maximum thickness of $\sim 7.5 \mathrm{~km}$ ). Oceanic crust is thinnest $(\sim 6.5 \mathrm{~km})$ along the bathymetrically flat middle section of the model and the northernmost end beyond the small seamount. Overall, seismic velocities are higher in the lower crust towards the southern end of the line $(6.8-7.2 \mathrm{~km} / \mathrm{s})$ compared to the northern end $(6.8-7.0 \mathrm{~km} / \mathrm{s})$. Regional features in the velocity structure of the lithosphere include a few low-velocity zones: in the upper mantle at $65-85 \mathrm{~km}$ and in the lower crust at $100-120 \mathrm{~km}$ and at $150-165 \mathrm{~km}$. The lateral variability observed in the velocity model corresponds to our travel time picks in the relevant instruments.

The observation of a strong upper mantle reflector in the seismograms is notable, as significant velocity discontinuities are not well constrained within the mantle. The high-amplitude nature and coherence of the seismic phase Pd may be indicative of some large-scale anomalous mantle structure or transitional zone across the lithosphere. Our inversion results place the seismic interface at a depth of $\sim 20-22 \mathrm{~km}$ within the shallow upper mantle, or approximately $8 \mathrm{~km}$ beneath the Moho. Velocities increase $\sim 0.2 \mathrm{~km} / \mathrm{s}$ across this interface, which is a significant change in velocity that may correspond with a phase transition in the upper mantle. The upper mantle reflector is observed in four instruments (OBSs E02, E03, E10, and E11) that have recorded rays crossing through the upper mantle at large offsets $(>100 \mathrm{~km})$ through the middle of Line E, where igneous features on the seafloor are largely absent. The limited observation of Pd may suggest that the seismic phase is most readily observed in lithosphere that is generally unaffected by secondary magmatic processes such as intraplate volcanism. 
Resolution tests typically performed to gauge the effectiveness of tomographic inversions were not done in this study, but may provide additional constraints on our seismic velocity results. The relatively simple lithospheric structure along the line suggests that lateral variations are on the order of tens of kilometers, possibly due to the nature of broadly distributed magmatic processes in the region. For example, crustal thickening beneath the large seamount at the southern end of the line occurs over a lateral distance of $\sim 30 \mathrm{~km}$. We can consider ray coverage from our instruments to evaluate how our preferred $\mathrm{P}$-wave model is affected by the limited distribution of travel time picks, as some nonphysical artifacts of the seismic inversion can be seen in localized zones of lowvelocity anomalies. Ray coverage is generally consistent within the crust and provides well-constrained Moho depths. Gaps in coverage occur from OBSs E04 and E05 in the middle of the line, but at those model offsets $(\sim 140-180 \mathrm{~km})$, the crustal structure appears to be generally very similar to that of typical oceanic lithosphere, as indicated by the lack of bathymetric features on the seafloor.

\section{Discussion}

The results of our tomographic inversion highlight two major features within the subducting Pacific lithosphere: (1) large-scale thickening of the crust associated with seamount formation and (2) a strong upper mantle reflector at a depth of $\sim 8 \mathrm{~km}$ beneath the Moho. Magmatic additions to the lithosphere are not unexpected, as widespread Cretaceous volcanism has been associated with much of the intraplate volcanic features observed throughout the western Pacific [e.g., Koppers et al., 2003; Kaneda et al., 2010; Stadler and Tominaga, 2015], but better constraints on the structure of the lithosphere are key to understanding the processes and consequences of post-formation crustal magmatism. Thickening of oceanic Layers 2 and 3 associated with seamounts of differing sizes imply two distinct modes of melt transport within the lithosphere, either broadly pooling at the base of Layer 3 or channeling through the crust to form extrusive additions to Layer 2. Our observation of a seismic reflector in the shallow upper mantle may provide additional insight into lithospheric processes during the formation and evolution of oceanic lithosphere, as a better understanding of upper mantle seismic discontinuities may have important implications for models of mantle composition and dynamics. 
Our tomographic model shows that oceanic crust in the western Pacific along Line $\mathrm{E}$ of this study is generally thicker than typical values for oceanic crust [e.g., Raitt, 1963; White, 1984], with a maximum thickness of $\sim 9.5 \mathrm{~km}$ beneath OBS E11 at the southern end of the line. The thinnest sections of crust along our line are under OBSs E01 and E08 and have a total thickness of $\sim 6.5 \mathrm{~km}$. The lack of seafloor topography observed along these sections suggests that oceanic crust in the middle and northernmost end of the line are least affected by Cretaceous magmatism in our model. Increases in total crustal thickness correspond with the presence of seamounts, making it likely that the magmatic source responsible for seamount formation supplies melt throughout the lithosphere, creating significant lateral variation in the structure of oceanic crust at different scales. High-velocity additions to the crust beneath hotspots and flood basalt provinces are commonly interpreted as large igneous intrusions [e.g., Farnetani et al., 1996], which is consistent with the abundance of Cretaceous magmatic features in the western Pacific.

Changes in crustal thickness, especially within oceanic Layers 2 and 3, inferred from our lithospheric seismic velocity model may reveal how melt is emplaced within the lithosphere in an intraplate setting. We differentiate between oceanic Layers 2 and 3 by assuming that the transition between Layer 2 dikes and Layer 3 gabbros is associated with a change in the seismic velocity gradient at a P-wave velocity of $6.3 \mathrm{~km} / \mathrm{s}$ (Fig. 13), based on laboratory measurements of the velocities of dikes and gabbroic lithologies found in ophiolite complexes [e.g., Christensen and Smewing, 1981; Christensen and Salisbury, 1982]. Beneath the seamounts along the line (at model offsets of 30 and 210 $\mathrm{km})$, significant increases in the thicknesses of Layers 2 and 3 are observed. The largest change in thickness of a seismic layer along our line occurs beneath the large seamount in the south, where an increase of up to $2 \mathrm{~km}$ occurs in Layer 2 that is likely directly attributable to seamount formation via the accumulation of volcanic flows. Thickening of Layer 2 is much less pronounced beneath the small seamount in the north, as it is likely that the thickening of Layer 2 is proportional to seamount size. Our estimates of Layer 3 thickness also show increases beneath the seamounts that occur over much larger wavelengths (at least by $\sim 3 \mathrm{x}$ ) than the corresponding features in Layer 2 thickness along the line. The broader scale of crustal thickening at depth may be indicative of different emplacement mechanisms within the lithosphere. As has been suggested for other regions 
affected by seamount chains and oceanic plateaus, evidence of crustal thickening may be indicative of magmatic material that either ponded beneath or intruded the base of the oceanic crust [e.g., Caress et al., 1995; Grevemeyer et al., 2001]. Results from our tomographic model showing high-velocity additions and thickened Layer 3 may be interpreted as crustal underplating beneath the seamounts along our line.

Additionally, changes in the Layer 3/2 thickness ratio provide another perspective on emplacement processes within the lithosphere (Fig. 13). Our results suggest at least two modes of melt transport through the lithosphere, one capable of uniformly thickening crust from below and one that transports melt efficiently through the crust to form extrusive lava on the seafloor. At model offsets greater than $\sim 100 \mathrm{~km}$, the Layer $3 / 2$ ratio is relatively constant, around a value of $\sim 2.5$. The ratio decreases consistently towards the southern end of the line reaching a minimum value of $\sim 1.2$, corresponding to the presence of the large seamount at a model offset of $\sim 30 \mathrm{~km}$. Changes in the Layer $3 / 2$ ratio may signify how seamount development occurs through several stages of magmatic emplacement. At the location of the small seamount in the north, the Layer $3 / 2$ ratio is not distinctly different from adjacent lithosphere without igneous seafloor structures, indicating that the noticeable thickening of Layer 3 beneath the small seamount occurs proportionately with an increase in Layer 2 thickness. In contrast, the decrease in Layer $3 / 2$ ratio at the location of the large seamount in the south indicates that Layer 2 thickens more relative to Layer 3. This may be representative of a greater capability for melt transport through the lithosphere, perhaps having reached a threshold for melt supply that shifts the depth of emplacement towards the surface where it may exude onto the seafloor and into upper crustal layers more easily. Beneath larger seamounts, we infer that a mechanism exists for a sustained conduit to facilitate the transport of melt to the surface, whereas smaller seamounts may be limited by the lack of a transport mechanism to mobilize melt from the Moho and into the upper crust.

OBS records from this study also show strong upper mantle reflections that we are able to model as a seismic discontinuity at depths of $\sim 8 \mathrm{~km}$ beneath the Moho. The seismic phase Pd is clearly observed in four instruments (OBSs E02, E03, E10, and E11), and ray-tracing indicates that $\mathrm{Pd}$ is best constrained in the middle of Line E. Large amplitudes in the seismograms (e.g., Fig. 4) show that the seismic phase is surprisingly 
strong and coherent, corresponding with possible upper mantle structure(s) over a region of at least $\sim 100 \mathrm{~km}$. We extract a 1-D velocity profile from our tomographic model at a model offset of $170 \mathrm{~km}$ to further analyze the seismic discontinuity associated with Pd in the shallow upper mantle. Although the seismic phase Pd was not observed in all of our instruments along Line $\mathrm{E}$, it is possible that the structure of the upper mantle was altered by post-formation crustal magmatism associated with the Cretaceous event. Pd is difficult to identify in the upper mantle beneath seamount formations, and seismic reflections may have been obscured by melt emplacement and transport processes.

Past seismic experiments studying oceanic lithosphere provide relevant velocity models for comparison with our results (Fig. 14). To account for mantle anisotropy, we can infer that the orientation of Line E relative to Mesozoic magnetic anomalies in the Japanese Lineation Set is roughly parallel [Nakanishi et al., 1992], following plate kinematic flow lines and indicating that velocity estimates from our model are oriented in the slow direction. Our velocities lie comfortably within the range of observed and modeled crustal velocities, but are generally faster in the upper mantle than comparable seismic results with slow orientations [e.g., Orcutt and Dorman, 1977]. Notably, computationally derived models from Stixrude and Lithgow-Bertelloni [2005] and preliminary seismic results from the NoMelt experiment [Lizarralde, pers. comm., 2015] show significant changes in velocity gradient at depths of $\sim 8-12 \mathrm{~km}$ beneath the Moho that coincide with our tomographic model of a shallow mantle seismic discontinuity.

A physical explanation for the seismic discontinuity observed in our tomographic model may involve phase transitions in the upper mantle. Direct seismic observations corroborating the existence of a global seismic discontinuity that matches up well with our observation of Pd reflections are scarce, but we can consider comprehensive and selfconsistent, geophysical-petrological models of the upper mantle to relate known phase transitions with our seismic observation. Stixrude and Lithgow-Bertelloni [2005] model pyrolitic mantle and find an upper mantle discontinuity at $10 \mathrm{~km}$ depth, which they attribute to a phase transformation from plagioclase- to spinel-bearing assemblages at that depth. Afonso et al. [2008] find similar results for the plagioclase-spinel (pg/sp) solidstate phase transition in Vp models, with slight variations in depth and amplitude due to differences in phase equilibria/mineral assemblages used in their respective modeling 
processes. These results suggest that our observation of an upper mantle seismic discontinuity at $\sim 8 \mathrm{~km}$ beneath the Moho is not necessarily a unique or regionally limited feature in oceanic lithosphere.

Based on current notions of oceanic lithosphere, efficient melt extraction at midocean ridges from a pyrolite mantle results in an upper mantle depleted in basaltic component, resembling harzburgite. Seismic velocity models for harzburgite do not predict a significant upper mantle discontinuity at the depth of the $\mathrm{pg} / \mathrm{sp}$ phase transition due to the lack of pg. Thus, our results showing a seismic discontinuity at the depth predicted for the $\mathrm{pg} / \mathrm{sp}$ phase transition suggest that the upper mantle does not have a harzburgite composition. Either melt extraction at the ridge may not be completely efficient, leaving enough pg in the mantle to create a seismically observable phase transition, or melt additions associated with Cretaceous Supervolcanism observed in the region may have added a basaltic component to the harzburgite mantle. Remnant melt from the widespread Cretaceous event may have frozen into the lithospheric mantle on the way to the surface. Either scenario would shift the average upper mantle composition away from harzburgite and towards pyrolite, resulting in a $\mathrm{pg} / \mathrm{sp}$ phase transition and seismic discontinuity at shallow mantle depths.

\section{Conclusion}

Our seismic dataset from the subducting plate in the western Pacific provides lithospheric-scale insight into the processes of oceanic crustal formation and evolution, building on the results from the previous chapter. Similar to the processes that have occurred in our study area in the Jurassic Quiet Zone, post-formation crustal magmatism has greatly affected oceanic lithosphere undergoing subduction at the Pacific-Philippine Sea plate boundary, where Line E of our seismic survey is located. A better understanding of the structure of modified, old oceanic lithosphere may be useful in regionally related studies of subduction zone processes since the downgoing plate may be more complex than typically expected. Our seismic results indicate that widespread magmatic activity has resulted in significant crustal thickening beneath seamounts, likely via crustal underplating. Thickening of oceanic Layers 2 and 3 associated with seamounts along our line imply two distinct modes of melt transport within the lithosphere, either 
broadly pooling at the Moho or channeling through the crust to form extrusive additions. Additionally, our observation of a strong seismic reflector originating in the shallow upper mantle suggests that detailed upper mantle structures exist as a result of mineralogical phase transitions in an enriched harzburgite mantle. Recent studies modeling the seismic velocities of equilibrium phase assemblages in the upper mantle show that the plagioclase-to-spinel transition corresponds with a seismic discontinuity at shallow depths $(\sim 10 \mathrm{~km})$ in the upper mantle [Stixrude and Lithgow-Bertelloni, 2005; Afonso et al., 2008]. These results are consistent with our tomographic model and may sufficiently provide a physical explanation for our observation of a strong seismic phase in the upper mantle. 


\section{References}

Afonso, J.C., Fernandez, M., Ranalli, G., Griffin, W.L., and Connolly, J.A.D., 2008, Integrated geophysical-petrological modeling of the lithosphere and sublithospheric upper mantle: Methodology and applications: Geochemistry, Geophysics, Geosystems, v. 9, No. 5, doi: 10.1029/2007/GC001834.

Bodine, J.H., and Watts, A.B., 1979, On lithospheric flexure seaward of the Bonin and Mariana Trenches: Earth and Planetary Science Letters, v. 43, p. 132-148.

Calvert, A.J., 2011, The seismic structure of island arc crust, in Brown, D., and Ryan, P.D., eds., Arc-Continent Collision, Frontiers in Earth Sciences, p. 87-119, doi: 10.1007/978-3-540-88558-0_4.

Caress, D.W., McNutt, M.K., Detrick, R.S., and Mutter, J.C., 1995, Seismic imaging of hotspot-related crustal underplating beneath the Marquesas Islands: Nature, v. 373 , p. 600-603.

Christensen, N.I., and Smewing, J.D., 1981, Geology and seismic structure of the northern section of the Oman ophiolite: Journal of Geophysical Research, v. 86, No. B4, p. 2545-2555.

Christensen, N.I., and Salisbury, M.H., 1982, Lateral heterogeneity in the seismic structure of the oceanic crust inferred from velocity studies in the Bay of Islands ophiolite, Newfoundland: Geophysical Journal International, v. 68, p. 675-688.

Collins, J.A., Purdy, M.G., and Brocher, T.M., 1989, Seismic velocity structure at Deep Sea Dilling Project Site 504B, Panama Basin: Evidence for thin oceanic crust: Journal of Geophysical Research, v. 94, No. B7, p. 9283-9302.

Contreras-Reyes, E., Grevemeyer, I., Watts, A.B., Planert, L., Flueh, E.R., and Peirce, C., 2010, Crustal intrusion beneath the Louisville hotspot track: Earth and Planetary Science Letters, v. 289, p. 323-333.

Emry, E.L., Wiens, D.A., and Garcia-Castellanos, D., 2014, Faulting within the Pacific plate at the Mariana Trench: Implications for plate interface coupling and subduction of hydrous minerals: Journal of Geophysical Research, v. 119, p. 3076-3095, doi: 10.1002/2013JB0170718.

Farnetani, C.G., Richards, M.A., and Ghiorso, M.S., 1996, Petrological models of magma evolution and deep crustal structure beneath hotspots and flood basalt provinces: Earth and Planetary Science Letters, v. 143, p. 81-94.

Gaherty, J.B., Kato, M., and Jordan, T.H., 1999, Seismological structure of the upper mantle: A regional comparison of seismic layering: Physics of the Earth and Planetary Interiors, v. 110, p. 21-41. 
Grevemeyer, I., Flueh, E.R., Reichert, C., Bialas, J., Kläschen, D., and Kopp, C., 2001, Crustal architecture and deep structure of the Ninetyeast Ridge hotspot trail from active-source ocean bottom seismology: Geophysical Journal International, v. 144, p. 414-431.

Janney, P.E., and Castillo, P.R., 1997, Geochemistry of Mesozoic Pacific mid-ocean ridge basalt: Constraints on melt generation and the evolution of the Pacific upper mantle: Journal of Geophysical Research, v. 102, No. B3, p. 5207-5229.

Kaneda, K., Kodaira, S., Nishizawa, A, Morishita, T, and Takahashi, N., 2010, Structural evolution of preexisting oceanic crust through intraplate igneous activities in the Marcus-Wake seamount chain: Geochemistry, Geophysics, Geosystems, v. 11, No. 10, doi: 10.1029/2010GC003231.

Koppers, A.A.P., Staudigel, H., and Duncan, R.A., 2003, High-resolution ${ }^{40} \mathrm{Ar} /{ }^{39} \mathrm{Ar}$ dating of the oldest oceanic basement basalts in the western Pacific basin: Geochemistry, Geophysics, Geosystems, v. 4, No. 11, doi: 10.1029/2003GC000574.

Lizarralde, D., Gaherty, J.B., Collins, J.A., Hirth, G., and Kim, S.D., 2004, Spreadingrate dependence of melt extraction at mid-ocean ridges from mantle seismic refraction data: Nature, v. 432, p. 744-747.

Moser, T.J., Nolet, G., and Snieder, R., 1992, Ray bending revisited: Bulletin of the Seismological Society of America, v. 82, p. 259-288.

Nakanishi, M., Tamaki, K., and Kobayashi, K., 1992, Magnetic anomaly lineations from Late Jurassic to Early Cretaceous in the west-central Pacific Ocean: Geophysical Journal International, v. 109, p. 701-719.

Orcutt, J.A., and Dorman, L.M., 1977, Oceanic long-range explosion experiment Preliminary report. Journal of Geophysics - Zeitschrift fur Geophysik. 43: 257263.

Raitt, R.W., 1963, The crustal rocks, in Hill, M.N., eds., The Sea, v. 3, WileyInterscience, New York, p. 85-102.

Roland, E., Lizarralde, D., McGuire, J.J., and Collines, J.A., 2012, Seismic velocity constraints on the material properties that control earthquake behavior at the Quedabra-Discovery-Gofar transform faults, East Pacific Rise: Journal of Geophysical Research, v. 117, doi: 10.1029/2012JB009422.

Stadler, T.J., and Tominaga, M., 2015, Intraplate volcanism of the western Pacific: New insights from geological and geophysical observations in the Pigafetta Basin: Geochemistry, Geophysics, Geosystems, v. 16, No. 9, p. 3015-3030. 
Stern, R.J., Fouch, M.J., and Klemperer, S.L., 2003, An overview of the Izu-BoninMariana subduction factory, in Eiler, J., eds., Inside the Subduction Factory, American Geophysical Union Geophysical Monograph 138, p. 175-222.

Stixrude, L., and Lithgow-Bertelloni, C., 2005, Mineralogy and elasticity of the oceanic upper mantle: Origin of the low-velocity zone: Journal of Geophysical Research, v. 110, doi: 10.1029/2004JB002965.

Taylor, B., 1992, Rifting and the volcanic-tectonic evolution of the Izu-Bonin-Mariana Arc, in Taylor, B., and Fujioka, K., et al., 1992, Proc. ODP, Sci. Results, 126: College Station, TX (Ocean Drilling Program).

Van Avendonk, H.J.A., Harding, A.J., Orcutt, J.A., and McClain, J.S., 1998, A twodimensional tomographic study of the Clipperton transform fault: Journal of Geophysical Research, v. 103, No. B8, p. 17885-17899.

Van Avendonk, H.J.A., Holbrook, W.S., Okaya, D., Austin, J.K., Davey, F., and Stern, T., 2004, Continental crust under compression: A seismic refraction study of South Island Geophysical Transect I, South Island, New Zealand: Journal of Geophysical Research, v. 109, doi: 10.1029/2003JB002790.

White, R.S., 1984, Atlantic ocean crust: Seismic structure of a slow-spreading ridge, in Gass, I.G., Lippard, S.J., and Shelton, A.W., eds., Ophiolites and Oceanic Lithosphere, Blackwell Scientific, London, p. 101-111.

White, R.S., McKenzie, D., and O’Nions, R.K., 1992, Oceanic crustal thickness from seismic measurements and rare earth element inversions: Journal of Geophysical Research, v. 97, No. B13, p. 19683-19715. 


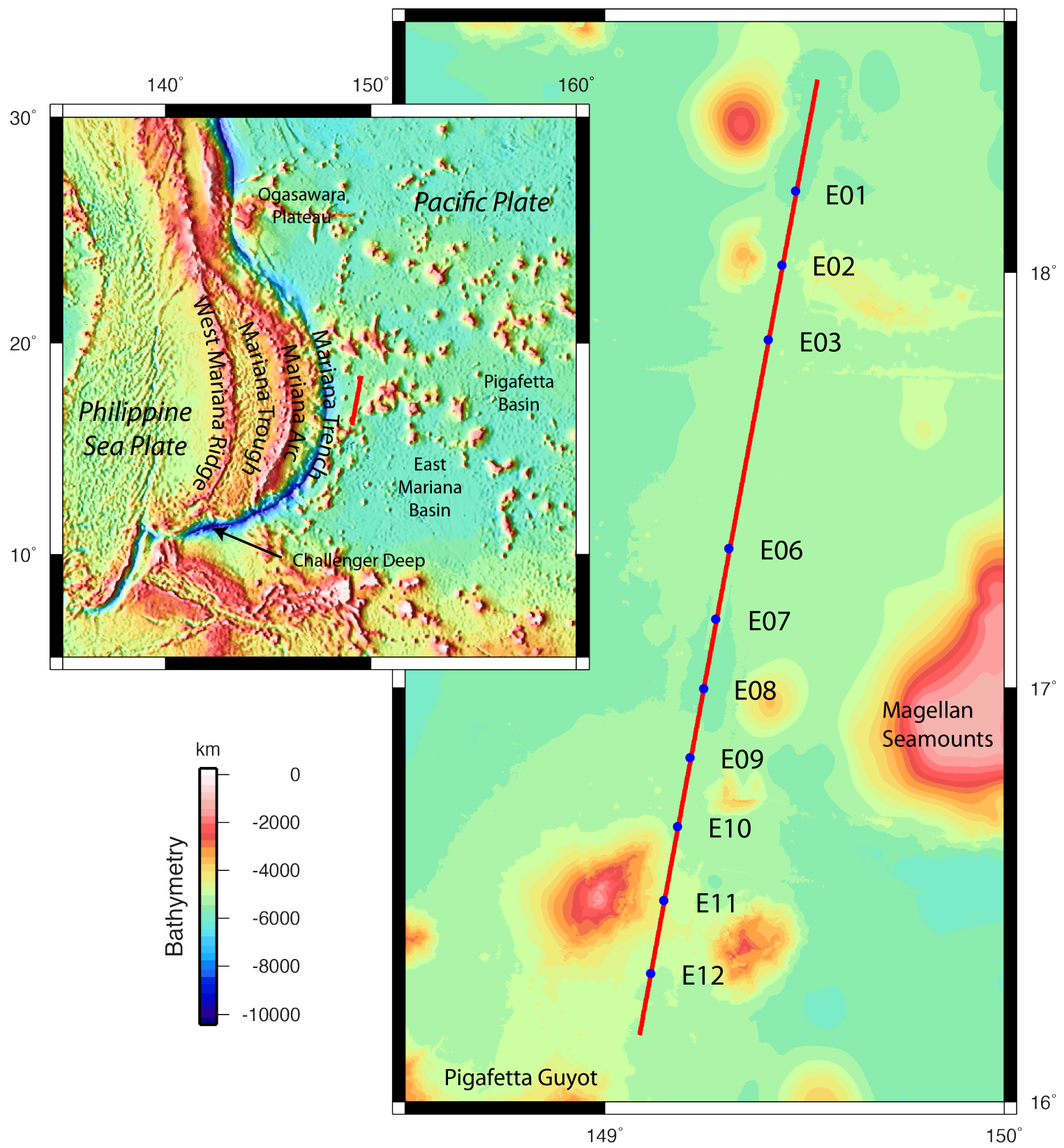

Figure 1. Bathymetric map of the study area, east of the Mariana Trench. Inset map shows the regional extent of the Mariana subduction system at the boundary between the Pacific and Philippine Sea Plates. The red line shows the location of Line E (one of several lines shot within the subduction zone as part of a larger mantle serpentinization seismic experiment from cruise MGL1204), and blue circles show the positions of the ten short-period (SP) ocean bottom seismometers (OBSs) recovered with useable data. 

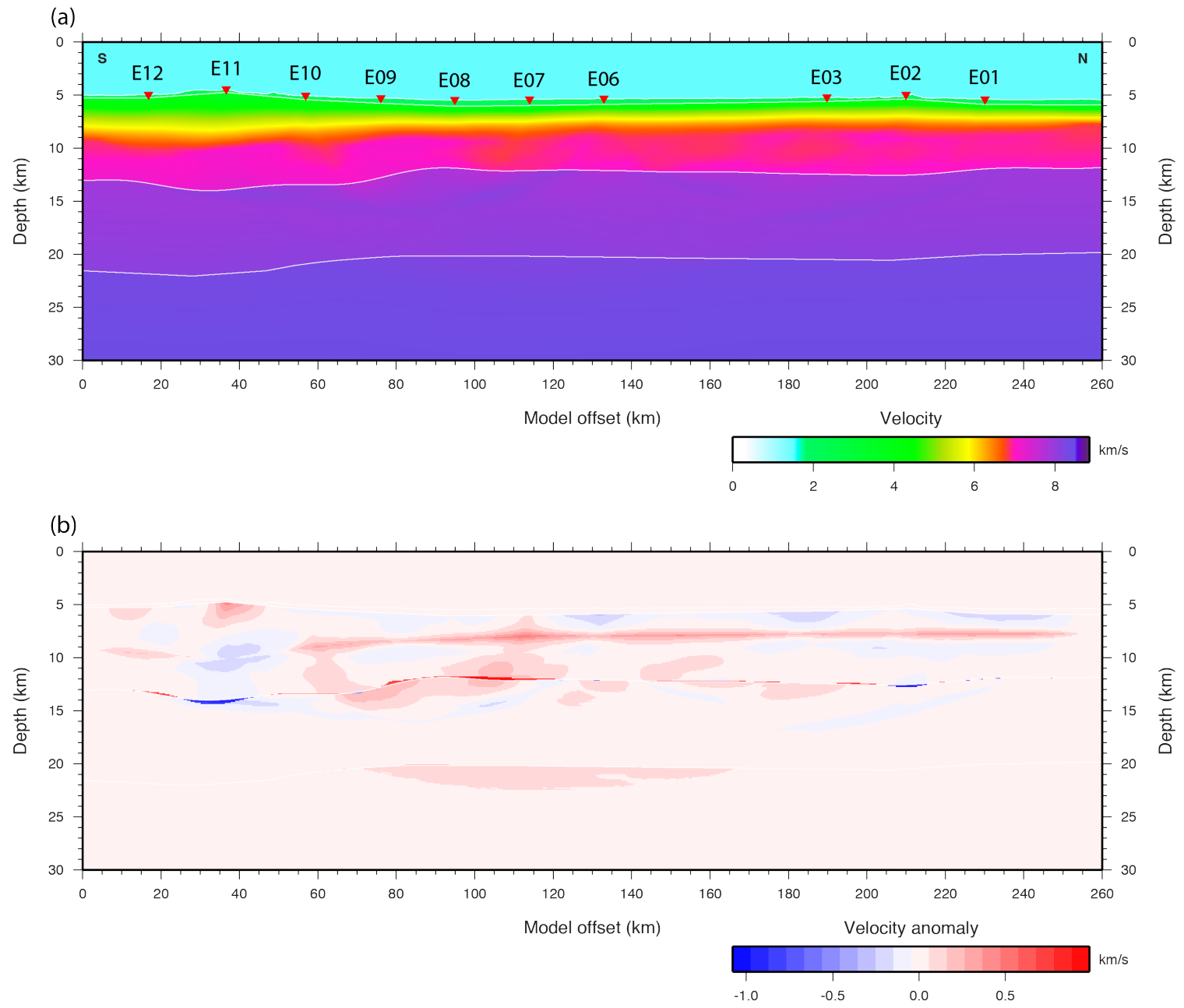

Figure 2. Seismic velocity results of tomographic inversion. (a) The preferred P-wave velocity model along Line E covers $260 \mathrm{~km}$ of oceanic lithosphere in the western Pacific, where wide-angle refraction data were collected. Variation in lithospheric structure of the old ( 150-160 Ma) oceanic lithosphere is associated with the presence of seamounts. Receivers (SP OBSs) located on the seafloor are labeled and depicted as red inverted triangles. White lines show layer interfaces in the model inversion, indicating depths to the seafloor, sediment-basement boundary, Moho, and upper mantle reflector. (b) Velocity anomalies are calculated as the difference between the initial velocity model and final preferred model obtained from the tomographic inversion. Notable results include faster-than-expected velocities (blue) in the upper crustal sedimentary layers in the middle of the line, as well as within the lower crust beneath the southern seamount feature. Slower velocities (red) are observed in the lower crust around the middle of the line (at model offsets $\sim 60-120 \mathrm{~km}$ ). 
(a)

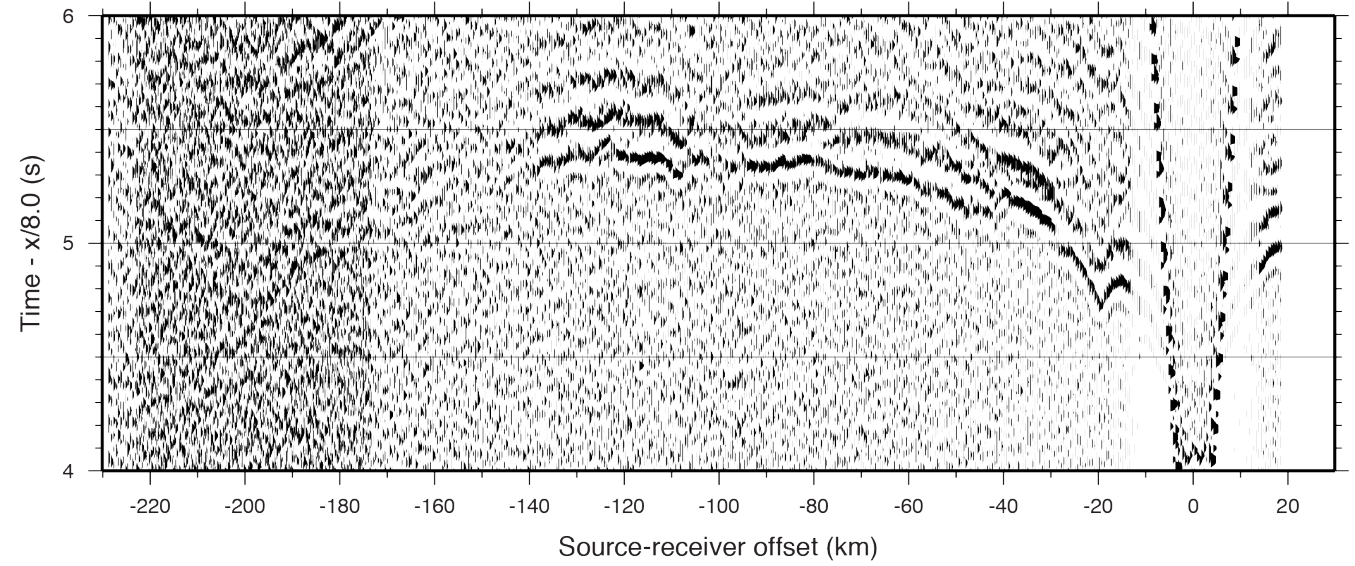

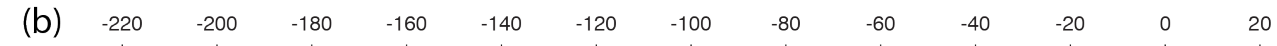
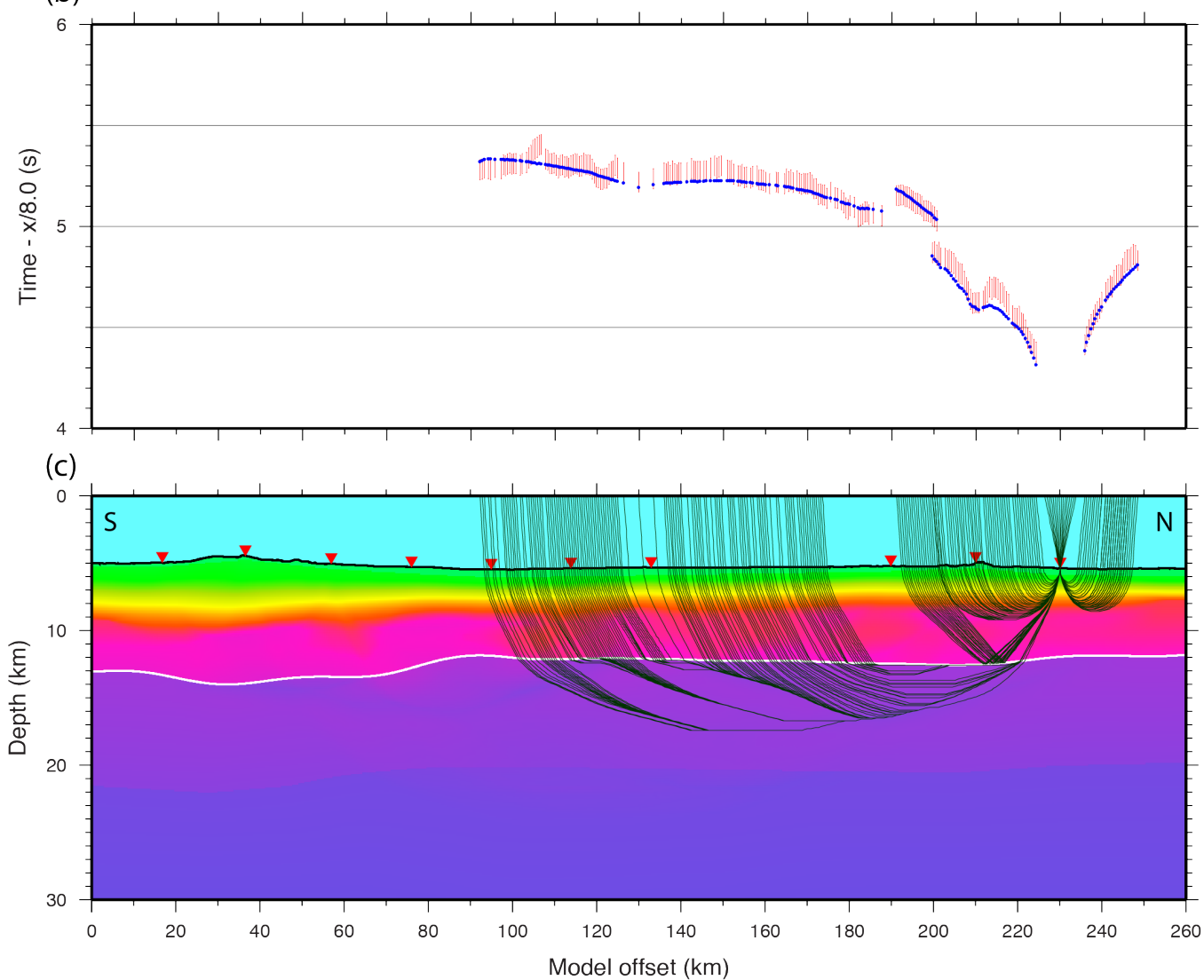

Figure 3. OBS E01 seismogram with travel time results and corresponding ray diagram from the tomographic inversion. (a) Data are reduced at $8.0 \mathrm{~km} / \mathrm{s}$. (b) Picks of first arrivals from $\mathrm{Pg}, \mathrm{P}_{\mathrm{M}} \mathrm{P}, \mathrm{Pn}$, and $\mathrm{Pd}$ phases used in the inversion are in red, bracketed by the red vertical bars to show travel time uncertainties assigned to the picks. Modeled travel times from the preferred P-wave velocity model are represented by blue dots. (c) Ray-tracing results from the tomographic inversion using the graph method are superimposed on the preferred P-wave velocity model. Depth to the seafloor is outlined in black, the Moho is indicated by the white line, and OBS positions are denoted by red inverted triangles. The velocity color scheme follows the same scale as in Figure 2a. 
(a)
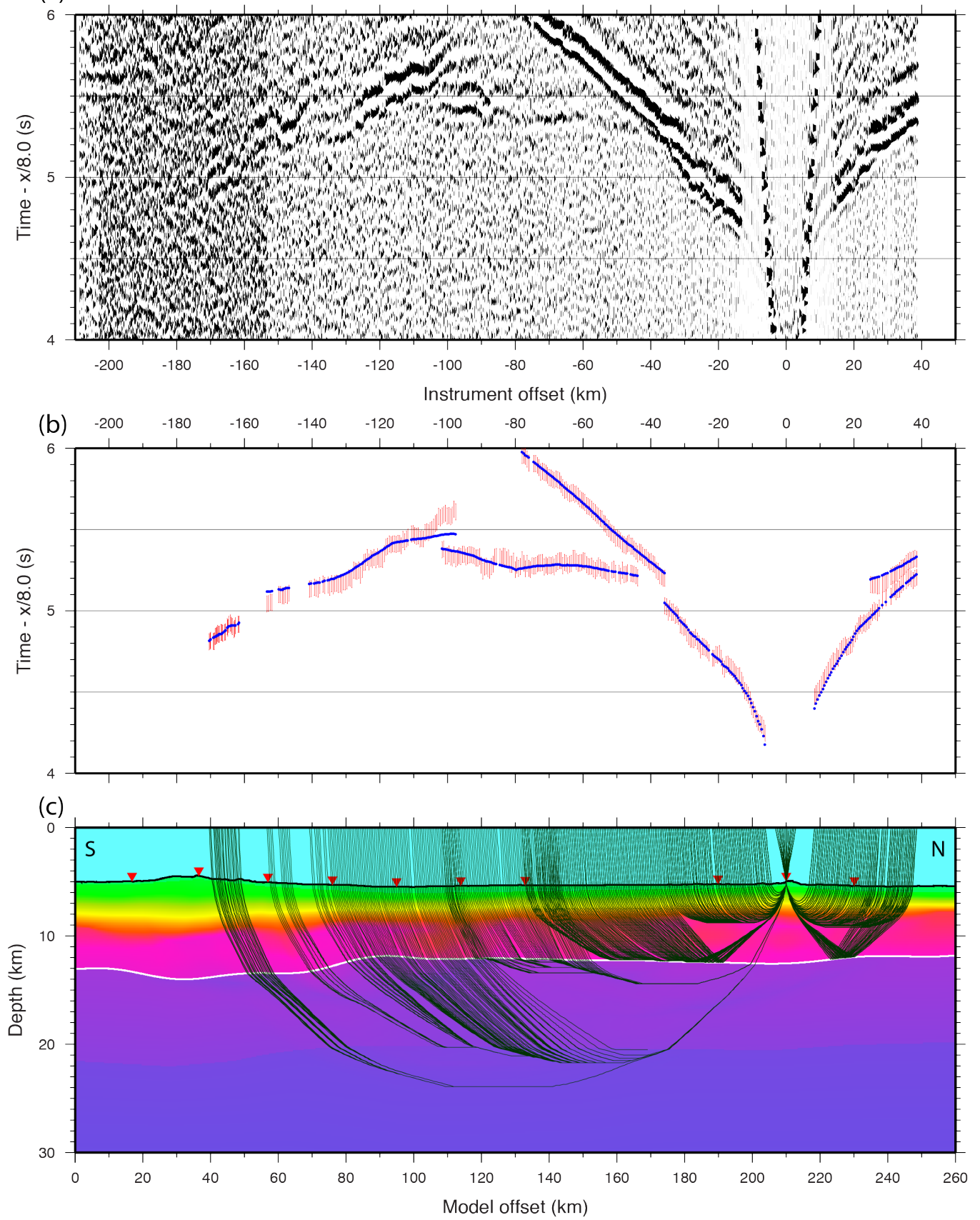

Figure 4. OBS E02 seismogram with travel time results and corresponding ray diagram from the tomographic inversion. (a) Data are reduced at $8.0 \mathrm{~km} / \mathrm{s}$. (b) Picks of first arrivals from $\mathrm{Pg}, \mathrm{P}_{\mathrm{M}} \mathrm{P}, \mathrm{Pn}$, and $\mathrm{Pd}$ phases used in the inversion are in red, bracketed by the red vertical bars to show travel time uncertainties assigned to the picks. Modeled travel times from the preferred P-wave velocity model are represented by blue dots. (c) Ray-tracing results from the tomographic inversion using the graph method are superimposed on the preferred P-wave velocity model. Depth to the seafloor is outlined in black, the Moho is indicated by the white line, and OBS positions are denoted by red inverted triangles. The velocity color scheme follows the same scale as in Figure 2a. 
(a)
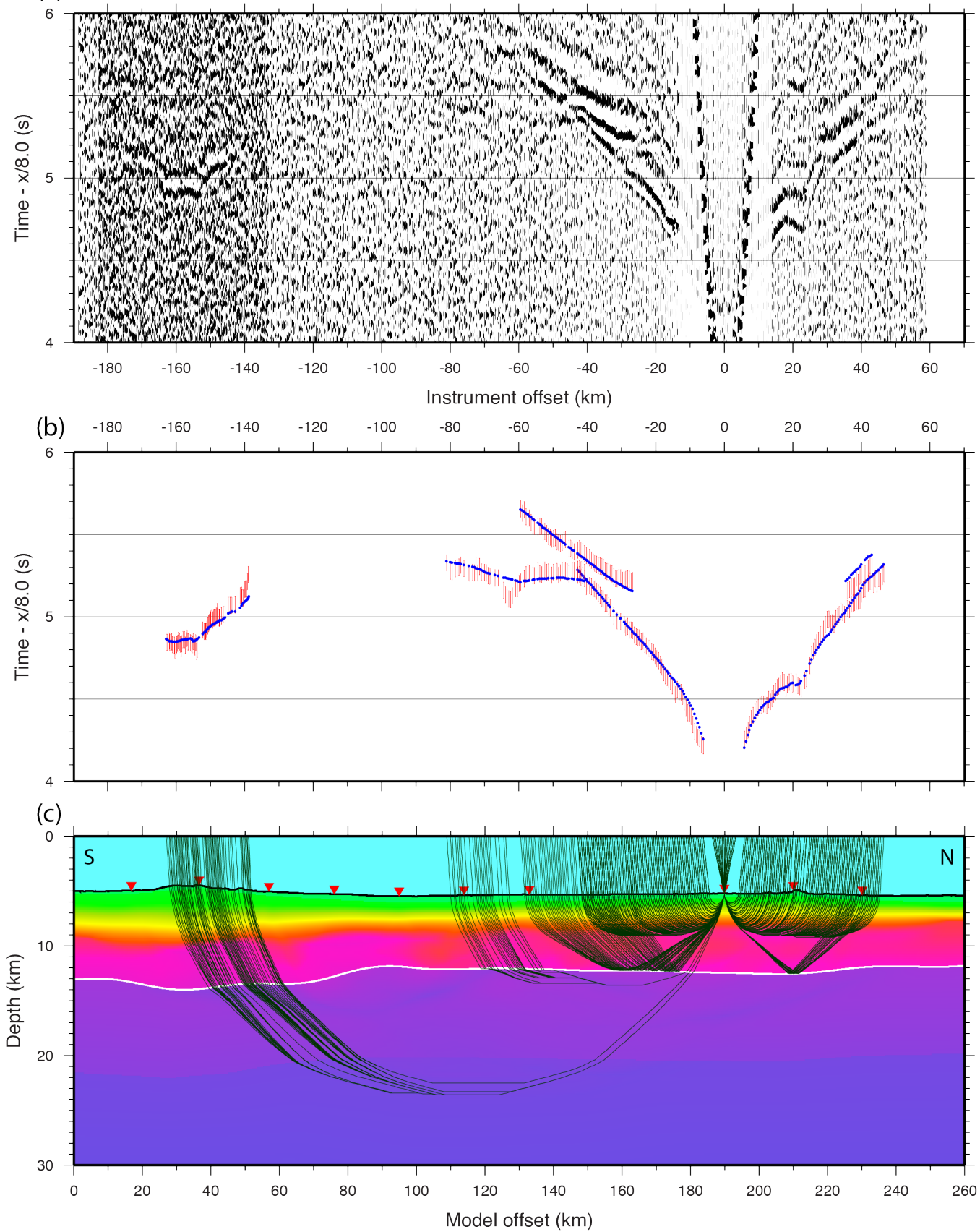

Figure 5. OBS E03 seismogram with travel time results and corresponding ray diagram from the tomographic inversion. (a) Data are reduced at $8.0 \mathrm{~km} / \mathrm{s}$. (b) Picks of first arrivals from $\mathrm{Pg}, \mathrm{P}_{\mathrm{M}} \mathrm{P}, \mathrm{Pn}$, and $\mathrm{Pd}$ phases used in the inversion are in red, bracketed by the red vertical bars to show travel time uncertainties assigned to the picks. Modeled travel times from the preferred P-wave velocity model are represented by blue dots. (c) Ray-tracing results from the tomographic inversion using the graph method are superimposed on the preferred P-wave velocity model. Depth to the seafloor is outlined in black, the Moho is indicated by the white line, and OBS positions are denoted by red inverted triangles. The velocity color scheme follows the same scale as in Figure 2a. 
(a)
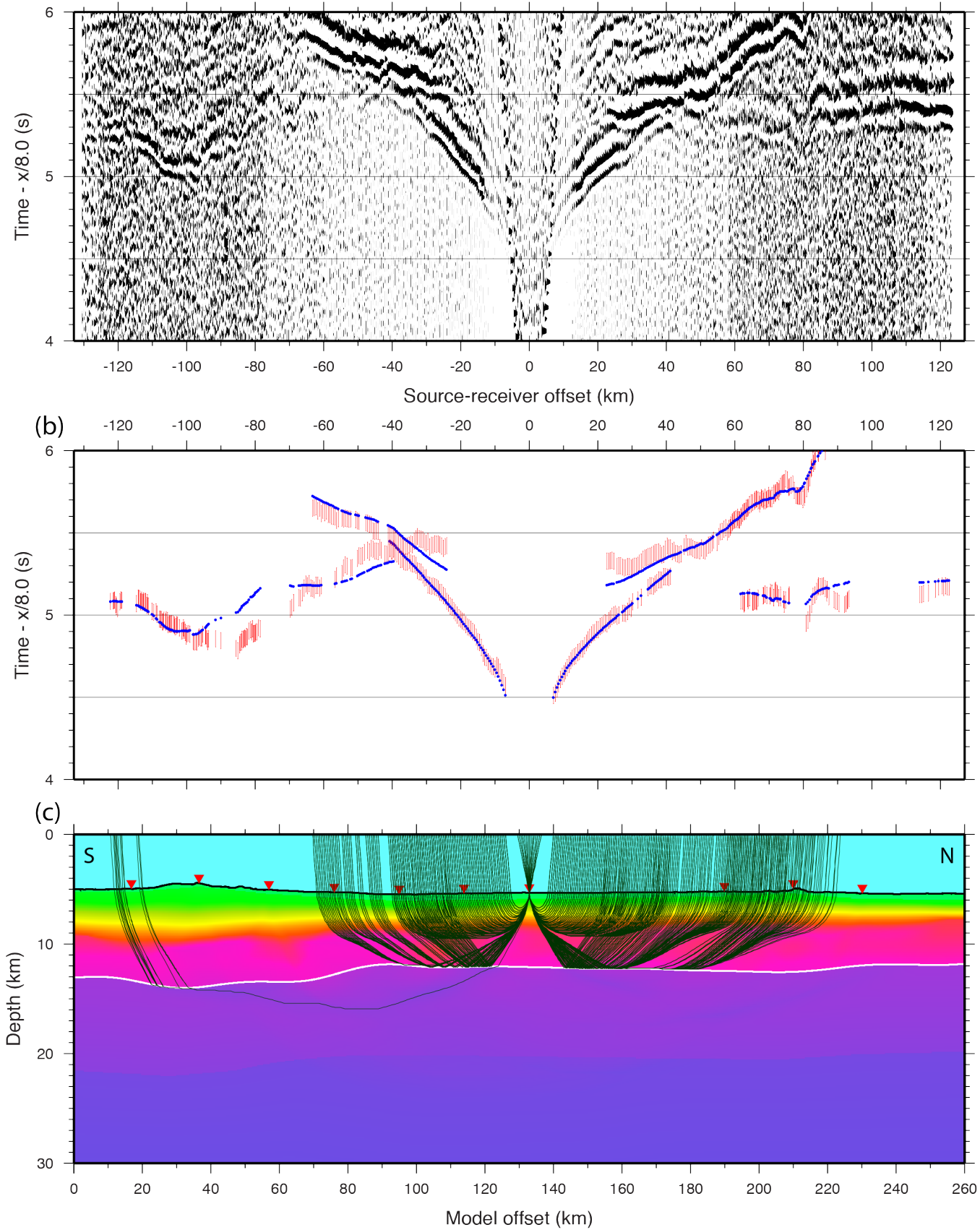

Figure 6. OBS E06 seismogram with travel time results and corresponding ray diagram from the tomographic inversion. (a) Data are reduced at $8.0 \mathrm{~km} / \mathrm{s}$. (b) Picks of first arrivals from $\mathrm{Pg}, \mathrm{P}_{\mathrm{M}} \mathrm{P}, \mathrm{Pn}$, and $\mathrm{Pd}$ phases used in the inversion are in red, bracketed by the red vertical bars to show travel time uncertainties assigned to the picks. Modeled travel times from the preferred P-wave velocity model are represented by blue dots. (c) Ray-tracing results from the tomographic inversion using the graph method are superimposed on the preferred P-wave velocity model. Depth to the seafloor is outlined in black, the Moho is indicated by the white line, and OBS positions are denoted by red inverted triangles. The velocity color scheme follows the same scale as in Figure 2a. 
(a)
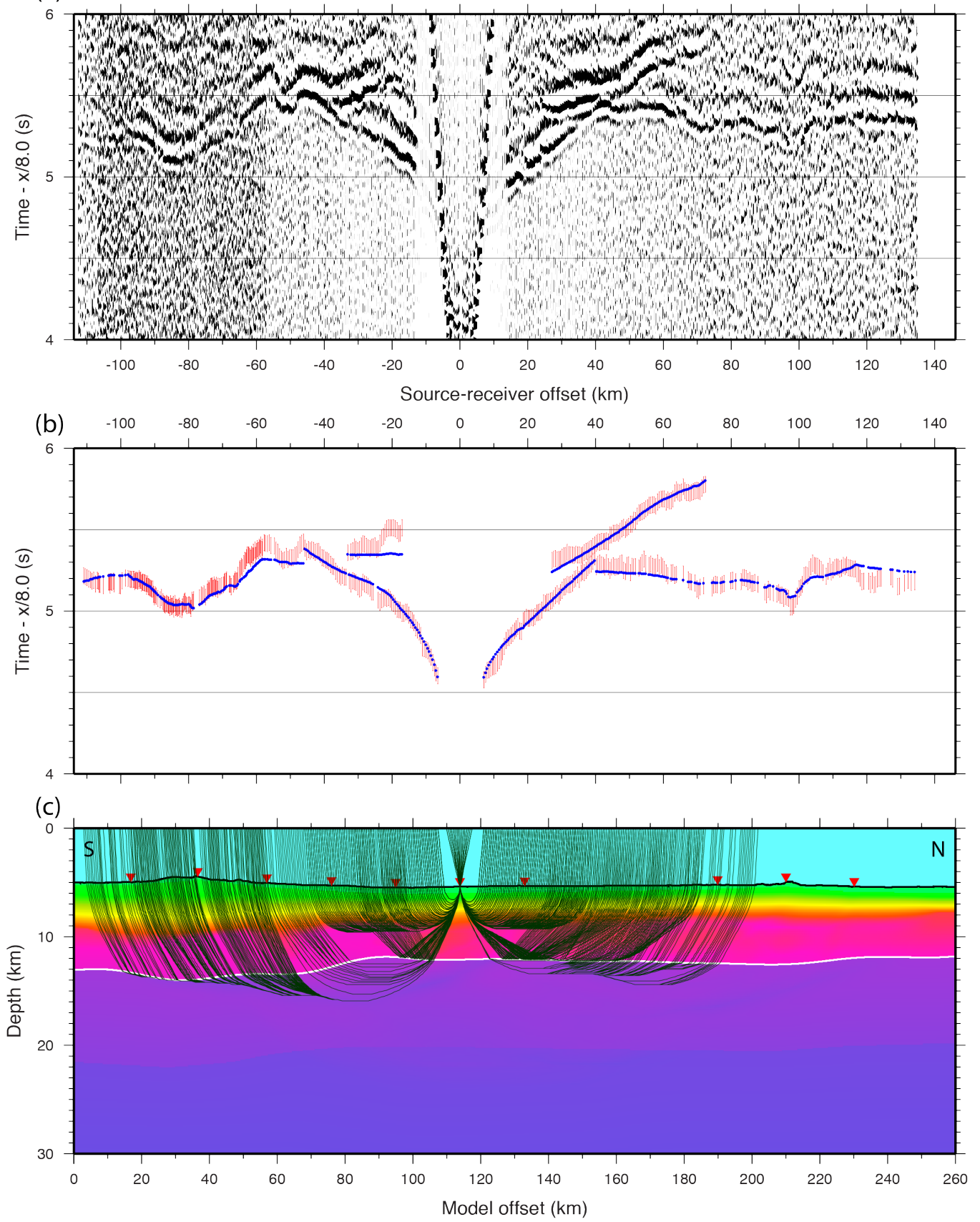

Figure 7. OBS E07 seismogram with travel time results and corresponding ray diagram from the tomographic inversion. (a) Data are reduced at $8.0 \mathrm{~km} / \mathrm{s}$. (b) Picks of first arrivals from $\mathrm{Pg}, \mathrm{P}_{\mathrm{M}} \mathrm{P}, \mathrm{Pn}$, and $\mathrm{Pd}$ phases used in the inversion are in red, bracketed by the red vertical bars to show travel time uncertainties assigned to the picks. Modeled travel times from the preferred P-wave velocity model are represented by blue dots. (c) Ray-tracing results from the tomographic inversion using the graph method are superimposed on the preferred P-wave velocity model. Depth to the seafloor is outlined in black, the Moho is indicated by the white line, and OBS positions are denoted by red inverted triangles. The velocity color scheme follows the same scale as in Figure 2a. 
(a)
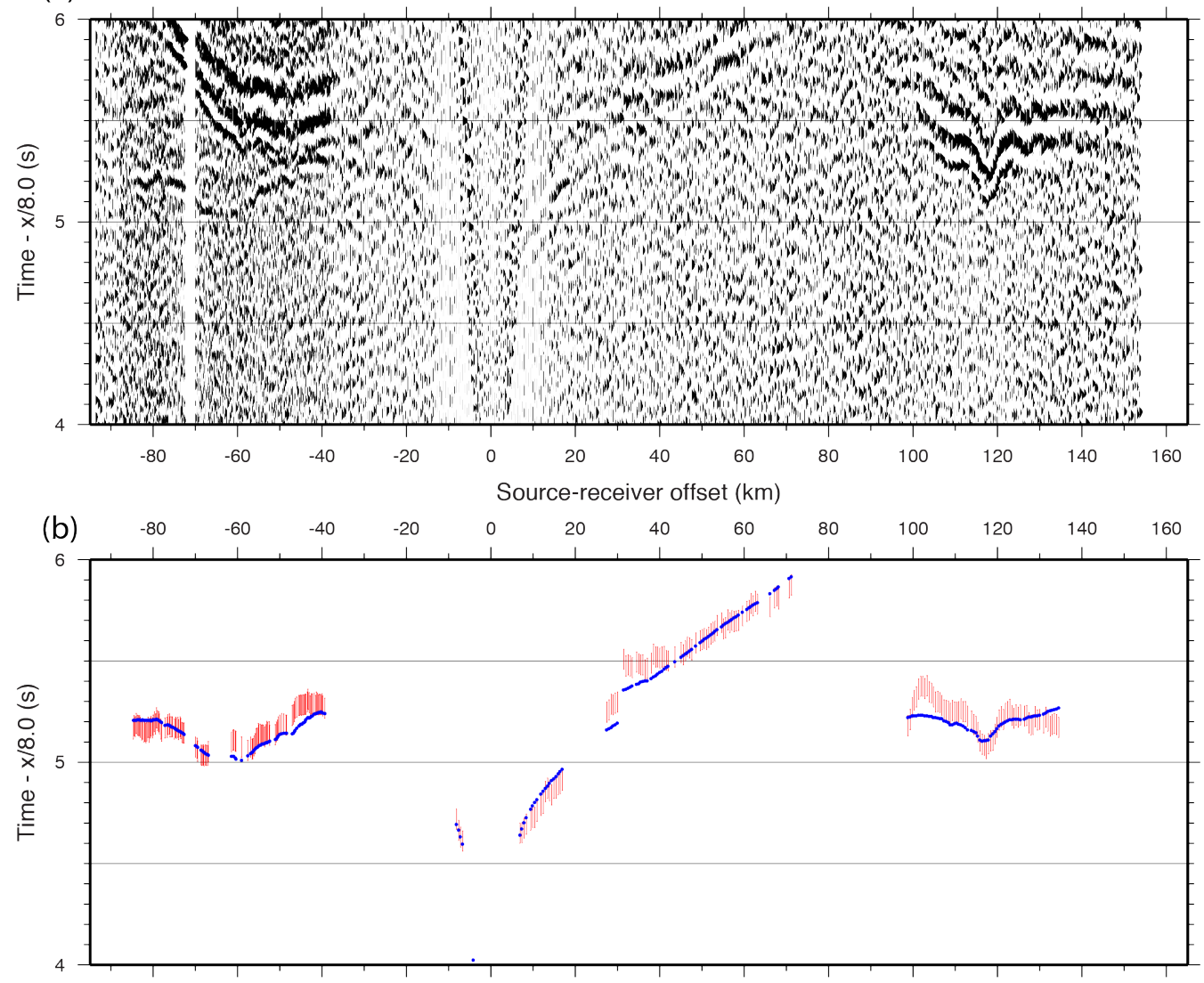

(c)

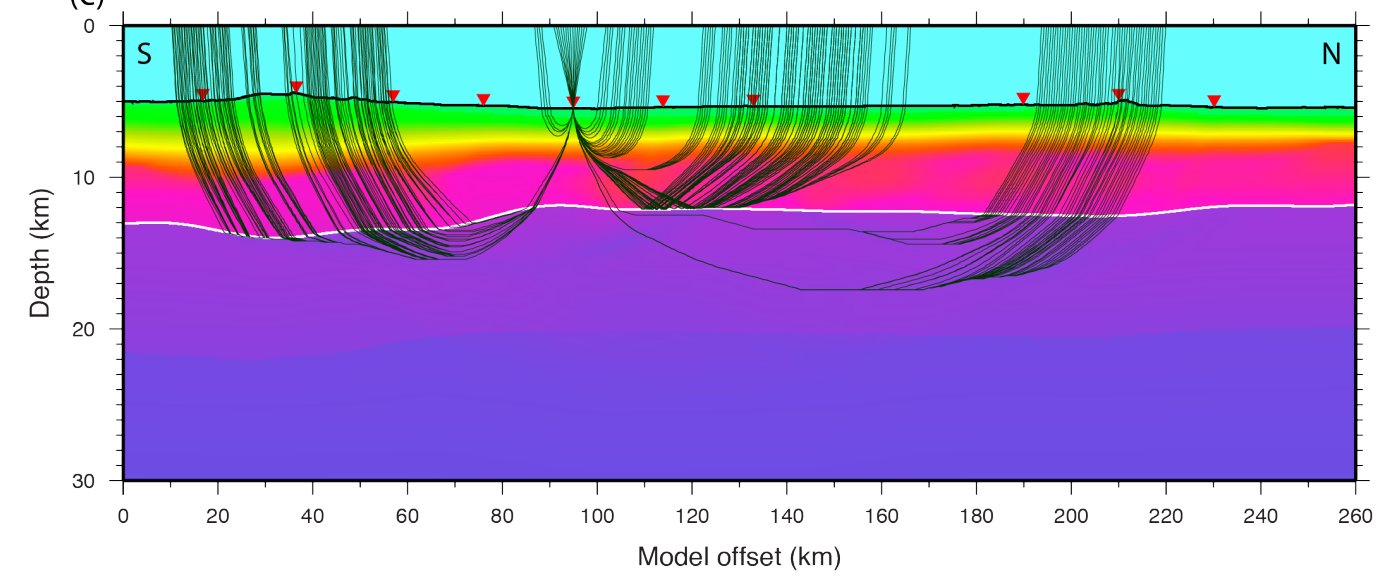

Figure 8. OBS E08 seismogram with travel time results and corresponding ray diagram from the tomographic inversion. (a) Data are reduced at $8.0 \mathrm{~km} / \mathrm{s}$. (b) Picks of first arrivals from $\mathrm{Pg}, \mathrm{P}_{\mathrm{M}} \mathrm{P}, \mathrm{Pn}$, and $\mathrm{Pd}$ phases used in the inversion are in red, bracketed by the red vertical bars to show travel time uncertainties assigned to the picks. Modeled travel times from the preferred P-wave velocity model are represented by blue dots. (c) Ray-tracing results from the tomographic inversion using the graph method are superimposed on the preferred P-wave velocity model. Depth to the seafloor is outlined in black, the Moho is indicated by the white line, and OBS positions are denoted by red inverted triangles. The velocity color scheme follows the same scale as in Figure 2a. 
(a)
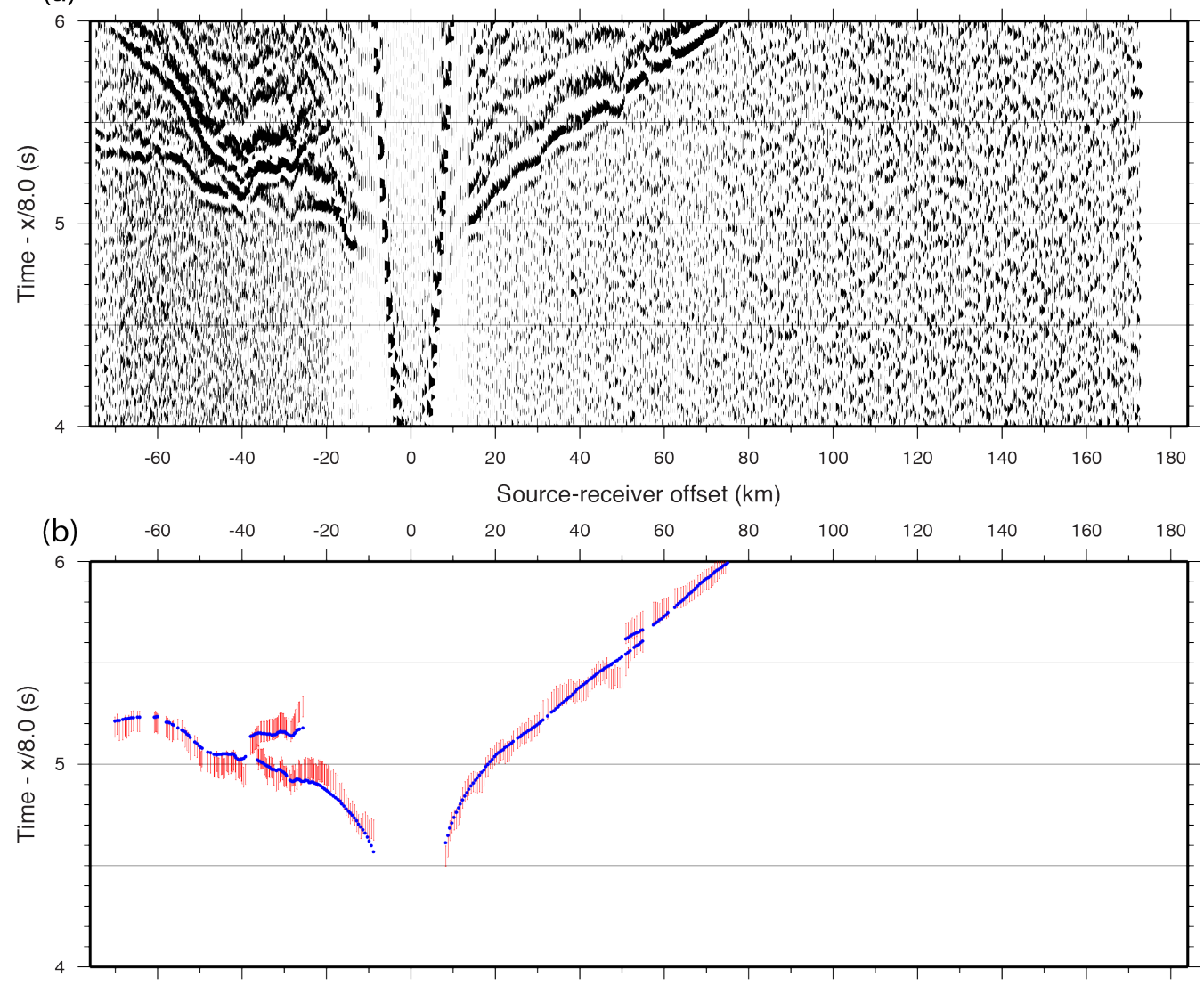

(c)

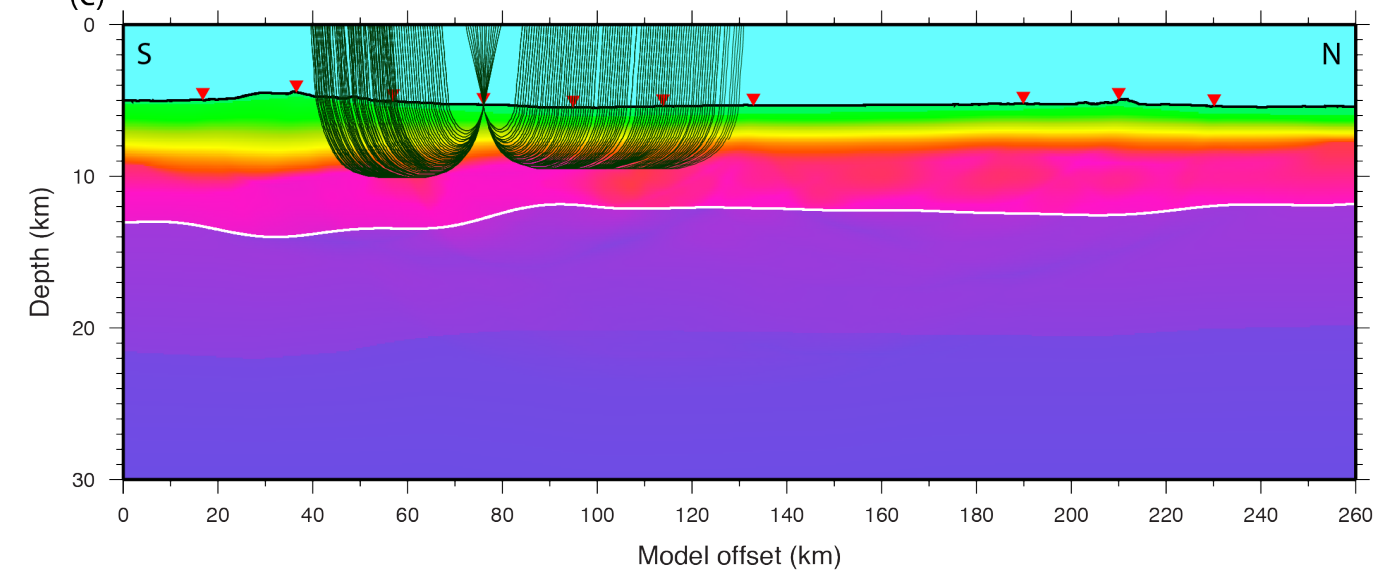

Figure 9. OBS E09 seismogram with travel time results and corresponding ray diagram from the tomographic inversion. (a) Data are reduced at $8.0 \mathrm{~km} / \mathrm{s}$. (b) Picks of first arrivals from $\mathrm{Pg}, \mathrm{P}_{\mathrm{M}} \mathrm{P}, \mathrm{Pn}$, and $\mathrm{Pd}$ phases used in the inversion are in red, bracketed by the red vertical bars to show travel time uncertainties assigned to the picks. Modeled travel times from the preferred P-wave velocity model are represented by blue dots. (c) Ray-tracing results from the tomographic inversion using the graph method are superimposed on the preferred P-wave velocity model. Depth to the seafloor is outlined in black, the Moho is indicated by the white line, and OBS positions are denoted by red inverted triangles. The velocity color scheme follows the same scale as in Figure 2a. 
(a)
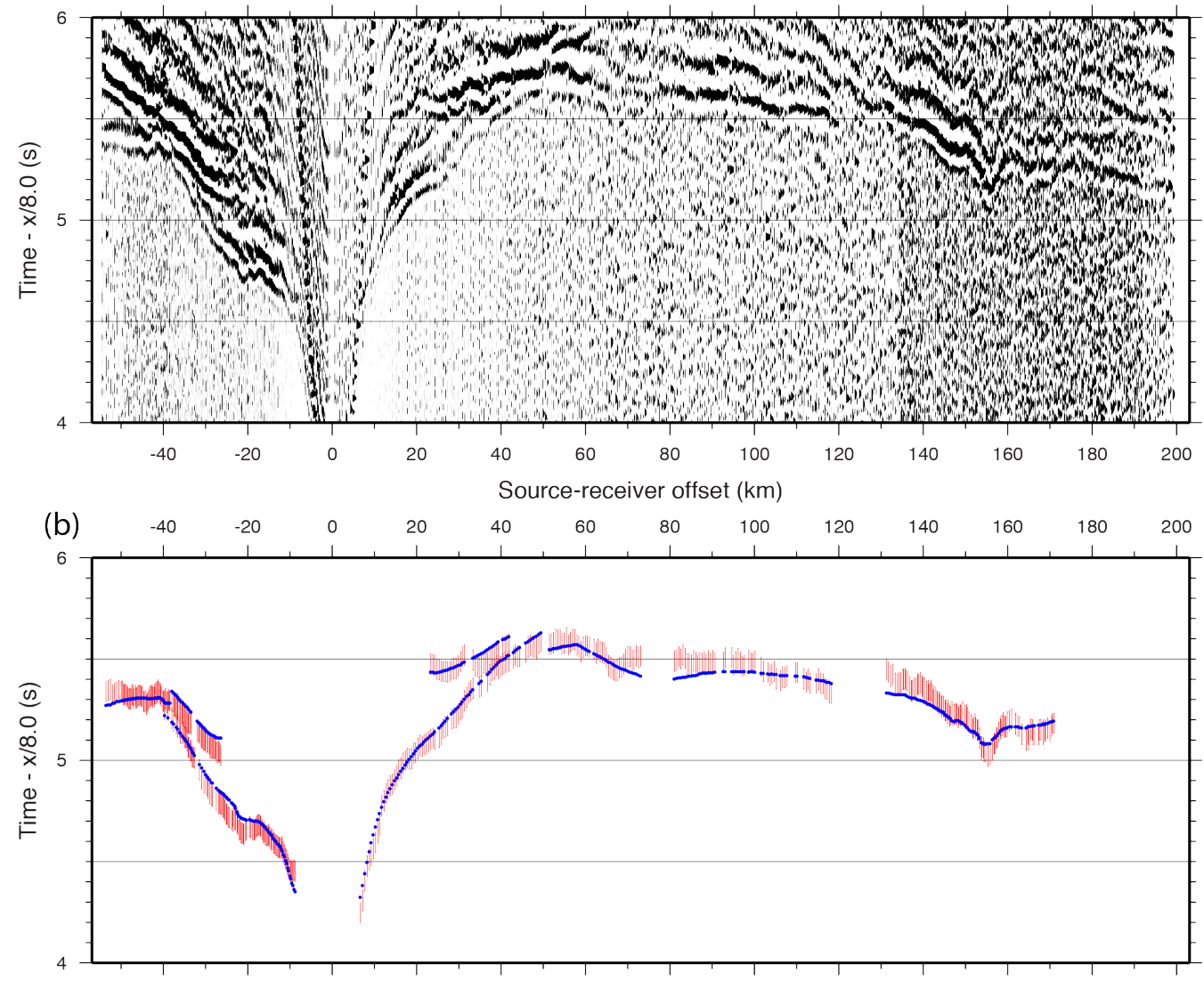

(c)

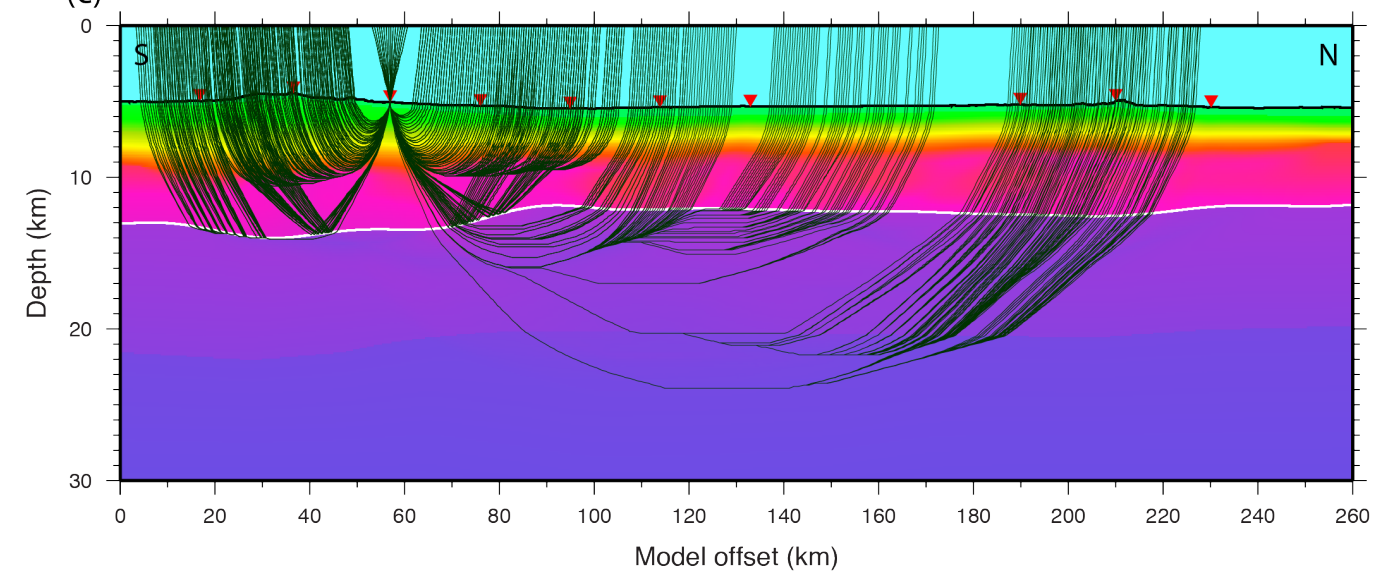

Figure 10. OBS E10 seismogram with travel time results and corresponding ray diagram from the tomographic inversion. (a) Data are reduced at $8.0 \mathrm{~km} / \mathrm{s}$. (b) Picks of first arrivals from $\mathrm{Pg}, \mathrm{P}_{\mathrm{M}} \mathrm{P}, \mathrm{Pn}$, and $\mathrm{Pd}$ phases used in the inversion are in red, bracketed by the red vertical bars to show travel time uncertainties assigned to the picks. Modeled travel times from the preferred P-wave velocity model are represented by blue dots. (c) Ray-tracing results from the tomographic inversion using the graph method are superimposed on the preferred P-wave velocity model. Depth to the seafloor is outlined in black, the Moho is indicated by the white line, and OBS positions are denoted by red inverted triangles. The velocity color scheme follows the same scale as in Figure $2 \mathrm{a}$. 
(a)
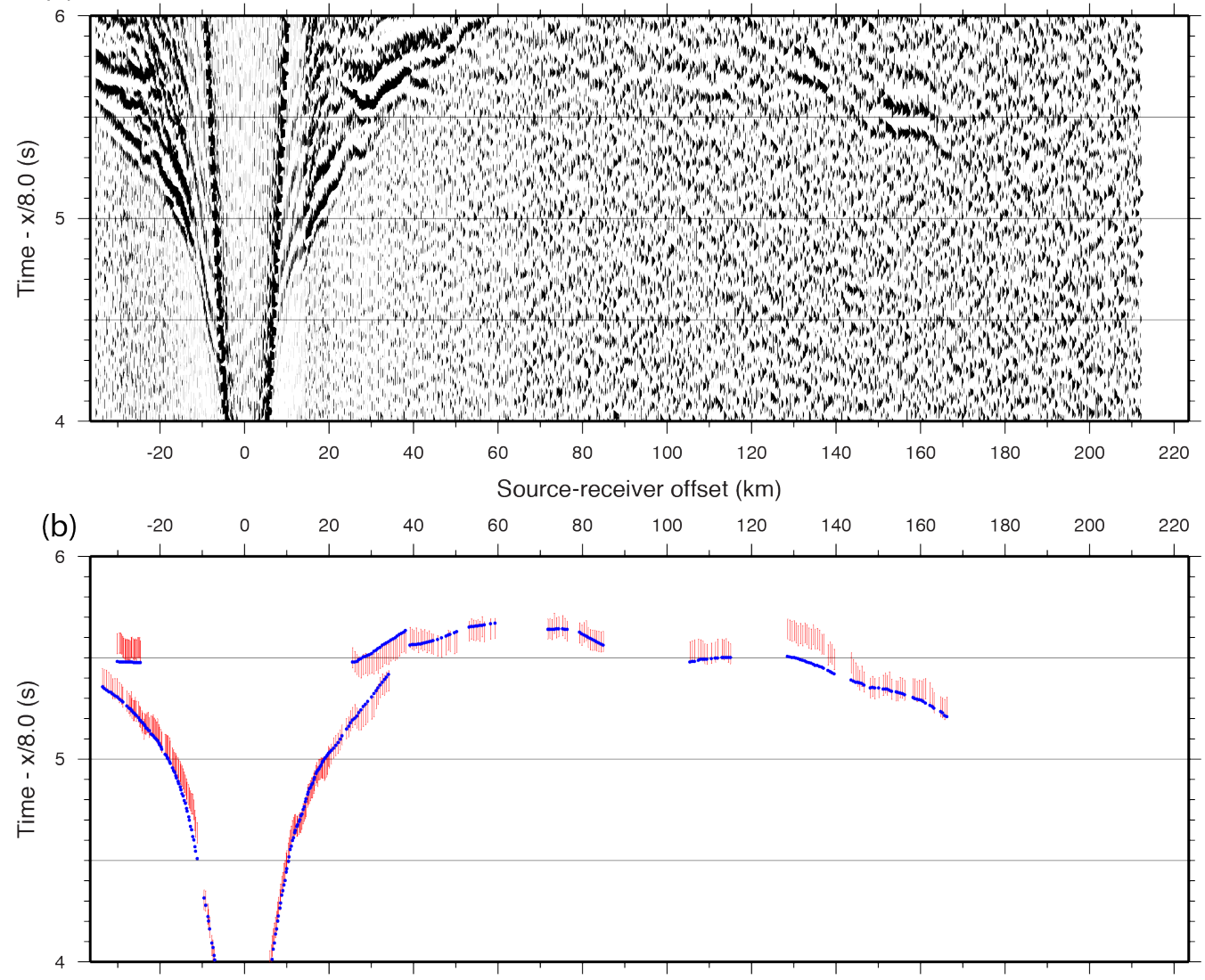

(c)

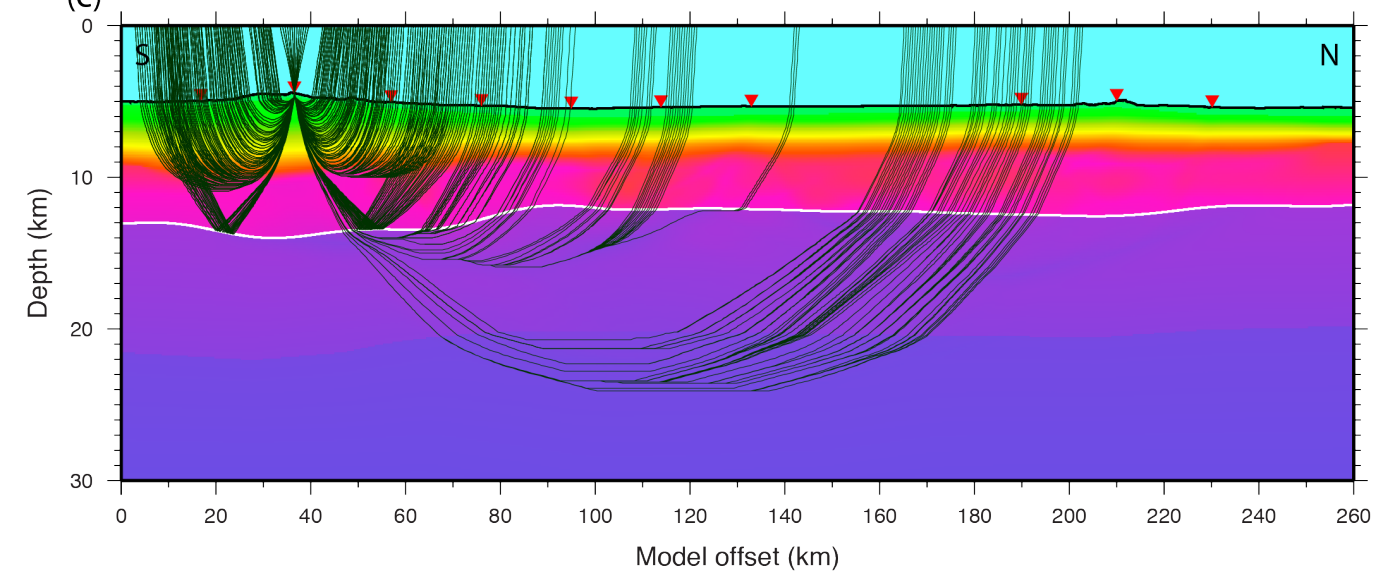

Figure 11. OBS E11 seismogram with travel time results and corresponding ray diagram from the tomographic inversion. (a) Data are reduced at $8.0 \mathrm{~km} / \mathrm{s}$. (b) Picks of first arrivals from $\mathrm{Pg}, \mathrm{P}_{\mathrm{M}} \mathrm{P}, \mathrm{Pn}$, and $\mathrm{Pd}$ phases used in the inversion are in red, bracketed by the red vertical bars to show travel time uncertainties assigned to the picks. Modeled travel times from the preferred P-wave velocity model are represented by blue dots. (c) Ray-tracing results from the tomographic inversion using the graph method are superimposed on the preferred P-wave velocity model. Depth to the seafloor is outlined in black, the Moho is indicated by the white line, and OBS positions are denoted by red inverted triangles. The velocity color scheme follows the same scale as in Figure 2a. 
(a)
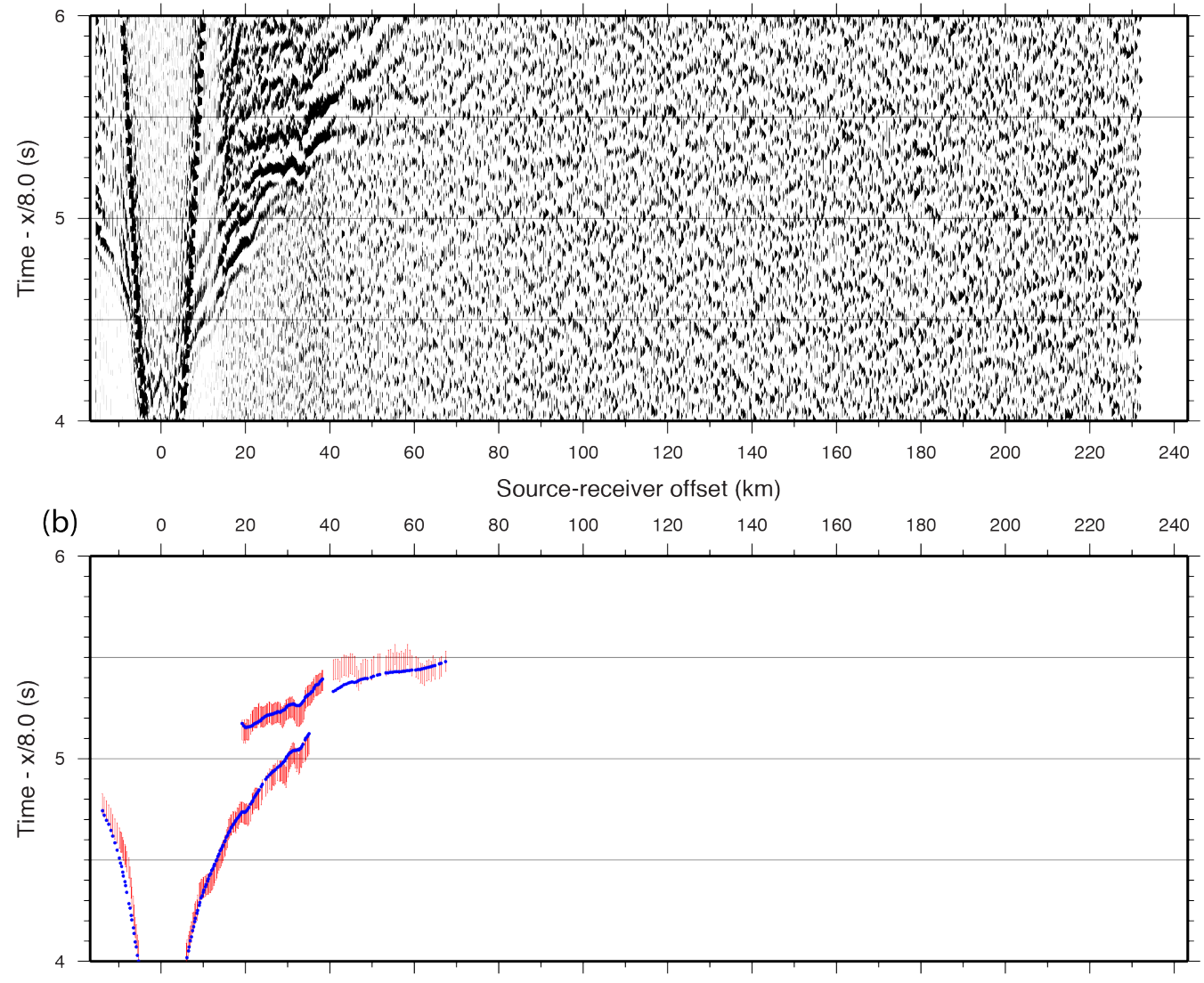

(c)

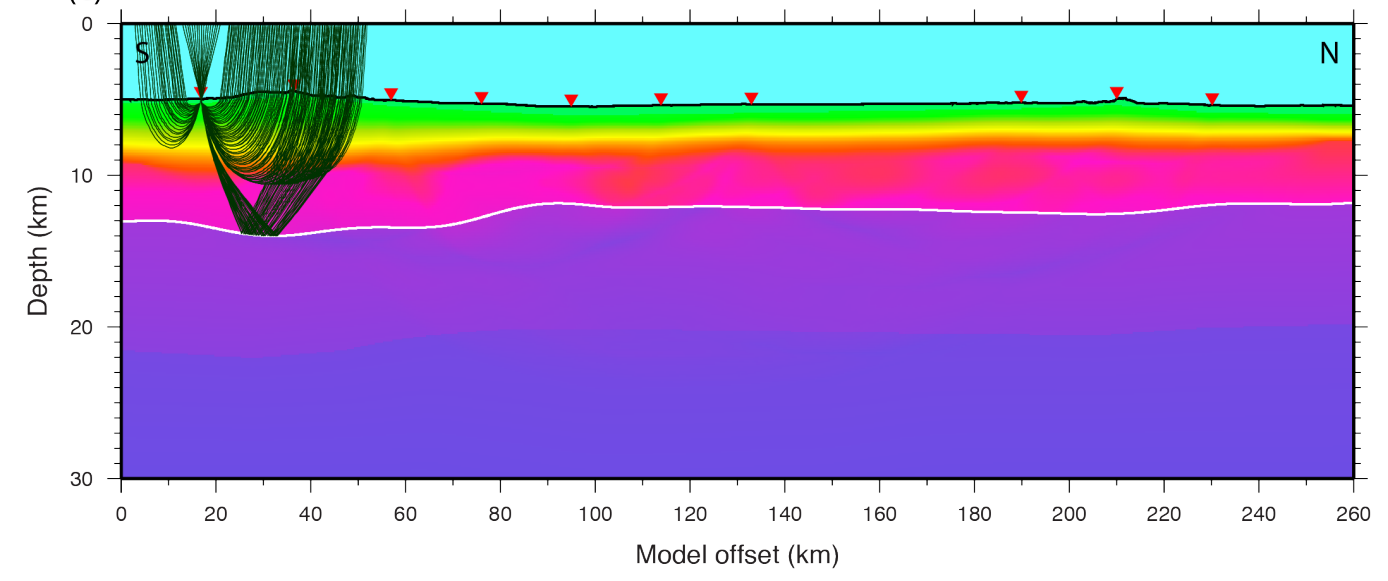

Figure 12. OBS E12 seismogram with travel time results and corresponding ray diagram from the tomographic inversion. (a) Data are reduced at $8.0 \mathrm{~km} / \mathrm{s}$. (b) Picks of first arrivals from $\mathrm{Pg}, \mathrm{P}_{\mathrm{M}} \mathrm{P}, \mathrm{Pn}$, and $\mathrm{Pd}$ phases used in the inversion are in red, bracketed by the red vertical bars to show travel time uncertainties assigned to the picks. Modeled travel times from the preferred P-wave velocity model are represented by blue dots. (c) Ray-tracing results from the tomographic inversion using the graph method are superimposed on the preferred P-wave velocity model. Depth to the seafloor is outlined in black, the Moho is indicated by the white line, and OBS positions are denoted by red inverted triangles. The velocity color scheme follows the same scale as in Figure $2 \mathrm{a}$. 

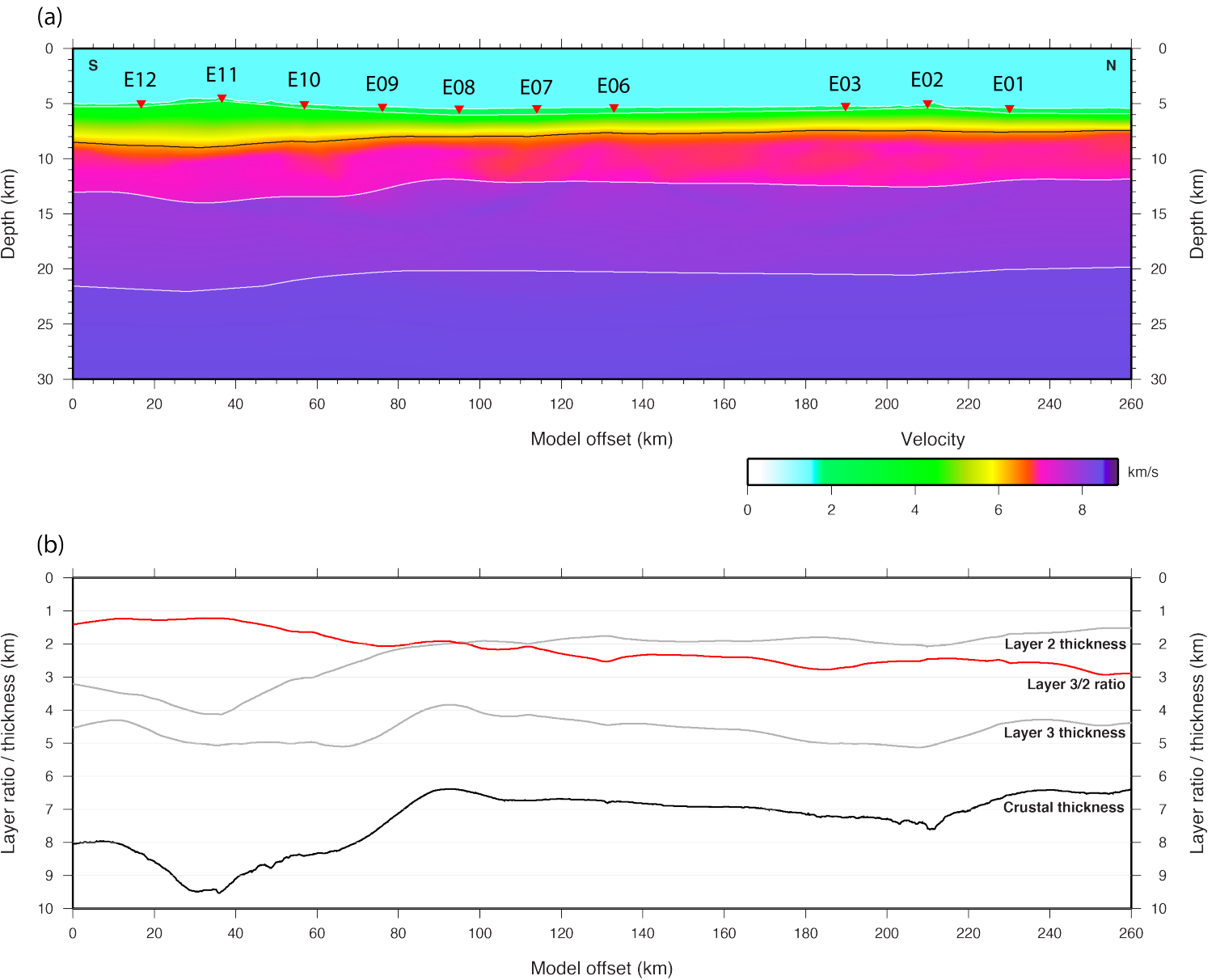

Figure 13. Results of seismic tomography along Line E used to analyze crustal thickness. (a) Preferred P-wave velocity model. White lines show layer interfaces in the model inversion, indicating depths to the seafloor, sedimentary layer, Moho, and upper mantle reflector. The black line contours velocities of $6.3 \mathrm{~km} / \mathrm{s}$ at depth, distinguishing between seismic Layers 2 and 3. (b) Thicknesses of oceanic Layers 2 and 3 and total crustal thickness along the line. Changes in the ratio of Layer $3 / 2$ thickness may be indicative of magmatic processes concerning melt transport through the lithosphere and emplacement within the crust. 


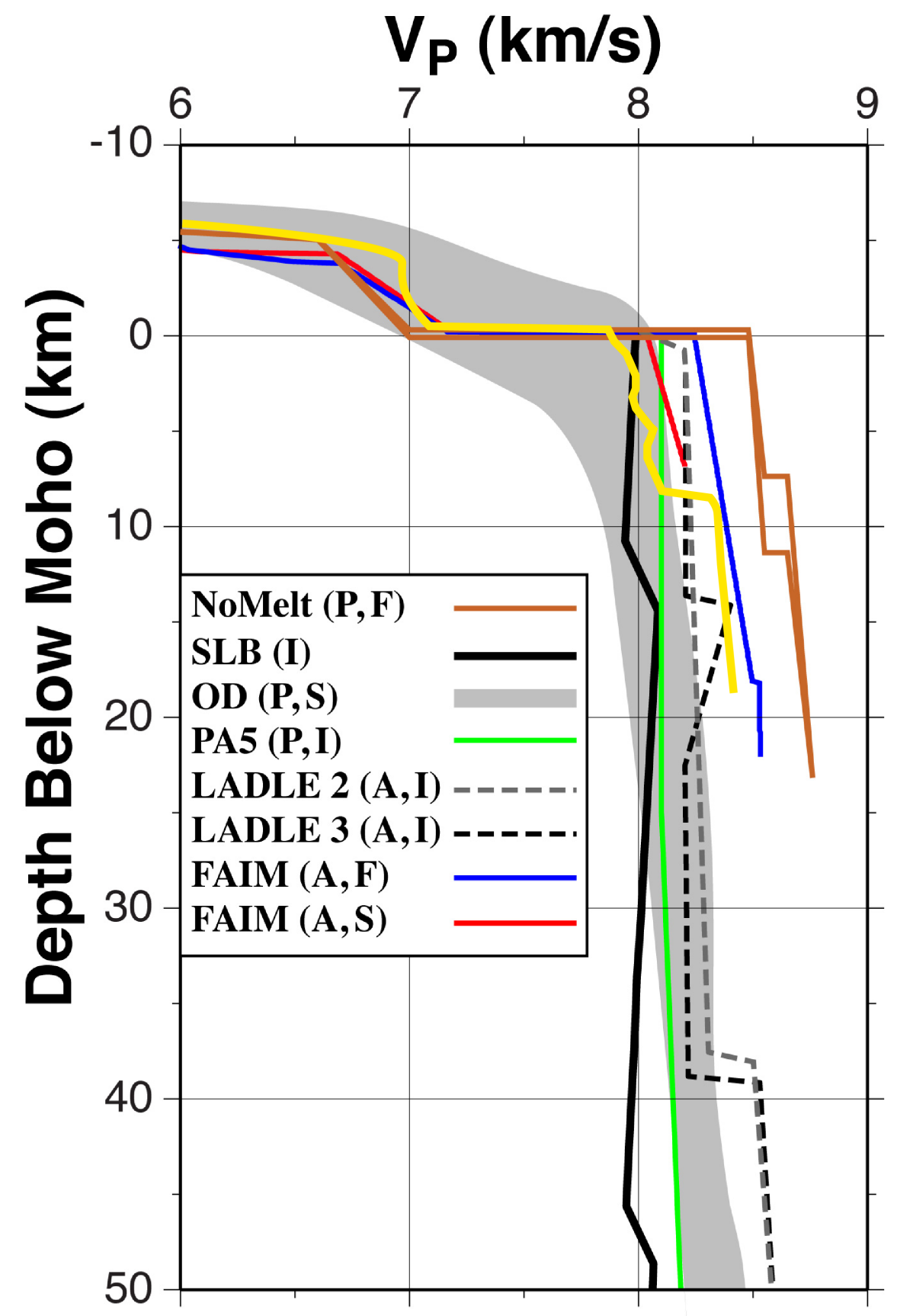

Figure 14. Velocity profile from our preferred tomographic model along Line E compared to previous studies of oceanic lithosphere. From this tomographic study of western Pacific lithosphere, a 1-D velocity profile (yellow line) shows several notable changes in the velocity gradient with depth; many of these features correlate with results from previous seismic experiments such as NoMelt (orange line), Stixrude and LithgowBertelloni [2005] (black line), Orcutt and Dorman [1977] (gray region), PA5 [Gaherty et al., 1999] (green line), LADLE [Whitmarsh et al., 1983] (grey and black dashed lines), and FAIM [Lizarralde et al., 2004] (red and blue lines). The black line models a pyrolite mantle formed at $100 \mathrm{Ma}$, with a noticeable seismic discontinuity at $10 \mathrm{~km}$ below the Moho predicted from the plagioclase-spinel phase transition. 


\section{Chapter 5: Conclusion}

This thesis presents results of seismic imaging of oceanic lithosphere that has been modified by magmatism after its formation at a divergent plate boundary. We refer to these processes as secondary modification to the lithosphere. Processes of secondary lithospheric modification are important because the lithosphere - the 'plate' in plate tectonics, and lithospheric evolution generally, are important. The constant operation of plate tectonics drives robust biogeochemical cycles that enable life on Earth as we know it, and this operation requires a certain consistency to the properties and behavior of lithospheric plates. These processes are also important because, as opposed to the majority of magmatism on Earth, which proceeds with a seemingly machine-like constancy, secondary modifications are commonly associated with discrete episodes of dramatic, voluminous magmatism over vast regions. These episodes of large igneous province formation tend to correlate with periods of global-scale changes in ocean and atmospheric chemistry and extinction events, and the processes of secondary magmatic modification are increasingly being implicated as the primary driver of these changes. Here we briefly summarize new knowledge about the processes of secondary magmatic modification of oceanic lithosphere resulting from the work presented in this thesis.

Igneous sill intrusions within sediments can be confidently identified remotely using seismic measurements. Igneous sill intrusion into sediments, and the consequent sediment alteration and hydrothermal activity that mobilizes alteration products, are the primary processes by which large igneous events are thought to affect ocean chemistry. Igneous sills have been interpretively identified within seismic data based on their reflection character, including their typically distinctive shapes and bright reflectivity. Verification of those interpretations have relied on geologic context and ground-truth observation via drilling. In Chapter 2 of this thesis, we show that isolation of sill reflections in the pre-stack intercept-time/ray-parameter domain reveals waveform and frequency-spectra characteristics that are diagnostic of sills and enable a direct determination of their thickness as well as compressional and shear seismic velocity. This result provides a means of exploring the processes of sill-driven sediment alteration by relating the important parameter of sill thickness to observations of sediment alteration. 
Visible indicators of sediment alteration above sill intrusions observed in processed multi-channel seismic profiles are related to changes in seismic properties. Drill-core and outcrop observations of igneous sills emplaced within sediments have shown that metamorphic aureoles within sediments surrounding these sills extend to distances comparable to the sill's thickness. There are relatively few such observations, however. Seismic sections show disturbance to sediments that overlie intruded igneous sills, and these data reveal a large spectrum of expressions of sediment disturbance, suggestive of a range of alteration intensities. In Chapter 2 of this thesis, we show that visibly disturbed sediments above a sill have increased seismic velocities consistent with the physical and chemical changes that have been observed from drill-core observations of sediments within the aureoles of intruded sills. This observation and approach, combined with the methodology for characterizing underlying sills, provides a means for relating the visible indicators of sediment alteration to key factors that are likely to control alteration processes, such as the size of the intruded sill, the intrusion depth of the sill, and sediment type.

Modes of secondary magmatic emplacement inform us about mechanisms of melt transport through the lithosphere. Jurassic-age western Pacific lithosphere is marked by Cretaceous-age seamounts and other volcanic constructions. The processes leading to this secondary magmatic emplacement are distinct from what occurs at plate boundaries in a number of ways. Plate-boundary magmatism occurs along effectively two-dimensional lineaments of focused accretion; melt transport into the crust involves generally limited interaction with the lithosphere; and crustal magmatic emplacement occurs in two main modes, extrusive or intrusive. The areal distribution of Cretaceous additions to the western Pacific lithosphere indicates a much more three-dimensional process, and one that involved transport of melt through existing lithosphere. In Chapter 3 of this thesis, our characterization of Cretaceous additions to Jurassic crust, based on seismic observations, led us to introduce a broader concept of magmatic-emplacement modes that incorporates the scale and dimensionality of secondary magmatic additions.

Within the Jurassic Quiet Zone (Chapter 3), we observe seamounts that likely result from the focused transport of melt through the lithosphere and into the crust, and we also observe uniform apparent thickening of oceanic Layer 2 over a distance of $\sim 400$ 
$\mathrm{km}$. This thickening probably reflects the repeated intrusion of igneous sills into sediments just above igneous basement. This broad intrusive mode of magmatic emplacement implies a correspondingly broad zone of melt crossing the Moho, and by extension, a distributed network of small melt conduits through the lithosphere, conduits smaller than those that fed seamount growth. We find similar results to the southwest, outboard of the Mariana Trench, where we again observe a broad, intrusive mode of magmatic emplacement in the form of uniform thickening of the crust over $\sim 200 \mathrm{~km}$ between two small seamounts. In this case, thickening occurs within Layer 3, presumably as crustal underplating. Crustal thickening of the seamount at the end of the Mariana seismic profile occurred primarily through extrusive thickening of the upper igneous layer, suggesting efficient melt transport through both the lithosphere and the crust in this location.

The upper mantle of the western Pacific is more enriched in basaltic component than harzburgite. This conclusion is based on the observation from Chapter 4 of a strong reflection/refraction event that originates from a depth where the plagioclase-to-spinel ( $\mathrm{pg} / \mathrm{sp}$ ) phase transition is predicted to occur. Reflection events from a boundary at similar depth are also observed in large-offset seismic profiles from other experiments. The $\mathrm{pg} / \mathrm{sp}$ phase transition is not predicted to produce a strong velocity contrast in harzburgite, owing to the lack of plagioclase in this depleted mantle composition. Thus, if the event is in fact due to the $\mathrm{pg} / \mathrm{sp}$ transition, then either the oceanic mantle is not as depleted in basaltic component as is currently believed, or a basaltic component has been added as a secondary modification. We have speculated that the observed broad, intrusive modes of secondary crustal growth imply broadly distributed melt transport through the lithosphere. Melt frozen into those conduits at the later stages of the Cretaceous event could explain the observed reflection phase. This would imply that secondary magmatic modifications affect both the crust and the lithospheric mantle. 